NBER WORKING PAPER SERIES

THE CROSS-SECTION AND TIME-SERIES OF STOCK AND BOND RETURNS

\author{
Ralph S.J. Koijen \\ Hanno Lustig \\ Stijn Van Nieuwerburgh \\ Working Paper 15688 \\ http://www.nber.org/papers/w15688 \\ NATIONAL BUREAU OF ECONOMIC RESEARCH \\ 1050 Massachusetts Avenue \\ Cambridge, MA 02138 \\ January 2010
}

First version: February 2009. For excellent research assistance, we thank Rustom Irani and Michelle Zemel. We thank Jaewon Choi and Ed Altman for sharing data with us. We thank Jules van Binsbergen, John Campbell, John Cochrane, George Constantinides, Greg Duffee, Eugene Fama, Lars Hansen, John Heaton, Martin Lettau, Lars Lochstoer, Tobias Moskowitz, Stavros Panageas, Lubos Pastor, Monika Piazzesi, Maxim Ulrich, Pietro Veronesi, Bas Werker, Mungo Wilson, and seminar participants at Tilburg University, APG Investments, ULB ECARES, Temple University, University of Texas at Austin, New York University Stern finance, Boston University, Chicago Booth, University of Vienna, Erasmus University of Rotterdam, U.C. Berkeley Haas, New York University Stern's macro lunch, Washington University at St. Louis, the Adam Smith Asset Pricing Conference in Oxford, the macro-finance conference at the University of Minnesota, the Amsterdam Asset Pricing Retreat, the Society for Economic Dynamics in Istanbul, the CEPR Financial Markets conference in Gerzensee, the European Finance Association conference in Bergen, and the American Finance Association conference in Atlanta for useful comments and suggestions. The views expressed herein are those of the authors and do not necessarily reflect the views of the National Bureau of Economic Research.

NBER working papers are circulated for discussion and comment purposes. They have not been peerreviewed or been subject to the review by the NBER Board of Directors that accompanies official NBER publications.

(C) 2010 by Ralph S.J. Koijen, Hanno Lustig, and Stijn Van Nieuwerburgh. All rights reserved. Short sections of text, not to exceed two paragraphs, may be quoted without explicit permission provided that full credit, including $(\mathcal{C}$ notice, is given to the source. 
The Cross-Section and Time-Series of Stock and Bond Returns

Ralph S.J. Koijen, Hanno Lustig, and Stijn Van Nieuwerburgh

NBER Working Paper No. 15688

January 2010, Revised September 2013

JEL No. E21,E43,G00,G12

\begin{abstract}
Value stocks have higher exposure to innovations in the nominal bond risk premium, which measures the markets' perception of cyclical variation in future output growth, than growth stocks. The ICAPM then predicts a value risk premium provided that good news about future output lowers the marginal utility of investors' wealth today. In support of the business cycle as a priced state variable, we show that low value minus growth returns, typically realized at the start of recessions when nominal bond risk premia are low and declining, are associated with lower future dividend growth rates on value minus growth and with lower future output growth in the short term. Because of this new nexus between stock and bond returns, a parsimonious three-factor model can jointly price the book-to-market stock and maturity-sorted bond portfolios and reproduce the time-series variation in expected bond returns. Structural dynamic asset pricing models need to impute a central role to the business cycle as a priced state variable to be quantitatively consistent with the observed value, equity, and nominal bond risk premia.
\end{abstract}

Ralph S.J. Koijen

London Business School

Regent's Park

London NW1 4SA

United Kingdom

and NBER

rkoijen@london.edu

Hanno Lustig

UCLA Anderson School of Management

110 Westwood Plaza, Suite C413

Los Angeles, CA 90095-1481

and NBER

hlustig@anderson.ucla.edu
Stijn Van Nieuwerburgh

Stern School of Business

New York University

44 W 4th Street, Suite 9-120

New York, NY 10012

and NBER

svnieuwe@stern.nyu.edu 
Value strategies buy stocks that have low prices relative to measures of fundamentals such as dividends or book assets, and sell stocks that have high prices relative to fundamentals. These strategies earns high returns that appear anomalous relative to standard models such as the CAPM (e.g., Basu, 1977; Fama and French, 1992). The profession has hotly debated whether these superior returns reflect a compensation for systematic risk or a behavioral bias. Under the behavioral hypothesis, extrapolative investors push up the price of growth ("glamour") stocks that performed well in the recent past, allowing contrarian investors to profit from their over-optimism by investing in out-of-favor value stocks and/or shorting the growth stocks (De Bondt and Thaler, 1985). In support of a risk-based explanation, Cochrane (2008) points out that "Our lives would be so much easier if we could trace price movements back to visible news about dividends or cash flows."

Early attempts to connect the cash flows of value and growth firms to macro-economic sources of risk came up empty handed (Lakonishok, Schleifer, and Vishny, 1994, LSV). Our paper provides new evidence that links the excess return on high minus low book-to-market stock portfolios to cash flow and output risk at business cycle frequencies. We make progress on this same issue because we study a much longer sample with more adverse macroeconomic events (1926-2011 compared to 1968-1989 in LSV, or 15 recessions compared to 4), and because we use a new methododology to study macroeconomic events.

The connection between the value spread and the macro-economy is easiest to detect in the bond market. We study several linear combinations of bond yields which forecast future economic activity: the slope of the term structure $(Y S P)$, the Cochrane-Piazzesi factor $(C P)$, and the best linear predictor of economic activity at the one-year horizon $(Y G R)$. Innovations in these bond market factors co-move strongly with returns on the value-minus-growth strategy. Our findings assign a central role to the business cycle itself as a priced state variable.

We discern three contributions. The first contribution of the paper is to document that value portfolio returns have a higher covariance with innovations in the bond factors $C P, Y S P$, and $Y G R$ than growth portfolio returns. Figure 1 shows covariances between unexpected returns on each of the quintile book-to-market portfolios, ordered from growth (low B/M) to value (high B/M), with 
innovations to these factors. The monotonically increasing pattern in exposures will generate a value premium if the price of risk associated with innovations in the bond factors is positive. Standard ICAPM logic implies that this price of risk is positive provided that innovations to the factors lower the marginal utility of wealth for the average investor. This is natural because innovations to $C P$, $Y S P$, and $Y G R$ represent good news about future economic performance. Indeed, all are strong predictors of the level of economic activity 12 to 24 months ahead.
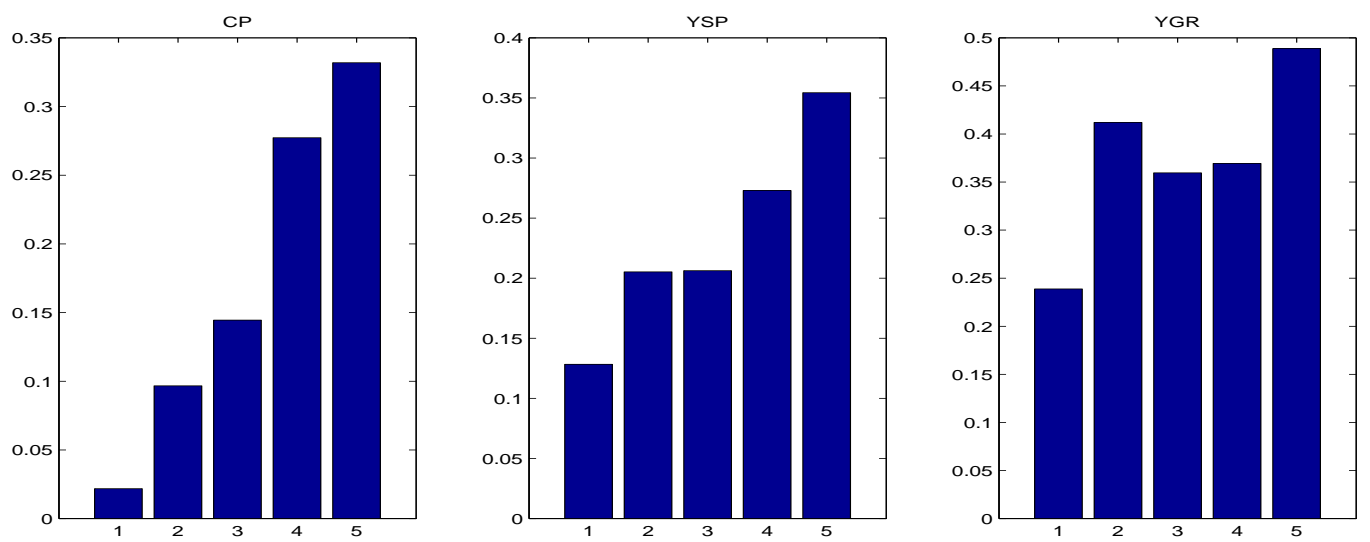

Figure 1: Exposure of value and growth portfolio returns to bond risk premium innovations.

The figure shows the covariance of innovations to returns on five quintile portfolios sorted on the book-to-market ratio with innovations to three bond market factors. In the left panel, the bond factor is the Cochrane and Piazzesi $(C P)$ factor. In the middle panel, it is the yield spread $(Y S P)$. In the right panel, it is the bond factor that maximally predicts economic activity CFNAI twelve months out $(Y G R)$. Innovations to bond factors and returns are described in detail in Section 3. On the horizontal axes, Portfolio 1 denotes the lowest book-to-market (growth) portfolio; portfolio 5 is the highest book-to-market (value) portfolio. The covariances are multiplied by 10,000. The sample is monthly from June 1952 until December 2012.

The second contribution of the paper is to attribute these different bond exposures to differences in the underlying cash flow dynamics. We find that value stocks experience negative cash-flow shocks in economic downturns (Section 2), and we find large differences in the behavior of cashflow growth on value and growth over the macroeconomic cycle. For example, over the course of the average NBER recession, dividends on value stocks fall $21 \%$ while dividends on growth stocks increase by $3 \%$. The $24 \%$ average gap hides interesting differences across recessions. During the Great Recession of 2007-2009, the fall in value-minus-growth dividends was 45\%. During the Great Depression the relative log change was $-318 \%$. The drop measured during the NBER recession months understates the drop during the broader bust period because the NBER dates may neither coincide with the peak nor the trough for real dividends, and because dividends may be sluggish 
to adjust to bad aggregate news (Yoon and Starks, 1995). For the ten episodes in our sample that witness a protracted fall in real dividends on the market portfolio ( $27 \%$ decline on average), we find that real dividends on the highest book-to-market portfolio fall by $54 \%$ more than those on the lowest book-to-market portfolio.

Finally, we show that periods where the $C P$ or $Y S P$ factors are low are periods of significantly lower future dividend growth rates on the market portfolio and on value-minus-growth. On average across low- $C P$ events, dividends on value stocks fall $55 \%$ more than those on growth stocks relative to their unconditional mean. Value-growth dividend growth turns negative 5-15 quarters after the low-CP events, compared to a 3-4 quarter lag between the same low- $C P$ events and the level of macro-economic activity.

One useful way to highlight the macro-economic risk in value strategies is to select periods during which value stocks and the value-minus-growth strategy experience exceptionally low returns, "lowvalue events." Such low-value events are not only associated with low contemporaneous $C P$ and $Y S P$ realizations, but also with low future economic activity and lower future dividend growth on value-minus-growth, consistent with a risk-based explanation. This event-based approach provides a novel method to detect the link between prices, cash-flows, and macroeconomic aggregates in high marginal utility states of the world that matter most for pricing. The approach could prove fruitful for investigating other return anomalies and their link to the macroeconomy.

The evidence on the link between the value spread and the $C P / Y S P$ factor suggests a connection between stock and bond returns. The third contribution of the paper is to provide a unified pricing model for the cross-section of book-to-market equity portfolios, the equity market portfolio, and the cross-section of maturity sorted bond portfolios (Section 3). Naturally, our first pricing factor is the bond factor $(C P, Y S P$, or $Y G R)$ : differential exposure of the five book-to-market portfolios accounts for the average value spread in the data. Second, differential exposure to shocks to the level of the term structure $(L V L)$ accounts for the difference between the excess returns on five government bond portfolios, consistent with Cochrane and Piazzesi (2008). Third, exposure to the market return $(M K T)$ accounts for the aggregate equity premium. This three-factor model reduces 
mean absolute pricing errors on our test assets from $4.89 \%$ per year in a risk-neutral benchmark economy to $0.45 \%$ per year. By having the price of $L V L$ risk depend on the lagged bond factor, the model also captures the predictability of bond returns by the $C P, Y S P$, or $Y G R$ factor. All estimated risk prices have the expected sign, and are collectively different from zero. We cannot reject the null hypothesis that the model's pricing errors are jointly zero. The three-factor model works for different sub-samples and for different sets of test assets. For example, it does a good job pricing corporate bond portfolios sorted by credit rating, jointly with equity and government bond portfolios. Finally, we present individual stock-level evidence that exposure to the $C P$ shocks is priced and results in a higher risk premium on stocks.

What results is a coherent picture of value-minus-growth returns, the bond factor $C P$ or $Y S P$, the level of macroeconomic activity, and dividend growth on value-minus-growth that is potentially consistent with a risk-based resolution of the value premium puzzle. Whether the market price assigned to transitory business cycle risk in existing dynamic asset pricing models is large enough to match these moments with reasonable parameter choices is an open question. For example, Bansal, Kiku, and Yaron (2010) extend the model of Bansal and Yaron (2004) by adding a cyclical component to consumption. In their model, good news about future output growth lowers the marginal utility of wealth today because investors have a preference for the early resolution of uncertainty so that the income effect dominates the substitution effect. However, in their preferred calibration, business cycle risk is not strong enough to generate large risk premia.In this class of models with recursive utility, persistent shocks dominate the pricing of long-term assets.

\section{Related Literature}

A small but growing literature models stock and bond returns jointly, most often in affine settings like ours. This literature mostly explores the relation between the aggregate stock and bond markets, ${ }^{1}$ with the exception of Lettau and Wachter (2009) and Gabaix (2012), who also

\footnotetext{
${ }^{1}$ Examples are the affine models of Bakshi and Chen (1997) in a square-root diffusion setting, Bakshi and Chen (2005) and Bekaert, Engstrom, and Grenadier (2010); Bekaert, Engstrom, and Xing (2009) in a Gaussian setting,
} 
study the cross-section of stock returns. The former is a model with common shocks to the risk premium in stock and bond markets, while the latter is a time-varying rare disasters model. In addition, there is closely related work in production-based asset pricing by Zhang (2005) that has linked the investment behavior of value and growth firms during recessions to the value premium.

The business cycle itself plays a secondary role in modern dynamic asset pricing theory. ${ }^{2}$ Our work uncovers new evidence that the business cycle in output and consumption growth is itself a priced state variable in stock markets. Value stock returns are more sensitive than growth stock returns to innovations in bond market factors such as $C P$ and the yield spread, and hence are more exposed to cyclical news about the economy's future cash flow growth, because their subsequent cash flow growth is more sensitive to output growth. Value stocks earn a premium as a result. Relative to existing dynamic asset pricing models, our work uncovers the cyclical component in expected output growth as a new priced, state variable, distinct from the low frequency state variables in long-run risk and external habit models of Bansal and Yaron (2004) and Campbell and Cochrane (1999). The latter are designed to match the lower frequency variation in the market dividend yield. ${ }^{3}$

Our paper also advances the empirical ICAPM literature, starting with the seminal work of Chen, Roll, and Ross (1986), which routinely uses term structure factors either as a predictor of the aggregate return on the stock market or as a conditioning variable in an estimation of a conditional beta model of the cross-section of stock returns. Ferson and Harvey (1991) study stock and bond returns' sensitivity to aggregate state variables, among which the slope of the yield curve. They conclude that time variation in equity risk premia is important for understanding the cross-sectional

and the linear-quadratic model of Campbell, Sunderam, and Viceira (2012). Finally, Lustig, Van Nieuwerburgh, and Verdelhan (2012) price both nominal bond yields and the aggregate stock market return in a no-arbitrage model in order to measure the wealth-consumption ratio in the data; they do not study the cross-section of bond nor stock returns.

${ }^{2}$ A related literature studies the temporal composition of risk in asset prices, (e.g., Cochrane and Hansen, 1992; Kazemi, 1992; Bansal and Lehman, 1997; Hansen, Heaton, and Li, 2008).

${ }^{3}$ These models are successful in accounting for many of the features of both stocks and bonds. For the external habit model, the implications for bonds were studied by Wachter (2006) and the implications for the cross-section of stocks were studied by Menzly, Santos, and Veronesi (2004) and Santos and Veronesi (2010). Likewise, the implications of the long-run risk model for the term structure of interest rates were studied by Piazzesi and Schneider (2006) and Bansal and Shaliastovich (2010), while Bansal, Dittmar, and Lundblad (2005); Bansal, Dittmar, and Kiku (2007); Hansen, Heaton, and Li (2008) study the implications for the cross-section of equity portfolios. 
variation in size and industry equity portfolios, and that interest rate risk premia are important for understanding the cross-sectional variation in bond return portfolios. Ang and Bekaert (2007) find some predictability of nominal short rates for future aggregate stock returns. Brennan, Wang, and Xia (2004) write down an ICAPM model where the real rate, expected inflation, and the Sharpe ratio move around the investment opportunity set and show that this model prices the cross-section of stocks. Similarly, Petkova (2006) studies the connection between the Fama-French factors and innovations in state variables such as the default spread, the dividend-price ratio, the yield spread, and the short rate. Using a VAR model, Campbell and Vuolteenaho (2004) and Campbell, Polk, and Vuolteenaho (2010) argue that common variation in book-to-market portfolio returns can be attributed to news about future cash flow growth on the market. In this approach, the cash flow innovations are highly persistent. In contrast to this literature, our focus is on the joint pricing of stock and bond returns, business cycle shocks, and the link with dividend growth on stock portfolios. Baker and Wurgler (2012) show that government bonds co-move most strongly with "bond-like stocks," which are stocks of large, mature, low-volatility, profitable, dividend-paying firms that are neither high growth nor distressed. They propose a common sentiment indicator driving stock and bond returns.

\section{Measuring Business Cycle Risk in Value}

In this section, we provide new evidence that value stocks are risky. We start by documenting that value stocks suffer from bad cash-flow shocks during aggregate bad times, times of high marginal utility growth for the representative investor. Because dividends adjust to bad shocks with a lag, it is natural to look for early indicators of poor future economic performance. The literature has traditionally looked at bond markets for expectations about future economic activity. We follow in that tradition and document the predictive ability of several linear combinations of bond yields, among which the Cochrane-Piazzesi (CP) factor. These bond market variables are strong predictors of both future aggregate economic activity, future aggregate dividend growth, and future dividend growth on value minus growth stocks. To bolster the macro-economic risk explanation, the last 
part of this section studies periods where realizations on both the value and the value-minus-growth portfolios are exceptionally low, and finds that these are periods characterized by bad news about future aggregate economic activity.

\subsection{Value Cash Flow Risk and the Business Cycle}

We use monthly data on dividends and inflation from July 1926 until December 2012 (1038 observations). Inflation is measured as the change in the Consumer Price Index from the Bureau of Labor Statistics. Dividends on book-to-market-sorted quintile portfolios are calculated from cum-dividend and ex-dividend returns available from Kenneth French' data library. To eliminate seasonality in dividends, we construct annualized dividends by adding the current month's dividends to the dividends of the past 11 months. ${ }^{4}$ We form log real dividends by subtracting the log change in the CPI from the log of nominal dividends. Our focus is on cash dividends. ${ }^{5}$ It is important to note that all quintile portfolios, including the growth portfolio 1, pay substantial amounts of dividends. The average annual dividend yield varies only modestly across book-to-market quintile portfolios: $2.5 \%$ (portfolio 1), 3.5\% (2), 3.9\% (3), 4.0\% (4), and 3.0\% (5). The market portfolio has a dividend yield of $3.4 \%$.

The left panel of Figure 2 plots log real dividends on book-to-market quintile portfolios 1 (G), 5 (V), and the market portfolio (M) against the NBER recession dates defined by the NBER's Business Cycle Dating committee. For consistency with the results below, the figure focuses on the post1952.7 sample. The figure shows strong evidence that dividends on value stocks fall substantially more in recessions than in expansions. Value stocks show strong cyclical fluctuations whereas dividends on growth stocks are, if anything, slightly pro-cyclical. The picture for the pre-1952

\footnotetext{
${ }^{4}$ Investing dividends at the risk-free rate yields similar results. Binsbergen and Koijen (2010) show that reinvesting monthly dividends at the market return severely contaminates the properties of dividend growth.

${ }^{5}$ Cash dividends are the right measure in the context of a present-value model that follows a certain portfolio strategy, such as value or growth (Hansen, Heaton, and Li, 2008). An alternative is to include share repurchases to cash dividends, but this would correspond to a different dynamic strategy (Larrain and Yogo, 2007). However, in the recent recession, which is the largest downturn in cash dividends during the period in which repurchases became more popular, share repurchases also declined substantially. This suggests that during the episodes that we are most interested in, cash dividends and share repurchases comove positively and are exposed to the same aggregate risks.
} 
period, reported in Online Appendix A, is consistent with this behavior. The two starkest examples of the differential cash-flow behavior of value and growth are the Great Depression (September 1929 - March 1933) and the Great Recession (December 2007 - June 2009), but the same pattern holds during most post-war recessions (e.g., 1973, 1982, 1991, 2001). During the Great Depression, the $\log$ change in real dividends from the peak is $-356 \%$ for value, $-62 \%$ for the market, and $-38 \%$ for Growth. In the Great Recession, dividends fell 35\% for value, $14 \%$ for the market, while growth dividends actually rose $10 \%$.
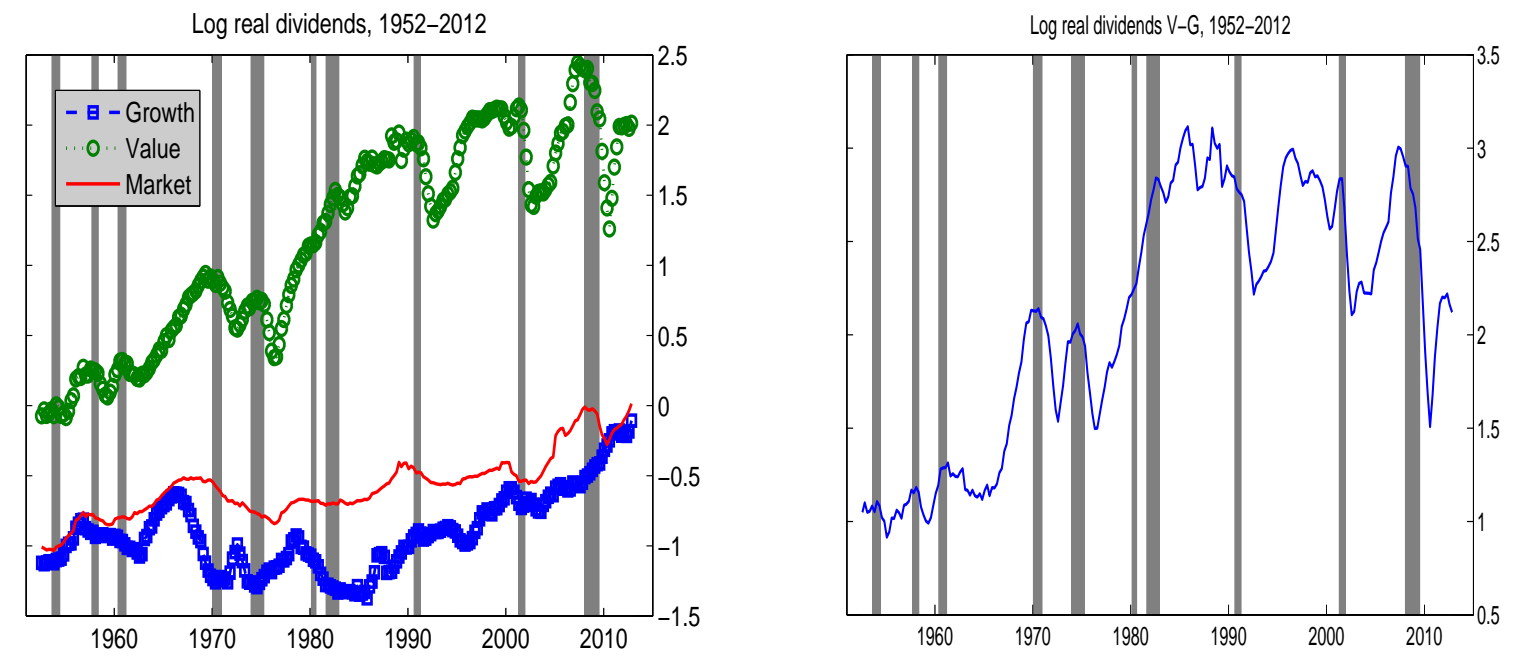

Figure 2: Dividends on value, growth, and market portfolios.

The left panel plots the log real dividend on book-to-market quintile portfolios 1 (growth, dashed line with squares) and 5 (value, dotted line with circles) and on the CRSP value-weighted market portfolio. The right panel plots the log real dividend on book-to-market quintile portfolios 5 (value) minus the log real dividend on the boot-to-market portfolio 1 (growth), plotted against the right axis. The grey bars indicate official NBER recession dates. Dividends are constructed from the difference between cum- and ex-dividend returns on these portfolios, multiplied by the previous month's ex-dividend price. The ex-dividend price is normalized to 1 for each portfolio in 1926.06. Monthly dividends are annualized by summing dividends received during the year. We take logs and subtract the log of the CPI price level (normalized to 100 in 1983-84) to obtain log real dividends. The data are monthly from July 1952 until December 2012 and are sampled every three months in the figure.

Strictly adhering to the NBER recession dates understates the change in dividends from the highest to their lowest point over the cycle. For example, annual dividends on value-minus-growth fall by $45 \%$ during the December 2007-June 2009 recession, but they fall $11 \%$ between April and December of 2007 and continue to fall longer after the official recession is over. The decline from June 2009 until June 2010 is a massive 106\%. Thus, the total decline over the cycle measured from May 2007 until June 2010 is 162\%, eclipsing the 45\% decline over the official NBER cycle. Similarly, value-minus-growth dividends fall by $82 \%$ (90\%) in the period surrounding the 2001 (1991) recession 
compared to a $25 \%(12 \%)$ drop between the NBER peak and the last month of the recession. The right panel of Figure 2 plots the log difference between value and growth portfolios (right axis) as well as NBER recessions (bars). The figure illustrates not only large declines in dividends on valueminus-growth around recessions, but also that declines usually lag the official recession. This may reflect the downward stickiness in dividend adjustments that is well understood in the literature on firms' dividend payment behavior. ${ }^{6}$ The corresponding picture for the pre-1952 period, reported in Online Appendix A, is consistent with this behavior.

To get at these broader boom-bust cycles in dividends more systematically, we alternatively define busts as periods where real dividends on the market portfolio drop by $5 \%$ or more over a protracted period (6 months or more). There are ten such periods in the 1926 to 2012 sample. They last an average of 31 months and real dividends on the market portfolio fall by $27 \%$ on average. Real dividends on the growth portfolio fall by $15 \%$ on average, while those on the value portfolio fall by $68 \%$, a difference of $54 \%$. For comparison, during the average NBER recession, dividends on value-minus-growth fall by 24\%. In all but two of these periods (starting in 1941 and 1951), dividends on value stocks fall by more than those on growth stocks. The average ratio of the fall in the $\mathrm{V}-\mathrm{G}$ dividend to the fall in the market dividend is 1.5. In other words, the periods with large sustained decreases in real dividends on the market are associated with much larger declines in the dividends on value than on growth, fifty percent larger than the decline in the market dividend growth itself.

\subsection{Value, Bond Yield Factors and the Business Cycle}

Having shown that dividends on value-minus-growth fall during and after recessions, this section shows that several bond yield factors predict future aggregate economic activity, as well as future aggregate dividend growth and future dividend growth on value minus growth stocks.

\footnotetext{
${ }^{6}$ For example, Yoon and Starks (1995) present evidence that firms cut their dividends much less frequently than they increase them, but when they cut them, they cut them at a rate that is five times larger than when they increase them. See also Chen (2009) for aggregate evidence on dividend smoothing.
} 
The slope of the yield curve, $Y S P$, which we define as the difference between the 5-year and the 1-year Fama-Bliss yield, is a well known predictor of future economic growth. Cochrane and Piazzesi (2005) combine bond yields of maturities one to five years to form the $C P$ factor and show predicts future excess bond returns. We show that the $C P$ factor also predicts of future economic activity. $^{7}$ It is natural to also consider the linear combination of the same bond yields that best forecasts future economic activity. We refer to that bond market variable as $Y G R$. The variable $Z$ denotes one of these bond market variables. Our findings contribute to the recent literature that links bond market variables to macroeconomic series. ${ }^{8}$

\section{Bond Factors Predict Macroeconomic Activity We consider the following predictive regres-} sion in which we forecast future economic activity, measured by the Chicago Fed National Activity Index $(C F N A I),{ }^{9}$ using the current $C P$ factor:

$$
C F N A I_{t+k}=c_{k}+\beta_{k} Z_{t}+\varepsilon_{t+k},
$$

where $k$ is the forecast horizon expressed in months. The regressions are estimated by OLS and we calculate Newey-West standard errors with $k-1$ lags. The sample runs from March 1967 until

\footnotetext{
${ }^{7}$ We follow Cochrane and Piazzesi (2005) in constructing the $C P$ factor from the term structure of government bond yields. In particular, we use monthly Fama-Bliss yield data for nominal government bonds of maturities onethrough five-years. These data are available from June 1952 until December 2012. We construct one- through fiveyear forward rates from the one- through five-year bond prices. We then regress the equally-weighted average of the one-year excess return on bonds of maturities of two, three, four, and five years on a constant, the one-year yield, and the two- through five-year forward rates. The yields are one-year lagged relative to the return on the left-hand side. The $C P$ factor is the fitted value of this predictive regression. The $R^{2}$ of this regression in our sample of monthly data is $18.1 \%$, roughly twice the $10.3 \% R^{2}$ of the five-year minus one-year yield spread, another well-known bond return predictor.

${ }^{8}$ Brooks (2011) shows that the $C P$ factor has a 35\% contemporaneous correlation with news about unemployment, measured as deviations of realized unemployment from the consensus forecast. Gilchrist and Zakrajsek (2012) shows that a credit spread, and in particular a component related to the bond risk premium, forecasts economic activity. A related literature studies the predictability of macro-economic factors for future bond returns. Cooper and Priestly (2008) show that industrial production in deviation from its trend forecasts future bond returns; Joslin, Priebsch, and Singleton (2010) incorporate this finding in an affine term structure model. Ludvigson and Ng (2009) shows that a principal component extracted from many macroeconomic series also forecasts future bond returns. While macroeconomic series do not fully soak up the variation in bond risk premia, there clearly is an economically meaningful link between them.

${ }^{9}$ The CFNAI is a weighted average of 85 existing monthly indicators of national economic activity. CFNAI peaks at the peak of the business cycle and bottoms out at the through. Since economic activity tends toward trend growth over time, a positive index reading corresponds to growth above trend and a negative index reading corresponds to growth below trend. CFNAI is normalized to have mean zero and standard deviation one.
} 
December 2012 (550 months), dictated by data availability. Figure 3 shows the coefficient $\beta_{k}$ in the top panel, its t-statistic in the middle panel, and the regression R-squared in the bottom panel. The forecast horizon $k$ is displayed on the horizontal axis and runs from 1 to 36 months. The left panels are for $Z=C P$, the middle for $Z=Y S P$, and the right panels for $Z=Y G R$. The variable $Y G R$ is the linear combination that best predicts CFNAI twelve months out. For this exercise, all predictors are rescaled so that they have the same volatility as the CP factor over the 1967-2012 sample. This makes the magnitude of the slope coefficients directly comparable.

All three predictors are strongly and significantly positively associated with future economic activity. All three statistics for all three predictors display a hump-shaped pattern, gradually increasing until approximately 12-24 months and gradually declining afterwards. The left column shows that $C P$ is a strong predictor of economic activity. The maximum slope is 24.9 with a tstatistic of 4.2 and an $R^{2}$ value of $14.7 \%$. This maximum predictability is for CFNAI 21 months later. The figure suggests that a high $C P$ factor precedes higher economic activity about 12 to 24 months later. The predictability is statistically significant for horizons from 1 to 31 months.

The middle panel uses the yield spread as a predictor. It too strongly predicts economic activity, but at a slightly shorter horizon. The predictability peaks at 18 months with a slope of 20.6, a t-stat of 3.7 , and an $R^{2}$ value of $10.5 \%$. The predictability is statistically significant for horizons from 2 to 25 months.

The right panel shows the results for $Y G R$, which by construction has the highest slope coefficient (27.4), t-statistic (4.9), and $R^{2}$ value at the 12-month forecast horizon (18.5\%). For comparison, the yield spread is a slightly stronger predictor of economic activity 12 months out (slope of 19.6) than $C P$ (slope of 18.2), but the $R^{2}$ values are about half of those for the best linear combination of yields $(10.9 \%$ and $7.9 \%$, respectively). The predictive ability of $Y G R$ deteriorates with the horizon. At 24 months the slope is 10.5 and the point estimate is no longer significantly different from zero. Around the same horizon $Y S P$ loses its predictive ability. The $C P$ factor in contrast is a much stronger predictor than $Y S P$ or $Y G R 24$ months out. In fact, it is close to the best linear predictor at that horizon. 

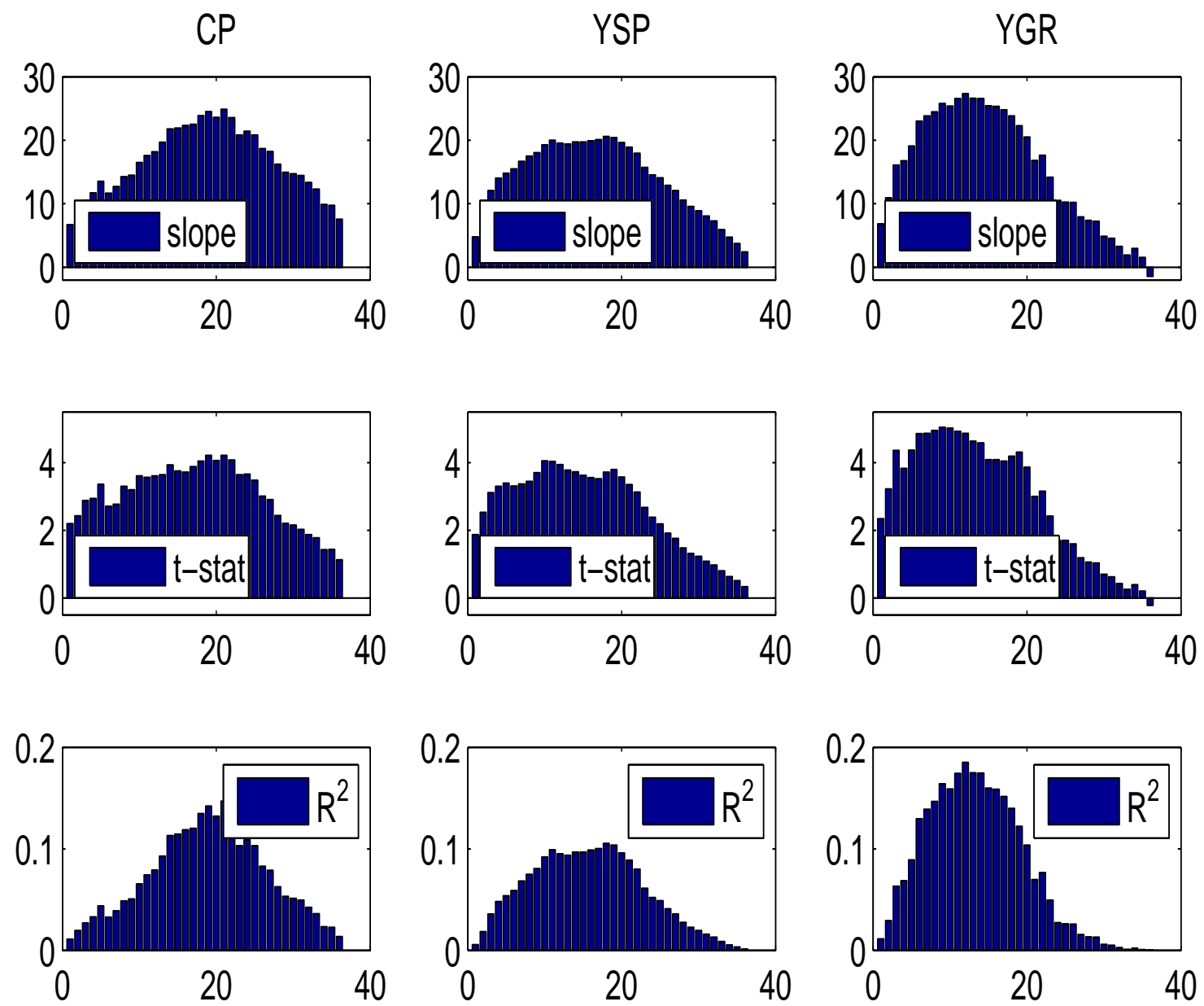

Figure 3: Economic activity predicted by bond factors.

The top panel displays the predictive coefficient $\beta_{k}$ in (1), the middle panel the t-statistic, and the bottom panel the corresponding R-squared value. We consider $k=1, \ldots, 36$ months of lags, displayed on the horizontal axis in each panel, and the t-statistics are computed using Newey-West standard errors with $k-1$ lags. The left column is for the $C P$ factor as predictor $(Z=C P)$, the middle column for the yield spread $(Z=Y S P)$, and the right column for the best linear yield curve forecaster of $C F N A I_{t+12}(Z=Y G R)$. The sample is March 1967 until December 2012.

Online Appendix A shows similar results when forecasting GDP growth rather than CFNAI.

Bond Factors Predict Dividend Growth Having shown earlier that both aggregate dividend growth and dividend growth on value minus growth stocks declines around periods of economic recession, we now ask whether these same three bond yield factors predict aggregate dividend growth and dividend growth on value-minus-growth stocks. We employ linear regressions like equation (1). 
Since dividend growth is constructed using twelve months of data, we only consider horizons $k \geq 12$. The predictive coefficients are summarized in Panels B and C of Table 1; Panel A summarizes the corresponding slope coefficients in the CFNAI equation. Numbers in bold have Newey-West t-statistics in excess of 1.96. Panel B shows that all three measures strongly predict aggregate dividend growth. The yield spread has stronger predictive ability at shorter horizons, while YSP and $C P$ have similar predictability at $k=24$, that is, the similarly predict cumulative dividend growth over the year between months $t+13$ and $t+24$. YGR also displays statistically significant predictability. Panel $\mathrm{C}$ shows that our bond market variables also linearly predict dividend growth on value minus growth. The predictability of $C P$ is concentrated at longer horizons of 33-36 months ahead, that of $Y S P$ is the strongest and present at horizons of 22-33 months, while that of $Y G R$ is concentrated at horizons of 22-26 months ahead. This regression evidence confirms that the term structure of interest rates contains useful information about future cash flow growth in the aggregate and about differential cash-flow prospects for value and growth firms.

Table 1: Predicting Economic Activity and Dividend Growth

This table reports slope coefficients from predictive regressions. The predictors $Z$ are listed in the first row. they are the CP factor, the yield spread $Y S P$, and the best linear forecaster of $C F N A I_{t+12}, Y G R$. The forecast horizon is listed in the first column. All predictors have the same standard deviation over the sample so that the slope coefficients within each panel are directly comparable. In Panel A, the bond market variables forecast CFNAI. In Panel B, they forecast real dividend growth on the market portfolio. In Panel C, they forecast dividend growth on the value minus the growth portfolio. The data are monthly from March 1967 through December 2012.

\begin{tabular}{l|ccc|ccc|ccc}
\hline & \multicolumn{2}{|c|}{ CP } & YSP & YGR & \multicolumn{2}{c|}{ CP } & YSP & YGR & \multicolumn{2}{c}{ CP } & YSP & YGR \\
$k$ & \multicolumn{3}{|c|}{ Panel A: CFNAI } & \multicolumn{2}{c|}{ Panel B: Div. Growth M } & \multicolumn{2}{c}{ Panel C: Div. Growth V-G } \\
\hline 12 & $\mathbf{1 8 . 1 6}$ & $\mathbf{1 9 . 5 6}$ & $\mathbf{2 7 . 3 5}$ & 0.59 & $\mathbf{1 . 0 9}$ & 0.40 & -1.97 & -2.29 & -1.89 \\
15 & $\mathbf{2 1 . 9 3}$ & $\mathbf{1 9 . 7 0}$ & $\mathbf{2 5 . 4 2}$ & $\mathbf{0 . 9 4}$ & $\mathbf{1 . 4 3}$ & 0.64 & -0.24 & 0.29 & 0.46 \\
18 & $\mathbf{2 3 . 8 7}$ & $\mathbf{2 0 . 5 6}$ & $\mathbf{2 3 . 8 4}$ & $\mathbf{1 . 1 3}$ & $\mathbf{1 . 6 8}$ & $\mathbf{0 . 8 7}$ & 1.08 & 2.42 & 2.06 \\
21 & $\mathbf{2 4 . 8 7}$ & $\mathbf{1 8 . 9 0}$ & $\mathbf{1 6 . 8 0}$ & $\mathbf{1 . 2 8}$ & $\mathbf{1 . 8 6}$ & $\mathbf{1 . 0 9}$ & 2.15 & 4.11 & 3.46 \\
24 & $\mathbf{2 1 . 3 9}$ & $\mathbf{1 4 . 5 2}$ & 10.52 & $\mathbf{1 . 3 1}$ & $\mathbf{1 . 9 6}$ & $\mathbf{1 . 2 2}$ & 3.02 & $\mathbf{5 . 3 2}$ & $\mathbf{4 . 3 9}$ \\
27 & $\mathbf{1 8 . 2 2}$ & 12.06 & 7.93 & $\mathbf{1 . 3 2}$ & $\mathbf{2 . 0 0}$ & $\mathbf{1 . 2 6}$ & 3.51 & $\mathbf{5 . 6 5}$ & $\mathbf{4 . 6 2}$ \\
30 & $\mathbf{1 4 . 7 0}$ & 8.87 & 4.86 & $\mathbf{1 . 5 4}$ & $\mathbf{2 . 1 4}$ & $\mathbf{1 . 3 6}$ & 3.90 & $\mathbf{5 . 6 4}$ & 4.39 \\
33 & 12.30 & 5.92 & 1.90 & $\mathbf{1 . 6 2}$ & $\mathbf{2 . 1 7}$ & $\mathbf{1 . 3 4}$ & $\mathbf{4 . 6 2}$ & $\mathbf{5 . 5 2}$ & 3.53 \\
36 & 7.56 & 2.38 & -1.44 & $\mathbf{1 . 6 0}$ & $\mathbf{2 . 0 4}$ & $\mathbf{1 . 1 4}$ & $\mathbf{5 . 1 4}$ & 5.23 & 2.71 \\
\hline
\end{tabular}




\subsection{A Macro-Event Study of Value}

In this section, we take a different approach by letting the financial variables, not the macrovariables, determine the event dates.

Low-CP Events While the bond yield variables clearly lead the cycle, their exact timing vis-a-vis the official NBER recession dating may be fragile because the lead-lag pattern may fluctuate from one recession to the next (see figure in the Online Appendix). Thus, it may be productive to isolate periods in which $Z$ is low and then to ask how the level of economic activity behaves in and around such events. We focus on $Z=C P$ in the main text, but present similar evidence for $Z=Y S P$ in the Appendix.

In each quarter since 1952.III, we compute quarterly $C P$ as the $C P$ factor value in the last month of that quarter, and we select the $25 \%$ of quarters with the lowest quarterly $C P$ readings. Figure 4 shows how several series of interest behave six quarters before (labeled with a minus sign) until ten quarters after the low- $C P$ event (labeled with a plus sign), averaged across events. The quarter labeled ' 0 ' is the event quarter with the low $C P$ reading. The top RHS panel shows the dynamics of $C P$ itself, which naturally falls from a positive value in the preceding quarters to a highly negative value in the event quarter, after which it recovers.

The bottom RHS panel shows the economic activity index CFNAI over this $C P$ cycle. There is a strong pattern in economic activity in the quarters surrounding the low $C P$ event. When $C P$ is at its lowest point, economic activity is about average (CFNAI is close to zero). CFNAI then turns negative for the next ten quarters, bottoming out five to six quarters after the $C P$ event. This lead-lag pattern is consistent with the predictability evidence. The change in CFNAI from four quarters before until four quarters after is economically large, representing 1.2 standard deviations of CFNAI. The Online Appendix shows similarly strong dynamics in real GDP growth around low- $C P$ events.

The bottom LHS panel of Figure 4 shows annual dividend growth on value (fifth book-to-market) 

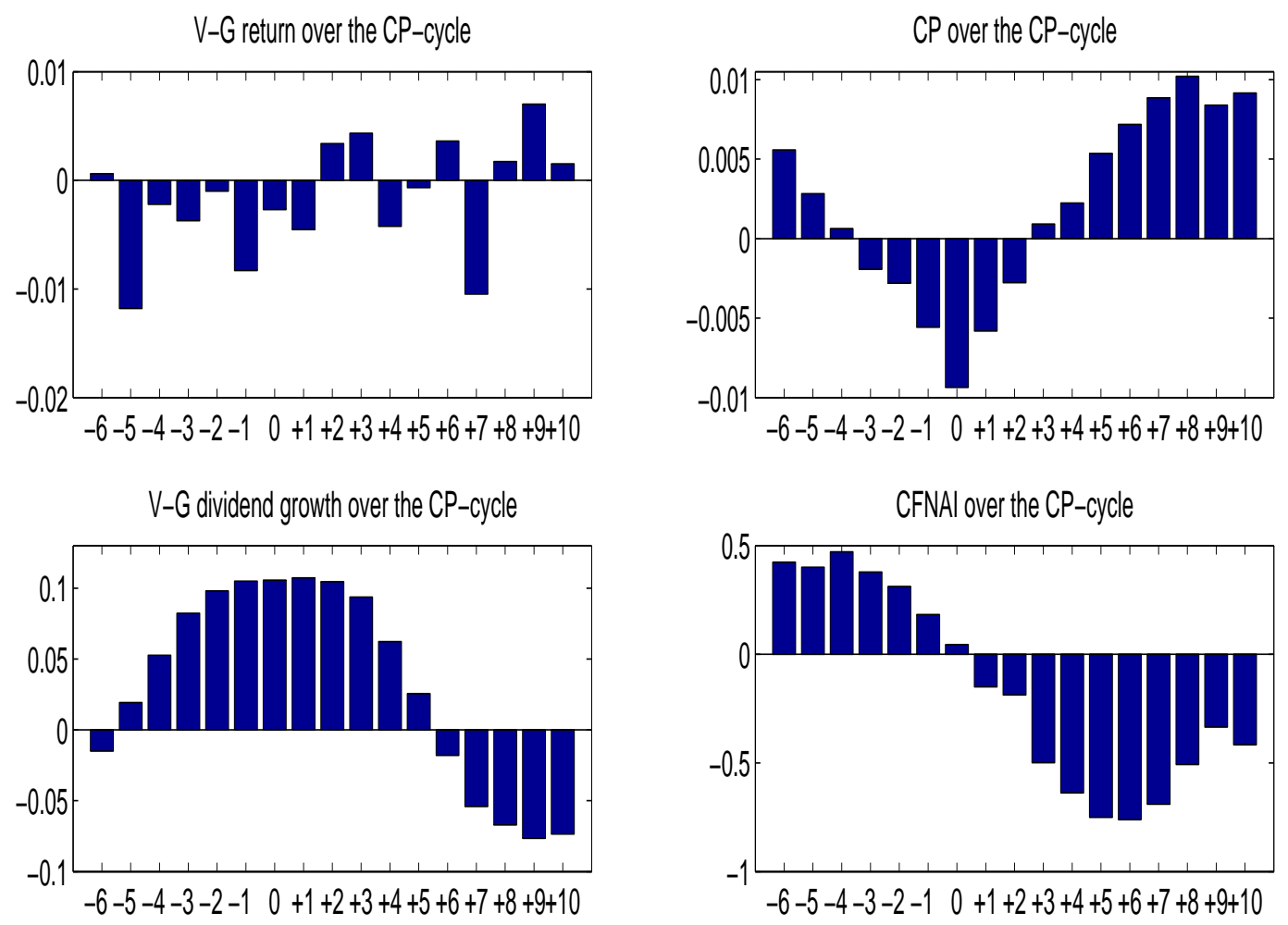

Figure 4: Low $C P$ Events

The figure plots four quarterly series in event time. The event is defined as a quarter in which the quarterly $C P$ factor in its respective lowest $25 \%$ of observations. This selection leads to 60 events out of 242 quarters. The sample runs from 1953.III until 2012.IV. In each panel, the period labeled ' 0 ' is the quarter in which the event takes place. The labels $-1,-2,-3$, etc refer to one, two, three, etc quarters before the event whereas the labels $+1,+2,+3$, etc. refer to one, two, three, etc quarters after the event. The top left panel plots the realization of the quarterly log return on value minus growth. The bottom left panel reports annual log dividend growth on value minus growth. The top right panel plots the $C P$ factor. The bottom right panel plots the CFNAI index of economic activity. The latter is available only from 1967.II onwards. Formally, the graph reports $c_{k}+\beta_{k}$ from a regression $X_{t+k}=c_{k}+\beta_{k} \mathcal{I}_{C P_{t}<L B}+\epsilon_{t+k}$, for various $k$, where $\mathcal{I}$ is an indicator variable, LB is the 25th percentile of $\mathrm{CP}$, and $X$ is the dependent variable which differs in each of the four panels. Value-minus growth returns and value-minus-growth dividend growth have been demeaned over the full sample; CFNAI is also mean zero by construction.

minus growth (first book-to-market portfolio) over the $C P$ cycle. The dividend growth differential is demeaned over the full sample, so as to take out the trend in the dividend growth rate differential. Dividend growth on $\mathrm{V}-\mathrm{G}$ is high when $C P$ is at its nadir and starts falling immediately afterwards. This decline in $\mathrm{V}-\mathrm{G}$ dividend growth is persistent and economically large. Over the ten quarters following the $C P$ event, annual dividends on value stocks fall by $20.8 \%$ points more than on growth stocks, a 0.9 standard deviation decline. Dividend growth on value minus growth (relative to its unconditional mean) stays negative until 15 quarters after the event (not shown). We find that cumulative V-G dividend growth between the end of quarters 6 and 15 is $-55 \%$. That means that 
dividends on value stocks are $55 \%$ lower than those on growth stocks, relative to trend, on average after low-CP events. Comparing the bottom two panels, we see that dividend growth lags economic activity by several quarters. This lagged reaction arises in part because firms are reluctant to cut dividends, and only do so after a bad shock (like a low-CP event). In other part, the lag arises from the construction of the dividend growth measure. Since dividend growth is computed using the past twelve months of dividends, it is not until the end of quarter +4 that all dividends, used in the measured growth rate, are realized after the time- 0 shock. In sum, low $C P$ realizations predict low future dividend growth rates on V-G, but with a considerable lag. This evidence confirms the formal regression evidence discussed above.

Finally, the top LHS panel of Figure 4 shows quarterly returns on value minus growth. The value spread is demeaned over the full sample. The evidence presented in the introduction suggests a link between innovations in $C P$ and returns on $\mathrm{V}-\mathrm{G}$. This panel is consistent with that evidence. Between quarters -2 and -1 and -1 and 0 , the $C P$ factor falls sharply while between quarter 0 and $+1, C P$ rises sharply. The top LHS figure shows that realized returns on the V-G strategy are negative in quarter -1 and but rises in quarter 0 and 1 (at which point they are slightly positive once we add back in the $0.5 \%$ quarterly mean). This is consistent with the higher exposure of value stocks to $C P$ innovations than the exposure of growth stocks. The top left panel provides evidence against the interpretation of the $C P$ shock as a discount rate shock (instead of, or in addition to, a shock to expected cash flows on value minus growth). Indeed, for $C P$ shocks and realized V-G returns to be positively contemporaneously correlated, expected future returns on V-G would have to be particularly high upon a negative $C P$ shock. This is belied by the negative average V-G returns following the low $C P$ event on display in the top left panel of the figure. We return to the relationship between $\mathrm{V}-\mathrm{G}$ returns and the $C P$ factor in detail in the Section $3 .{ }^{10}$

\footnotetext{
${ }^{10}$ One may wonder whether the facts this section documents are consistent with a one-factor model that differentially affects cash flow growth rates and therefore returns on value versus growth stocks. The data suggest that they are not. An adequate description of dividend dynamics contains at least two shocks: one shock that equally affects dividend growth rates on all portfolios and a second shock (to the $Z$ factor) that affects value dividends relative to growth dividends. The Online Appendix discusses the evidence in detail.
} 
Low-value Events Alternatively, we can isolate periods in which value stocks do particularly poorly. In or around such periods, we should find evidence of poor performance of cash-flows and/or the macroeconomy. To investigate this possibility, we select quarters in which both the realized log real return on the fifth book-to-market portfolio (value) and the realized log return on value minus growth (first book-to-market portfolio) are in their respective lowest $30 \%$ of observations. These "low-value events" are periods in which value does poorly in absolute terms as well as relative to growth. The double criterion rules out periods in which value returns are average, but V-G returns are low because growth returns are very high. This intersection leads to 37 events out of 242 quarters (or about $15 \%$ of the sample). The top LHS panel plots the realization of the quarterly $\log$ return on value minus growth around the event quarter. The V-G returns are demeaned over the full sample. By construction, V-G returns are low in period 0 . They are on average $-7 \%,-8 \%$ below the $1 \%$ quarterly mean. The value spread declines in the three quarters leading up to the event and rebounds in the three quarters following the event.

The first result is that the $C P$ factor, plotted in the top right panel of Figure 5 shows the same pattern as $\mathrm{V}-\mathrm{G}$ returns when plotted in $\mathrm{V}-\mathrm{G}$ event time. The level of $C P$ falls in the two quarters leading up to the low V-G return, bottoms out in the quarter of the V-G return, and increases in the following two quarters. There is a positive contemporaneous relationship between V-G returns and changes in the $C P$ factor. This suggests that (innovations in) the $C P$ factor captures the risk associated with low value-minus-growth returns.

The second result, shown in the bottom left panel of Figure 5, is that dividend growth on valueminus-growth falls considerably in the aftermath of the return event. Annual dividend growth on V-G gradually falls by about $7 \%$ points over the six quarters around the event. Being one-quarter of a standard deviation, it is an economically meaningful drop. Dividend growth on V-G continues to fall until quarter 12 (not shown). Between the end of quarters 2 and 12, cumulative dividend growth on V-G is $-29.3 \%$, on average across low-value events. This finding dovetails nicely with the fall in dividends on value-minus-growth over the course of recessions, shown above. Indeed, many of the low-value events occur just prior to the official start of NBER recessions. 

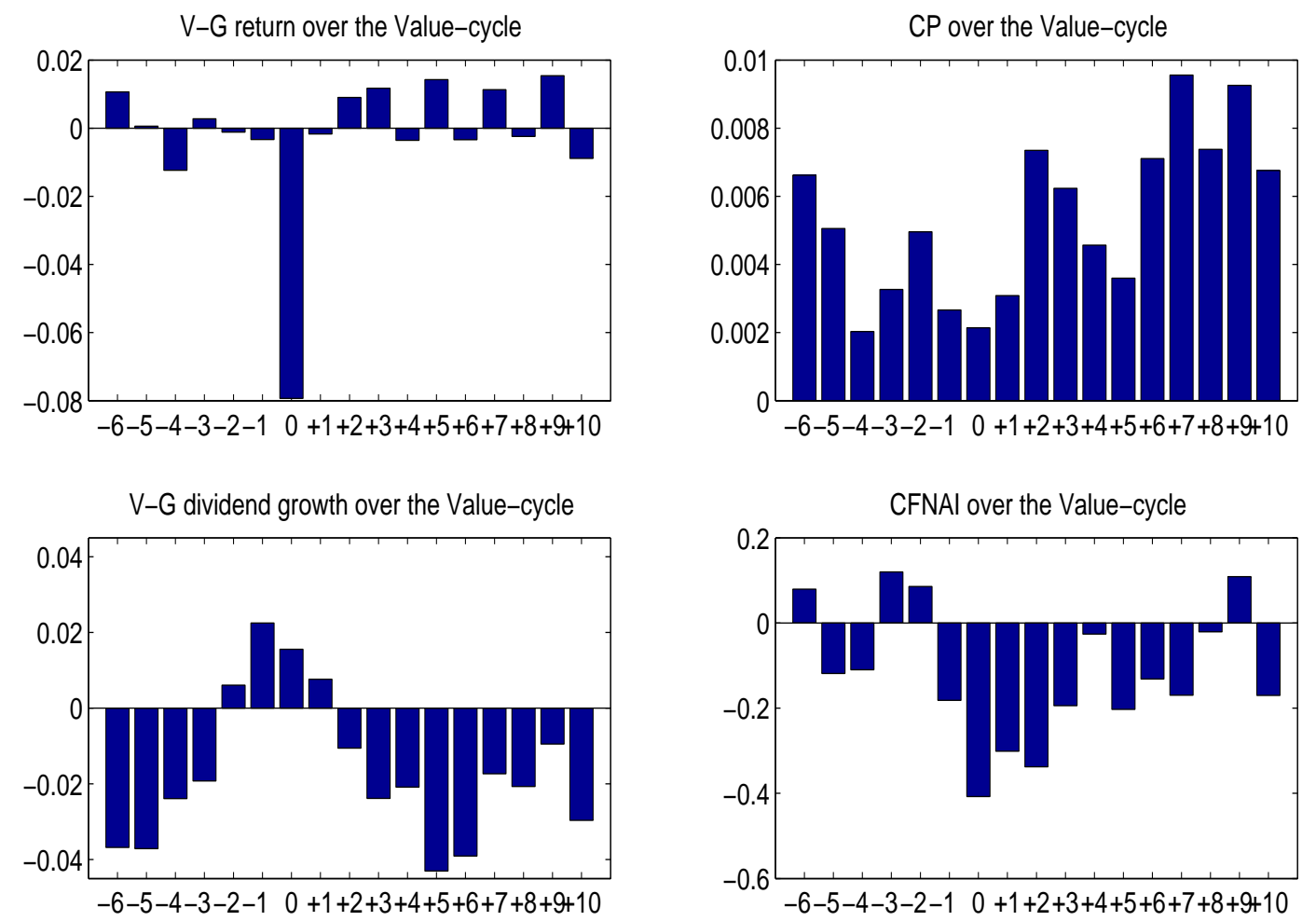

Figure 5: Low-value Events

The figure plots four quarterly series in event time. The event is defined as a quarter in which both the realized log real return on the fifth book-to-market portfolio (value) and the realized log return on value minus growth (first book-to-market portfolio) are in their respective lowest $30 \%$ of observations. This intersection leads to 37 events out of 242 quarters (15\%). The sample runs from $1953 . I I I$ until 2012.IV. In each panel, the period labeled ' 0 ' is the quarter in which the event takes place. The labels -1 , -2 , -3 , etc refer to one, two, three, etc quarters before the event whereas the labels $+1,+2,+3$, etc. refer to one, two, three, etc quarters after the event. The top left panel plots the realization of the quarterly log return on value minus growth. The bottom left panel reports annual log dividend growth on value minus growth. The top right panel plots the $C P$ factor. The bottom right panel plots the CFNAI index of economic activity. The latter is available only from 1967.II onwards. Formally, the graph reports $c_{k}+\beta_{1 k}+\beta_{2 k}$ from a regression $X_{t+k}=c_{k}+\beta_{1 k} \mathcal{I}_{\text {excret }_{V}<L B_{V}}+\beta_{2 k} \mathcal{I}_{\text {excret }_{V, t} \text {-excret }_{G, t}<L B_{S}}+\epsilon_{t+k}$, for various $k$, where $\mathcal{I}$ is an indicator variable, $L B_{V}$ is the 30 th percentile of excess returns on the value portfolio, $L B$ V is the 30th percentile of excess returns on the value-minus-growth portfolio, and $X$ is the dependent variable which differs in each of the four panels. Value-minus growth returns and value-minus-growth dividend growth have been demeaned over the full sample; CFNAI is also mean zero by construction.

Third, we see the same decline in macro-economic activity following the return event. The bottom right panel of Figure 5 shows the level of CFNAI. In the event quarter, the level of economic activity falls 0.4 standard deviations below average and it stays below zero for the ensuing quarters. The change in economic activity from two quarters before to two quarters after the event is onehalf of a standard deviation of CFNAI. The Online Appendix shows an equally large effect on real GDP growth. The delayed adjustment in dividends vis-a-vis that of macroeconomic activity is consistent with that in the low-CP events, discussed previously. The evidence in the bottom two 
panels suggests that firms only cut dividends (and those in the value more than those in the growth portfolio) after a prolonged period of below-average levels of economic activity. ${ }^{11}$

Methodologically, the advantage of the event-time approach is that it focuses on those periods where the investment strategy performs poorly. By looking at windows around these low value return events, the relationships between returns, cash flows, and macroeconomic activity become more transparent and therefore easier to detect. While the low V-G return events are clearly associated with recessions, the exact timing vis-a-vis the official NBER recession dates varies from recession to recession. This makes it hard to detect clear relationships between value returns and NBER recessions. Our approach could prove fruitful to understand other return anomalies like size or momentum (Daniel and Moskowitz, 2011).

\section{A Factor Model for Stocks and Bonds}

The evidence on the link between the value spread and the $C P$ factor suggests a connection between stock and bond returns. Based on this connection, this section provides a unified asset pricing model for the cross-section of book-to-market equity portfolios, the equity market portfolio, and the cross-section of maturity sorted bond portfolios. In a second pass, we also include corporate bond portfolios, sorted by credit rating. The model is parsimonious in that only three pricing factors are needed to capture the bulk of the cross-sectional return differences. The model is a reducedform stochastic discount factor model which imposes little more than unified pricing of risk (no arbitrage) between these equity and bond portfolios. Appendix D presents a more structural asset pricing model that provides an economic intuition for the empirical connection between stocks and bonds we document in the main text.

\footnotetext{
${ }^{11}$ Indeed, when we split the sample of low-value events in two equal groups based on the excess market return, we find that the largest decline in macro-economic activity and in dividend growth comes from those low-value events that are associated with low market returns. Conversely, the largest declines in economic activity and dividend growth occur in those low market return episodes that are also low-value events.
} 


\subsection{Setup}

Let $P_{t}$ be the price of a risky asset and $D_{t+1}$ its (stochastic) cash-flow, and $R_{t+1}$ the cum-dividend return. Then the nominal stochastic discount factor (SDF) implies $E_{t}\left[M_{t+1}^{\$} R_{t+1}\right]=1$. Lowercase letters denote natural logarithms: $m_{t}^{\$}=\log \left(M_{t}^{\$}\right)$. We propose a reduced-form SDF, akin to that in the empirical term structure literature (Duffie and Kan, 1996):

$$
-m_{t+1}^{\$}=y_{t}^{\$}+\frac{1}{2} \Lambda_{t}^{\prime} \Sigma \Lambda_{t}+\Lambda_{t}^{\prime} \varepsilon_{t+1}
$$

where $y_{t}^{\$}$ is the nominal short-term interest rate, $\varepsilon_{t+1}$ is a $N \times 1$ vector of shocks to the $N \times 1$ vector of demeaned state variables $X_{t}$, and where $\Lambda_{t}$ is the $N \times 1$ vector of market prices of risk associated with these shocks at time $t$. The state vector in (3) follows a first-order vector-autoregression with intercept $\gamma_{0}$, companion matrix $\Gamma$, and conditionally normally, i.i.d. distributed innovations, $\varepsilon_{t} \sim \mathcal{N}(0, \Sigma):$

$$
\begin{aligned}
X_{t+1} & =\Gamma X_{t}+\varepsilon_{t+1}, \\
\Lambda_{t} & =\Lambda_{0}+\Lambda_{1} X_{t} .
\end{aligned}
$$

The market prices of risk are affine in the state vector, where $\Lambda_{0}$ is an $N \times 1$ vector of constants and $\Lambda_{1}$ is an $N \times N$ matrix that governs the time variation in the prices of risk.

Log returns on an asset $j$ can always be written as the sum of expected and unexpected returns: $r_{t+1}^{j}=E_{t}\left[r_{t+1}^{j}\right]+\eta_{t+1}^{j}$. Unexpected log returns $\eta_{t+1}^{j}$ are assumed to be normally distributed and homoscedastic. We denote the covariance matrix between shocks to returns and shocks to the state variables by $\Sigma_{X j}$. We define log excess returns to include a Jensen adjustment:

$$
r x_{t+1}^{j} \equiv r_{t+1}^{j}-y_{t}^{\$}(1)+\frac{1}{2} V\left[\eta_{t+1}^{j}\right]
$$


The no-arbitrage condition then implies:

$$
E_{t}\left[r x_{t+1}^{j}\right]=\operatorname{Cov}_{t}\left[r x_{t+1}^{j},-m_{t+1}^{\$}\right]=\operatorname{Cov}\left[\eta_{t+1}^{j}, \varepsilon_{t+1}^{\prime}\right] \Lambda_{t} \equiv \Sigma_{X j}\left(\Lambda_{0}+\Lambda_{1} X_{t}\right)
$$

Unconditional expected excess returns are computed by taking the unconditional expectation of $(5)$ :

$$
E\left[r x_{t+1}^{j}\right]=\Sigma_{X j} \Lambda_{0}
$$

The main object of interest, $\Lambda_{0}$, is estimated below. Equation (6) suggests an interpretation of our model as a simple three-factor model. In Appendix C.1, we estimate how the market prices of risk vary with $X_{t}\left(\Lambda_{1}\right)$.

\subsection{Data and Implementation}

in our first main exercise, we aim to explain the average excess returns on the five valueweighted quintile portfolios sorted on their book-to-market ratio from Fama and French (1992), the value-weighted stock market return from CRSP (NYSE, Amex, and Nasdaq), and five zerocoupon nominal government bond portfolios with maturities 1, 2, 5, 7, and 10 years from CRSP. The return data are monthly from July 1952 until December 2012 (726 observations). In our second main exercise, we add corporate bond returns. We use data from Citibank's Yield Book for four investment-grade portfolios: AAA, AA, A, and BBB. Return data for these portfolios are available monthly from January 1980 until December 2012, which restricts our estimation to this sample (396 observations). Online Appendix Section 3.5 studies other sets of test assets for robustness.

We propose three asset pricing factors in $X_{t}$. The first factor is the term structure factor $Z$ that forecasts future macro-economic activity, as discussed in Section 2. In our main results, we consider two candidates for $Z$ : the $C P$ factor and the slope of the term structure $Y S P$. Later on, we consider two more $Z$ factors: the yield curve factor that maximally predicts economic activity 
12 months out, $Y G R$, and a new yield curve factor that best prices our benchmark cross-section of asset returns, $Y A P$. The second asset pricing factor is the level factor, $L V L$, constructed as the first principal component of the one- through five-year Fama-Bliss forward rates. The third factor, $M K T$, is the value-weighted stock market return from CRSP.

We construct the unexpected bond returns in $\eta$ as the residuals from a regression of each bond portfolio's $\log$ excess return on the lagged $Z$ factor. Similarly, we assume that stock returns are also predictable by the lagged $Z$ factor, and construct the unexpected stock returns in $\eta$ as the residual from a regression of each stock portfolio's log excess return on the lagged $Z$ factor. ${ }^{12}$

We estimate a single monthly $\operatorname{VAR}(1)$ with the $Z, L V L$, and $M K T$ factors to extract factor innovations $\varepsilon$. Innovations to the state vector $\varepsilon$ follow from equation-by-equation OLS estimation of the VAR model in (3). The innovation correlations between our three factors are close to zero. When $Z=C P$, we find correlations of 0.04 between $C P$ and $L V L, 0.04$ between $C P$ and $M K T$, and -0.10 between $L V L$ and $M K T .^{13}$ When $Z=Y S P$, we find innovation correlations of 0.04 between $Y S P$ and $L V L, 0.05$ between $Y S P$ and $M K T$, and -0.08 between $L V L$ and $M K T$.

The first column of Table 2 shows the full sample average excess returns, expressed in percent per year, on our 11 test assets we wish to explain. They are the pricing errors resulting from a model where all prices of risk in $\Lambda_{0}$ are zero, that is, from a risk-neutral SDF model $(R N S D F)$. Average excess returns on bonds are between 1.0 and 2.1\% per year and generally increase in maturity.

\footnotetext{
${ }^{12}$ Cochrane and Piazzesi (2005) provide evidence of predictability of the aggregate market return by the lagged $C P$ factor. Ang and Bekaert (2007) study the predictability of interest rates and the slope of the term structure for stock returns. In addition, we could include the aggregate dividend-price ratio $(D P)$ as a predictor of the stock market. Given the low $R^{2}$ of these predictive regressions, the resulting unexpected returns are similar whether we assume predictability by $Z, D P$, both, or no predictability at all.

${ }^{13}$ In the context of an annual model, Cochrane and Piazzesi (2008) argue that the $C P$ factor is not well described by an $\mathrm{AR}(1)$ process. In addition to the level of the term structure, they include the slope and the curvature (second and third principal components of the Fama-Bliss forward rates) as predictors in their VAR. The second difference is that they project forward rates on the $C P$ factor before taking principal components of the forward rates. Our results (in a monthly VAR) are not sensitive to either including slope and curvature factors in our VAR to form innovations or to computing level, slope, and curvature in the alternative fashion, or to making both changes at once. Results are available upon request. The only difference is that the VAR innovations for $C P, L V L$, and $M K T$ are nearly uncorrelated in our procedure, whereas the correlation between $C P$ shocks and $L V L$ shocks is highly negative when forward rates are orthogonalized on $C P$ before taking principal components. We focus on the three-factor structure because it is simpler and it maps more directly into the structural model of Appendix D. The latter also implies a $M K T, L V L$, and $C P$ factor structure whose innovations are nearly uncorrelated.
} 
The aggregate excess stock market return is $6.6 \%$, and the excess returns on the book-to-market portfolios range from $6.0 \%$ (BM1, growth stocks) to $10.1 \%$ (BM5, value stocks), implying a value premium of $4.1 \%$ per year.

The first column of Table 3 shows the average excess returns for the 1980-2012 sample. Average excess retruns on long-dated government bonds are substantially higher, for example 3.9\% per year for the 10-year bond. The equity risk premium is slightly higher at $6.9 \%$ while the value risk premium is slightly lower at 3.3\% per year. The table also shows that the credit portfolios have average excess returns between $3.4 \%$ per year for the highest-rated portfolio (AAA) and $4.6 \%$ for the lowest-rated portfolio (BBB). There is a 123 basis point annual excess return spread between the $\mathrm{BBB}$ and the AAA portfolio in this period.

\subsection{Estimation Results}

Turning first to the estimation for the full sample, we estimate the three price of risk parameters in $\hat{\Lambda}_{0}$ by minimizing the root mean-squared pricing errors on our $J=11$ test assets (no credit risk portfolios). This is equivalent to regressing the $J \times 1$ average excess returns on the $J \times 3$ covariances in $\Sigma_{X J}$. The results from our model with $Z=C P$ are in the second column of Table $2(C P S D F)$. The top panel shows the pricing errors. Our model succeeds in reducing the mean absolute pricing errors (MAPE) on the 11 stock and bond portfolios to a mere 45 basis points per year. The model largely eliminates most of the value spread: The spread between the fifth and the first book-to-market quintile portfolios is 105 basis points per year. We also match the market equity risk premium and the average bond risk premium. Pricing errors on the stock and bond portfolios are an order of magnitude lower than in the first column and substantially below those in several benchmark models we discuss below.

The bottom panel of the table shows the point estimates for $\hat{\Lambda}_{0}$. We estimate a positive price of $C P$ risk, while the price of $L V L$ risk is negative and that of $M K T$ risk is positive. The signs on these risk prices are as expected. As Section 2 explained at length, the positive price of $C P$ 
risk arises because positive shocks to $C P$ are good news for future economic activity, therefore indicating a negative innovation to the SDF or equivalently low marginal utility of wealth states for the representative investor. A positive shock to the level factor leads to a drop in bond prices and negative bond returns. A negative shock to bond returns increases the SDF and, hence, carries a negative risk price. A positive shock to the market factor increases stock returns and lowers the SDF, and should carry a positive risk price. We also compute asymptotic standard errors on the $\Lambda_{0}$ estimates using GMM with an identity weighting matrix. The standard errors are 34.69 for the $C P$ factor price (point estimate of 95.84$), 8.70$ for the $L V L$ factor price $(-19.27)$, and 1.24 for the $M K T$ factor price (2.27). Hence, the first two risk prices are statistically different from zero (with t-stats of 2.8 and -2.2), whereas the last one is only significant at the $10 \%$ level (t-stat of 1.8).

The last but one row of Table 2 tests the null hypothesis that the market price of risk parameters are jointly zero. This null hypothesis is strongly rejected. The asymptotic p-value for the $\chi^{2}$ test, computed by GMM using the identity weighting matrix, is $0.25 \%$ for the CP SDF model. The last row reports the $\mathrm{p}$-value for the $\chi^{2}$ test that all pricing errors are jointly zero. Interestingly, the null hypothesis cannot be rejected at the $5 \%$ level with a p-value of $5.8 \%$. Test of whether individual pricing errors are zero cannot be rejected for all but one of the test assets, namely the aggregate market portfolio (not reported). These tests lend statistical credibility to our results. In sum, our three-factor pricing model with $Z=C P$ is able to account for the bulk of the cross-sectional variation in stock and bond returns with a single set of market price of risk estimates.

The results from our model with $Z=Y S P$ are in the third column of Table 2 ( $Y S P S D F)$. The pricing errors and market prices of risk are qualitatively similar to the ones with the $C P$ factor, maybe unsurprisingly given the $76 \%$ time-series correlation between the yield spread and $C P$. The model with the yield spread leads to a larger MAPE of 70bp per year, and leaves more of the value risk premium and the difference between long and short-term bonds unexplained than the model with $C P$ as a factor. The signs on the market prices of risk are the same, with a large positive pricing error for $Y S P$ of 100.1 , close to the one for $C P$ in column $2 .^{14}$ The latter is strongly

\footnotetext{
${ }^{14}$ For comparability of the market prices of risk, $Y S P$ is normalized so that it has the same standard deviation as $C P$ over the estimation sample. This makes little difference because their standard deviations are close to begin
} 
significant with a standard error of 31.9 (t-statistic of 3.1). The $M K T$ factor has a t-statistic of 2.1 but the $L V L$ factor is insignificant (t-stat of -0.6). The null hypothesis that all risk prices are jointly zero is strongly rejected. Finally, the null that the pricing errors are all zero can be rejected at the $1 \%$ level but not at the $5 \%$ level (p-value of $3.9 \%$ ).

To shed further light on the statistical significance of our results, we perform a bootstrap analysis. The details are discussed in Online Appendix C.2. In short, we generate random bond yields with the same covariance structure and persistence as in the data and form the yield curve factors (CP, YSP, LVL) based on these generated yields. This allows us to take into account the estimation uncertainty coming from the fact that $C P$ is a generated regressor. The exercise produces a p-value which indicates how likely we are to find our MAPE point estimate by chance. We find a p-value of $8.6 \%$ for our $C P \mathrm{SDF}$ and of $35.1 \%$ for our $Y S P \mathrm{SDF}$. The result shows that the pricing results are unlikely to arise from chance alone, despite having three factors, two of which have non-trivial persistence, and a strong factor structure in the test asset returns. Below we show that the p-values are lower still when we include corporate bond portfolios in the set of test assets.

To help us understand the separate roles of each of the three risk factors in accounting for the risk premia on these stock and bond portfolios, we switch on only one risk factor and set the other risk prices to zero. Column 4 of Table 2 minimizes the pricing errors on the same 11 test assets but only allows for a non-zero price of level risk (Column $L V L$ ). This is the bond pricing model proposed by Cochrane and Piazzesi (2008). They show that the cross-section of average bond returns is well described by differences in exposure to the level factor. Long-horizon bonds have returns that are more sensitive to interest rate shocks than short-horizon bonds; a familiar duration argument. However, this bond SDF is unable to jointly explain the cross-section of stock and bond returns; the MAPE is $4.4 \%$. All pricing errors on the stock portfolios are large and positive, there is a $4.4 \%$ value spread, and all pricing errors on the bond portfolios are large and negative. Clearly, exposure to the level factor alone does not help to understand the high equity risk premium nor the value risk premium. Value and growth stocks have similar exposure to the level factor, i.e., a with. 


\section{Table 2: Unified SDF Model for Stocks and Bonds - Pricing Errors}

Panel A of this table reports pricing errors on five book-to-market sorted quintile stock portfolios, the value-weighted market portfolio, and five bond portfolios of maturities 1, 2, 5, 7, and 10 years. They are expressed in percent per year (monthly numbers multiplied by 1200). Each column corresponds to a different stochastic discount factor (SDF) model. The first column contains the risk-neutral SDF and therefore reports the average pricing errors that are to be explained. The second column presents our CP SDF model with three priced factors. The third column presents our YSP SDF model where the slope of the yield curve in the factor that replaces the $C P$ factor. The fourth column presents the results for a bond pricing model, where only the level factor is priced $(L V L)$. In the fifth column, we only use the bond returns as moments to estimate the same SDF as in the third column ( $L V L$-only bonds). The SDF model of the sixth column has the market return as the only factor, and therefore is the CAPM model $(M K T)$. The seventh column allows for both the prices of $L V L$ and $M K T$ risk to be non-zero. The last column refers to the three factor model of Fama and French (1992). The last row of Panel A reports the mean absolute pricing error across all 11 securities (MAPE). Panel B reports the estimates of the prices of risk. The first six columns report market prices of risk $\Lambda_{0}$ for (a subset) of the following pricing factors : $\varepsilon^{C P} / \varepsilon^{Y S P}(C P / Y S P), \varepsilon^{L}$ $(L V L)$, and $\varepsilon^{M}(M K T)$. In the last column, the pricing factors are the innovations in the excess market return (MKT), in the size factor (SMB), and in the value factor (HML), where innovations are computed as the residuals of a regression of these factors on the lagged dividend-price ratio on the market. Panel $\mathrm{C}$ reports asymptotic p-values of $\chi^{2}$ tests of the null hypothesis that all market prices of risk in $\Lambda_{0}$ are jointly zero, and of the null hypothesis that all pricing errors are jointly zero. The data are monthly from June 1952 through December 2012 .

\begin{tabular}{|c|c|c|c|c|c|c|c|c|c|}
\hline & \multicolumn{9}{|c|}{ Panel A: Pricing Errors (in \% per year) } \\
\hline & RN SDF & CP SDF & YSP SDF & $L V L$ & $L V L$ only bonds & $M K T$ & $L V L+M K T$ & & $F F$ \\
\hline $10-\mathrm{yr}$ & 1.76 & 0.26 & 0.58 & -3.90 & -0.43 & 1.35 & 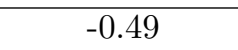 & & 0.37 \\
\hline $7-\mathrm{yr}$ & 2.08 & 0.43 & 0.29 & -2.95 & 0.13 & 1.78 & 0.15 & & 0.90 \\
\hline $5-\mathrm{yr}$ & 1.72 & -0.29 & -0.43 & -2.54 & 0.07 & 1.51 & 0.13 & & 0.82 \\
\hline $2-\mathrm{yr}$ & 1.22 & -0.86 & -1.09 & -0.89 & 0.41 & 1.07 & 0.39 & & 0.76 \\
\hline $1-y r$ & 0.97 & -0.61 & -0.79 & -0.11 & 0.55 & 0.87 & 0.52 & & 0.72 \\
\hline Market & 6.58 & -0.78 & -0.89 & 5.31 & 6.08 & -1.33 & -1.26 & & 0.07 \\
\hline BM1 & 6.01 & -0.36 & -0.82 & 4.76 & 5.52 & -2.28 & -2.18 & & 0.47 \\
\hline BM2 & 6.92 & -0.03 & -0.49 & 5.45 & 6.35 & -0.76 & -0.77 & & -0.58 \\
\hline BM3 & 7.80 & 0.61 & 0.69 & 6.33 & 7.23 & 0.62 & 0.57 & & -0.51 \\
\hline BM4 & 8.56 & -0.06 & 0.74 & 7.09 & 7.99 & 1.53 & 1.47 & & -0.74 \\
\hline BM5 & 10.14 & 0.69 & 0.95 & 9.12 & 9.75 & 2.38 & 2.52 & & 1.05 \\
\hline \multirow[t]{2}{*}{ MAPE } & 4.89 & 0.45 & 0.70 & 4.40 & 4.05 & 1.41 & 0.95 & & 0.63 \\
\hline & \multicolumn{9}{|c|}{ Panel B: Prices of Risk Estimates $\Lambda_{0}$} \\
\hline$M K T$ & 0 & 2.27 & 2.16 & 0 & 0 & 3.50 & 3.29 & MKT & 5.90 \\
\hline$L V L$ & 0 & -19.27 & -4.67 & -32.93 & -12.75 & 0 & -10.81 & SMB & -10.17 \\
\hline \multirow[t]{2}{*}{$C P / Y S P$} & 0 & 95.84 & 100.13 & 0 & 0 & 0 & 0 & HML & 6.58 \\
\hline & \multicolumn{9}{|c|}{ Panel C: P-values of $\chi^{2}$ Tests } \\
\hline$\Lambda_{0}=0$ & - & $0.25 \%$ & $0.04 \%$ & $0.00 \%$ & - & $0.04 \%$ & $0.02 \%$ & & $0.01 \%$ \\
\hline Pr. err. $=0$ & - & $5.79 \%$ & $3.86 \%$ & $0.00 \%$ & - & $0.00 \%$ & $0.00 \%$ & & $0.02 \%$ \\
\hline
\end{tabular}


similar "bond duration." The reason that this model does not do better pricing the bond portfolios is that the excess returns on stock portfolios are larger in magnitude. The estimation concentrates its efforts on reducing the pricing errors of stocks.

To illustrate that this bond SDF is able to price the cross-section of bonds, we estimate the same model by minimizing only the bond pricing errors (the first five moments in the table). The fifth column of Table 2 ( $L V L$ - only bonds) confirms that the bond pricing errors fall substantially: The mean absolute bond pricing error goes from 208bp in column 4 to 32bp with the "LVL-bonds only" kernel. However, the overall MAPE remains high at 4.05\%. The canonical bond pricing model offers one important ingredient for the joint pricing of stocks and bonds, bonds' heterogeneous exposure to the level factor, but this ingredient does not help to account for equity returns.

Another benchmark is the canonical Capital Asset Pricing Model. The only non-zero price of risk is the one corresponding to the $M K T$ factor. The sixth column of Table $2(M K T)$ reports pricing errors for the CAPM. Because past research has shown that the CAPM cannot price stock portfolios, it is not surprising that the CAPM is also unable to jointly price stock and bond returns. The MAPE is $1.41 \%$. One valuable feature is that the aggregate market portfolio is priced reasonably well and the pricing errors of book-to-market portfolio returns go through zero. This means that the model gets the common level in all stock portfolio returns right. However, the pattern of pricing errors contains a $4.6 \%$ value spread. Pricing errors on bond portfolios are sizeable as well and are all positive. Neither book-to-market nor bond portfolios display interesting heterogeneity in their exposure to $M K T$ shocks. So, while the $L V L$ factor helps to explain the cross-sectional variation in average bond returns and the $M K T$ factor helps to explain the level of equity risk premia, neither factor is able to explain why value stocks have much higher risk premia than growth stocks. The seventh column of Table 2 indeed shows that having both the level and market factor priced does not materially improve the pricing errors and leaves the value premium puzzle in tact.

This is where the $C P$ or $Y S P$ factors come in. For the case of $Z=C P$, Figure 6 decomposes each asset's risk premium into its three components: risk compensation for exposure to the $C P$ factor, the level factor, and the $M K T$ factor. The top panel is for the five bond portfolios, organized 
from shortest maturity on the left (1-year) to longest maturity on the right (10-year). The bottom panel shows the decomposition for the book-to-market quintile portfolios, ordered from growth to value from left to right, as well as for the market portfolio (most right bar). This bottom panel shows that all book-to-market portfolios have about equal exposure to both $M K T$ and $L V L$ shocks. If anything, growth stocks $(\mathrm{G})$ have slightly higher $M K T$ betas than value stocks (V), but the difference is small. The spread between value and growth risk premia entirely reflects differential compensation for $C P$ risk. Value stocks have a large and positive exposure to $C P$ shocks while growth stocks have a low exposure (recall Figure 1). The differential exposure between the fifth and first book-to-market portfolio is statistically different from zero. Multiplying the spread in exposures by the market price of $C P$ risk delivers a value premium of $30 \mathrm{bp}$ per month or $3.6 \%$ per year. That is, the $C P$ factor's contribution to the risk premia accounts for most of the $4.1 \%$ value premium. Given the monotonically increasing pattern in exposures of the book-to-market portfolios to $C P$ shocks, a positive price of $C P$ risk estimate is what allows the model to match the value premium. The risk premium decomposition looks similar using the yield spread instead of the $C P$ factor. Differential exposure to the innovations in the yield spread multiplied by the latter's price of risk contributes a value premium of $23 \mathrm{bp}$ per month or $2.7 \%$ per year.

The top panel of Figure 6 shows the risk premium decomposition for the five bond portfolios. Risk premia are positive and increasing in maturity due to their exposure to $L V L$ risk. The exposure to level shocks is negative and the price of level risk is negative, resulting in a positive contribution to the risk premium. This is the duration effect mentioned above. But bonds also have a negative exposure to $C P$ shocks. Being a measure of the risk premium in bond markets, positive shocks to $C P$ lower bond prices and realized returns. This effect is larger the longer the maturity of the bond. Given the positive price of $C P$ risk, this exposure translates into an increasingly negative contribution to the risk premium. Because exposure of bond returns to the equity market shocks $M K T$ is positive but near-zero, the sum of the level and $C P$ contributions delivers the observed pattern of bond risk premia that increase in maturity.

One might be tempted to conclude that any model with three priced risk factors can always 
Decomposition of bond risk premia
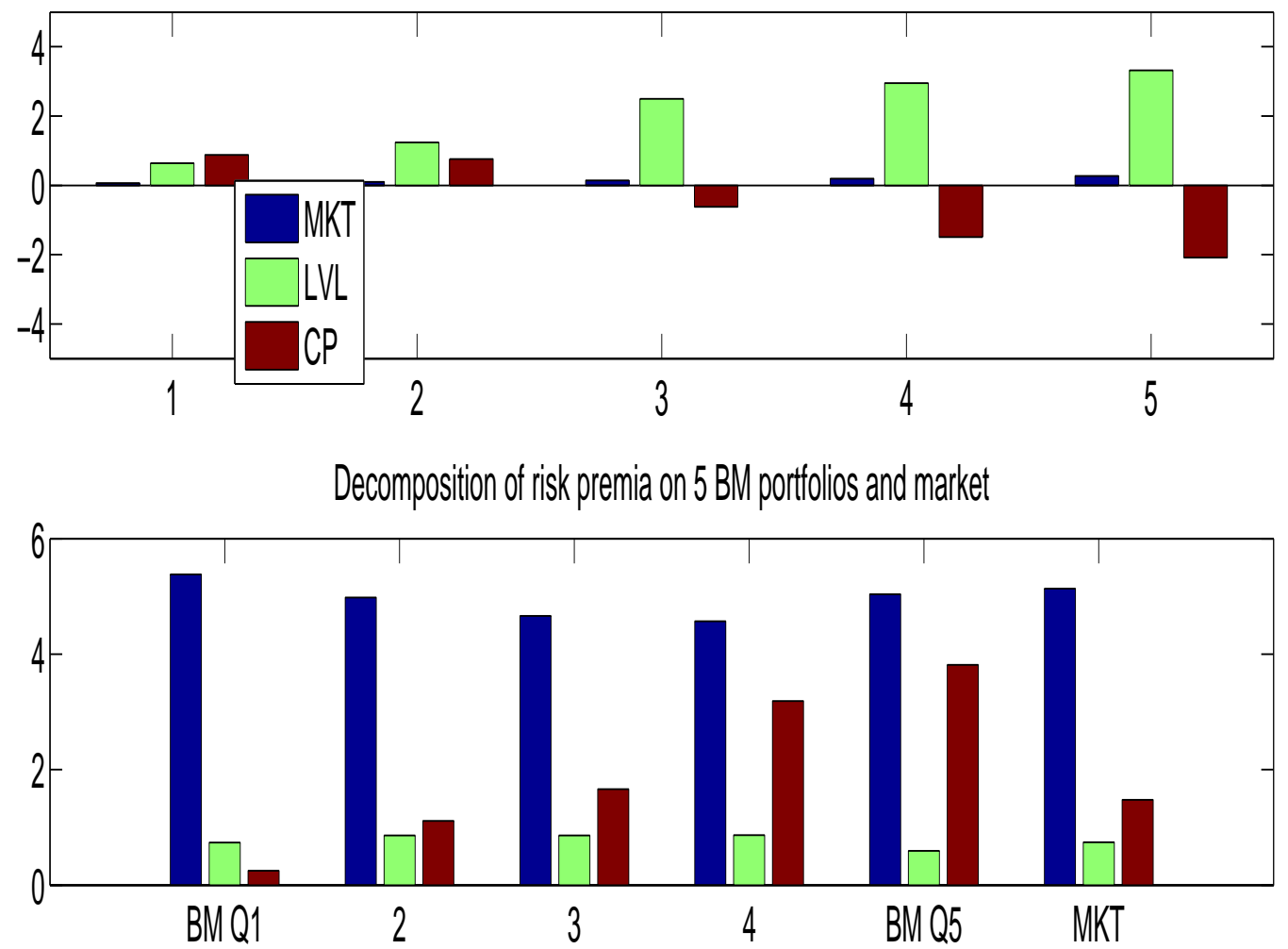

Figure 6: Decomposition of annualized excess returns in data.

The figure plots the risk premium (expected excess return) decomposition into risk compensation for exposure to the $M K T, L V L$, and $C P$ factors. Risk premia, plotted against the left axis, are expressed in percent per year. The top panel is for the five bond portfolios: one-, two-, five-, seven-, and ten-year maturities from left to right, respectively. The bottom panel is for the book-to-market decile quintile portfolios, from growth $(\mathrm{G})$ to value $(\mathrm{V})$, and for the market portfolio $(\mathrm{M})$. The three bars for each asset are computed as $\Sigma_{X R}^{\prime} \Lambda_{0}$. The data are monthly from June 1952 until December 2012.

account for the three salient patterns in our test assets. To highlight that such a conjecture is false and to highlight the challenge in jointly pricing stocks and bonds, online Appendix B develops a simple model where (1) the $C P$ factor is a perfect univariate pricing factor for the book-to-market portfolios (it absorbs all cross-sectional variation), (2) the $L V L$ factor is a perfect univariate pricing factor for the bond portfolios, and (3) the $C P$ and the $L V L$ factor are uncorrelated. It shows that such a model generally fails to price the stock and bond portfolios jointly. This failure arises because the bond portfolios are exposed to the $C P$ factor, while the stock portfolios are not exposed to the $L V L$ factor. Consistent risk pricing across stocks and bonds only works if the exposures of maturitysorted bond portfolios to $C P$ are linear in maturity, with the same slope (in absolute value) as the 
level exposures. The data happen to approximately satisfy the three assumptions underlying the stark model, but this is not a foregone conclusion. Appendix B thus underscores the challenges in finding a model with consistent risk prices across stocks and bonds, or put differently, the challenge of going from univariate to multivariate pricing models.

The final column in Table 2 reports results for the well-known Fama-French 3-factor model (Fama and French, 1992), which offers a better-performing alternative to the CAPM for pricing the cross-section of stocks. The MAPE is 63 basis points per year, which is in between the 45bp for our CP SDF model and the 70bp for the YSP SDF model. The slightly worse fit than the CP SDF model in the last column is due to higher pricing errors on the bond portfolios. Tests of the null hypothesis that all pricing errors are jointly zero are rejected at conventional levels. We have verified that this rejection is due to the higher pricing errors on the bond moments. This finding is consistent with the findings in Fama and French (1993) who introduce additional pricing factors (beyond MKT, SMB, and HML) to price bonds. Our results suggest that three factors suffice. ${ }^{15}$

We also study book-to-market decile instead of quintile portfolios, alongside the same bond portfolios and the aggregate stock market portfolio. The value spread between the tenth and first book-to-market portfolios is $4.94 \%$ per annum, $81 \mathrm{bp}$ higher than between the extreme quintile portfolios. Our CP SDF model's residual MAPE is a mere 50bp and generates a value premium of 4.67\%. The YSP SDF model performs better on this set of 16 test assets with a MAPE of 66bp and a predicted value premium of $4.16 \%$. The market price of risk estimates are very similar to those obtained with the quintile portfolios. Again, the null hypothesis that all market prices of risk are jointly zero is strongly rejected, while the null that all pricing errors are jointly zero cannot be rejected; the p-value is $19 \%$ for the $\mathrm{CP}$ SDF and $18 \%$ for the YSP SDF. The Fama-French model is in between these with a MAPE of 59bp, but with a lower p-value allowing us to statistically reject the FF model. Detailed results are available upon request.

\footnotetext{
${ }^{15}$ In unreported results, we find that the difference between the MAPE of our CP SDF model and the Fama-French model increases when we weight the 11 Euler equation errors by the inverse of their variance as opposed to equally. In addition, there remains a statistical difference between the p-values of $\chi^{2}$ tests of the null that all pricing errors are jointly zero between our CP SDF model $(5 \%)$ and the FF model $(<1 \%)$ with the alternative weighting matrix. The reason is that our model fits the bond return moments better.
} 


\subsection{Adding Corporate Bond Portfolios}

One asset class that deserves particular attention is corporate bonds. After all, at the firm level, stocks and corporate bonds are both claims on the firm's cash flows albeit with different priority structure. We ask whether, at the portfolio level, our SDF model is able to price portfolios or corporate bonds sorted by ratings class. Fama and French (1993) also include a set of corporate bond portfolios in their analysis but end up concluding that a separate credit risk factor is needed to price these portfolios. Instead, we find that the same three factors we used so far also do a good job pricing the cross-section of corporate bond portfolios.

Because the sample of corporate bond data starts only in 1980, we start by re-estimating our main results on this subsample. The second and fifth columns of Table 3 shows the results. The MAPE on the 11 tests assets we considered in Section 3.3 is $44 \mathrm{bp}$ when we use $Z=C P$ and $69 \mathrm{bp}$ when $Z=Y S P$. These pricing errors are nearly identical to those in the full sample. ${ }^{16}$ In terms of risk prices, we find a similar price of market risk, a more negative price of $L V L$ risk, and a smaller price of $C P$ and $Y S P$ risk. However, the risk price estimates are not statistically different from their full sample values. The null hypothesis that all risk price estimates are zero is strongly rejected for both models. Finally, for both models we fail to reject the null that all pricing errors are jointly zero. Even the $Y S P$ SDF model now has a p-value of $25 \%$.

The third and sixth columns show the pricing errors on the credit portfolios if we do not reestimate the market prices of risk. The models do a good job pricing the corporate bonds: mean absolute pricing errors on the credit portfolios are 73bp per year, compared to excess returns of more than $4 \%$ per year under risk-neutral pricing. The mean absolute pricing error among all fifteen test assets is 52 (72) basis points per year in column 3 (6); only 8 (3) basis points are added by the corporate bond portfolios.

Equally interesting is to re-estimate the market price of risk parameters of the SDF model when

\footnotetext{
${ }^{16}$ In unreported results, we also studied the subsample 1963-2012, an often-used period for cross-sectional equity analysis (e.g., Fama and French, 1993). For that sample, the MAPE is 43bp for the CP SDF and 77bp for the YSP SDF, again very similar to the full sample. Detailed results are available upon request. The p-value of the null hypothesis that all pricing errors are jointly zero is $5.7 \%$ for the $\mathrm{CP} \mathrm{SDF}$ and $4.1 \%$ for the $Y S P \mathrm{SDF}$.
} 


\section{Table 3: Unified SDF Model for Stocks, Treasuries, and Corporate Bonds}

Panel A of this table reports pricing errors on five book-to-market-sorted stock portfolios, the value-weighted market portfolio, five Treasury bond portfolios of maturities 1, 2, 5, 7, and 10 years, and four corporate bond portfolios sorted by S\&P credit rating (AAA, AA, A, and BBB). They are expressed in percent per year. The sample is February 1980 until December 2011.

\begin{tabular}{|c|c|c|c|c|c|c|c|c|}
\hline & \multicolumn{8}{|c|}{ Panel A: Pricing Errors (\% per year) } \\
\hline & \multirow[t]{2}{*}{ RN SDF } & \multicolumn{3}{|c|}{ CP SDF } & \multicolumn{3}{|c|}{ ysp SDF } & \multirow[t]{2}{*}{ FF } \\
\hline & & \multicolumn{2}{|c|}{ not re-estimated } & \multirow{2}{*}{$\begin{array}{c}\text { reestimated } \\
0.58\end{array}$} & \multicolumn{2}{|c|}{ not re-estimated } & \multirow{2}{*}{$\begin{array}{c}\text { reestimated } \\
0.94\end{array}$} & \\
\hline $10-\mathrm{yr}$ & 3.91 & 0.22 & 0.22 & & 0.74 & 0.74 & & -0.41 \\
\hline $7-\mathrm{yr}$ & 3.80 & 0.15 & 0.15 & 0.51 & 0.15 & 0.15 & 0.51 & 0.29 \\
\hline $5-\mathrm{yr}$ & 3.08 & -0.15 & -0.15 & 0.18 & -0.53 & -0.53 & -0.11 & 0.53 \\
\hline $2-\mathrm{yr}$ & 1.86 & -0.41 & -0.41 & -0.18 & -0.92 & -0.92 & -0.52 & 0.75 \\
\hline $1-y r$ & 1.27 & -0.13 & -0.13 & 0.02 & -0.52 & -0.52 & -0.25 & 0.78 \\
\hline Market & 6.92 & -0.96 & -0.96 & -0.99 & -1.15 & -1.15 & -1.17 & 0.86 \\
\hline BM1 & 6.76 & -0.26 & -0.26 & -0.42 & -1.07 & -1.07 & -1.21 & 0.46 \\
\hline BM2 & 8.11 & 0.79 & 0.79 & 0.72 & 0.39 & 0.39 & 0.34 & -1.01 \\
\hline BM3 & 7.57 & 0.24 & 0.24 & 0.21 & 0.20 & 0.20 & 0.15 & -1.51 \\
\hline BM4 & 8.06 & -0.68 & -0.68 & -0.47 & 0.37 & 0.37 & 0.52 & -1.41 \\
\hline BM5 & 10.04 & 0.88 & 0.88 & 1.07 & 1.50 & 1.50 & 1.71 & 1.83 \\
\hline Credit1 & 3.40 & & -1.23 & -0.80 & & -1.33 & -0.79 & 0.43 \\
\hline Credit2 & 3.64 & & -0.95 & -0.54 & & -1.05 & -0.56 & 0.46 \\
\hline Credit3 & 4.12 & & -0.58 & -0.19 & & -0.77 & -0.28 & 1.06 \\
\hline Credit4 & 4.63 & & -0.14 & 0.23 & & -0.05 & 0.38 & 2.10 \\
\hline \multirow[t]{2}{*}{ MAPE } & 5.14 & 0.44 & 0.52 & 0.47 & 0.69 & 0.72 & 0.63 & 0.93 \\
\hline & \multicolumn{7}{|c|}{ Panel B: Prices of Risk Estimates } & \\
\hline \multirow{3}{*}{\multicolumn{2}{|c|}{$\begin{array}{l}\mathrm{LVL} / \mathrm{SMB} \\
\mathrm{CP} / \mathrm{YSP} / \mathrm{HML}\end{array}$}} & 2.20 & 2.20 & 2.31 & 2.84 & 2.84 & 2.89 & 6.77 \\
\hline & & -22.47 & -22.47 & -20.06 & -15.41 & -15.41 & -13.97 & -22.54 \\
\hline & & 51.47 & 51.47 & 45.81 & 66.25 & 66.25 & 53.20 & 2.53 \\
\hline \multicolumn{9}{|c|}{ Panel C: P-values of $\chi^{2}$ Tests } \\
\hline$\Lambda_{0}=0$ & - & $1.19 \%$ & - & $1.38 \%$ & $0.53 \%$ & - & $0.52 \%$ & $0.61 \%$ \\
\hline Pr. err. $=0$ & - & $25.96 \%$ & - & $9.75 \%$ & $25.09 \%$ & - & $13.50 \%$ & $0.87 \%$ \\
\hline
\end{tabular}


the corporate bond portfolios are included in the set of test assets. Columns 4 and 7 of Table 3 show that the corporate bond pricing errors go through zero. For the CP SDF, the MAPE on the credit portfolios is 44 basis points per year and the overall MAPE on all 15 assets is 47 basis points per year, 3 basis points above the MAPE when corporate bonds are not considered, and 5 basis points less than when the corporate bonds were not included in the estimation. For the YSP SDF, the MAPE on the credit portfolios is 50 basis points per year and the overall MAPE is 63 basis points per year, lower than the average without corporate bonds. Neither model is rejected, with p-values of $9.8 \%$ and $13.5 \%$.

Repeating the bootstrap exercise explained in Appendix C.2, we find a p-value of 3.5\% for our $C P \mathrm{SDF}$ and of $11.5 \%$ for the $Y S P$ SDF. These p-values are substantially lower than the ones for the full sample results without corporate bond portfolios. They imply that is is statistically unlikely that the pricing results are generated by chance alone (and once estimation error from generated regressors is taken into account). The additional test assets are useful in helping to statistically discriminate our model from a random one.

The last column of Table 3 reports results for the Fama-French three-factor model. Its pricing errors are higher than in our three-factor model; the MAPE is 93 basis points. Average pricing errors on the corporate bond portfolios are 1\% per year. The model severely underprices the BBBrated portfolio 4. Unlike our model, which we fail to reject, the Fama-French model is rejected with a p-value of $0.9 \%$.

\subsection{Robustness}

This section considers additional priced risk factors in lieu of $C P$ or $Y S P$ as well as additional sets of test assets. These exercises confirm the robustness of our empirical results. Detailed results are in the Online Appendix. 


\subsubsection{Other Yield Curve Factors}

The $C P$ factor and the yield spread $Y S P$ are both specific linear combinations of one- through five-year bond yields that predict economic activity and whose innovations have a monotonic covariance pattern with returns on the book-to-market portfolios. There are other linear combinations of the same five yields which may be better predictors of economic activity. Similarly, there may be other linear combinations of yields that do a better job pricing the cross-section of stock and bond returns. We briefly consider two alternatives to $C P$ and $Y S P$. The first one, $Y G R$, is the linear combination of bond yields that best forecasts economic activity levels 12 months ahead. The second one, $Y A P$, is the linear combination of bond yields that best prices the 11 test assets over the full sample. While both measures are constructed in sample, they constitute natural points of comparison. The $C P$ factor has a correlation of $58 \%$ with $Y G R$ and $74 \%$ with $Y A P$, while $Y S P$ has correlations of $69 \%$ with $Y G R$ and $30 \%$ with $Y A P .{ }^{17}$

The pricing model with $Z=Y G R$ generates a MAPE of 59bp for the full sample, 45bp for the post-1980 sample, and 57bp when we include the credit portfolios. In all three exercises, we cannot reject the model (p-values of 40\%,77\%, and 36\% respectively). The price of risk estimate for YGR in the main exercise is 112 , similar in magnitude and not statistically different from that of $C P .{ }^{18}$ These pricing results are better than for the $Y S P$ SDF and slightly worse than for the $C P$ SDF. They indicate that there is a lot of information about future economic growth in the term structure that is useful for pricing stocks and bonds. They also confirm that there is nothing special about $C P$ for asset pricing beyond its ability to forecast economic growth. ${ }^{19}$

Conversely, we find that we can lower MAPE to a mere 29bp per year in the full sample by finding the best-pricing linear combination of 1- through 5-year bond yields. Using that same linear combination $Y A P$, pricing errors are 33bp for the post-1980 sample, and 44bp for the same sample

\footnotetext{
${ }^{17}$ We discussed the ability of $C P, Y S P$, and $Y G R$ to forecast economic activity in Section 2 . The predictability of $Y A P$ peaks at 21 months with $R^{2}$ of $8.5 \%$. It is statistically significant predictor of $C F N A I$ for horizons ranging from 9 months to 27 months.

${ }^{18}$ We have scaled $Y G R$ so that it has the same standard deviation as $C P$.

${ }^{19}$ We find similar pricing results for the linear combination of 1- through 5-year bond yields that best forecasts CFNAI 24-months ahead, and for the linear combination that best forecasts GDP growth 5 quarters ahead.
} 
with credit portfolios. P-values for these three exercises are 25\%, 33\%, and 5\%. The $74 \%$ correlation of $C P$ with $Y A P$, relative to that the $30 \%$ correlation of $Y S P$ with $Y A P$, helps explain why the pricing results are stronger with $C P$. Both $C P$ and $Y A P$ are earlier indicators of the cycle than $Y S P$ and $Y G R$; they predict economic activity about two years out rather than about one year out.

\subsubsection{Other Test Assets}

In addition to the credit portfolios discussed above, Online Appendix $\mathrm{C}$ considers several additional equity portfolio sorts: ten size-sorted portfolios, ten earnings-to-price sorted portfolios, and twenty-five size and value double-sorted portfolios. Our model is able to reduce pricing errors on all of these sets of test assets substantially. We also discuss results using a different weighting matrix in the market price of risk estimation, which are very similar to our main results.

\subsection{Individual Firm Returns}

As a final robustness check, we investigate whether exposure to $C P$ shocks is associated with higher equity risk premia not only among stock and bond portfolios, but also among individual stocks. We look both at single-sorted portfolios as well as at equity portfolios that are doublesorted based on their $C P$ exposure and their book-to-market ratio.

Our sample is the CRSP/Compustat universe between July 1963 and December 2010. For each stock-month pair, we estimate the covariance between monthly $C P$ innovations and the stock's return based on 60-month rolling windows. If a shorter history is available of a certain stock, we require at least 12 observations to estimate the $C P$ exposure. We start our first sort in July 1968. This ensures that we have 60 months of data for a substantial cross section of stocks to estimate the $C P$ exposure more reliably. We sort stocks each year in June based on their $C P$-exposure and calculate the quintile portfolio returns over the next 12 months, value-weighting stocks within each portfolio. 
We first study returns of five portfolios sorted on their exposure to $C P$ shocks in the previous 60 months. Table 4 reports a spread in average returns between the highest- $C P$ exposure and the lowest- $C P$ exposure of $2.4 \%$ per year. The standard CAPM cannot explain these portfolio returns. The spread in CAPM alphas is $2.4 \%$, as high as the raw return spread. The MAPE of the CAPM for these CP-quintile portfolios is $82 \mathrm{bp}$ per year. In contrast, our three-factor model can explain the return spread in the $C P$ portfolios. The MAPE falls to 39bp and the Q5-Q1 spread in the "KLN alphas," the alphas with respect to our three factors, is only $0.5 \%$. Encouragingly, the point estimates for the prices of risk are quite similar to those presented in our main estimation, even though we used no bond portfolios and different equity portfolios. The risk price on CP equals 102, the risk price on the $L V L$ factor equals -45 , and that of the $M K T$ is close to zero. Because the exposure of the portfolios to $L V L$ and $M K T$ are about the same, the risk prices on these factors are hard to estimate separately with these five portfolios. If we remove the level factor, we find that the risk price from $C P$ hardly changes (from 102 to 97 ), but the price of market risk is now positive at 0.93. Finally, we compute the covariances of the five $C P$ portfolios with the $C P$ factor and find that the difference between the high- and low- $C P$ beta portfolios is positive. The positive risk price and positive spread in covariances allows our model to explain most of the spread in average returns between the $C P$ portfolios.

\section{Table 4: Individual Firm Returns: Single Sorts}

This table reports the results of sorting individual firms into five portfolios based on their exposure to $C P$ shocks. We use 60 -month rolling window estimates of $C P$ betas, where we require at least 12 months of data for a stock to be included in one of the five portfolios. The table reports the average excess return per portfolio, the CAPM alphas, the alphas for our three-factor model ("KLN alphas"), the $C P$ exposures of the five portfolios, the risk prices, and the mean absolute pricing error (MAPE) for the different models. The last row reports results for a version of our model where we omit the $L V L$ factor; we do this because the exposures of the five portfolios to $L V L$ and $M K T$ are very similar. The data are monthly from July 1963 through December 2010.

\begin{tabular}{|c|c|c|c|c|c|c|c|c|c|c|}
\hline & \multirow{2}{*}{$\begin{array}{l}\text { low } C P \\
\text { Exposure }\end{array}$} & & & & \multirow{2}{*}{$\begin{array}{l}\text { High } C P \\
\text { Exposure }\end{array}$} & \multirow[b]{2}{*}{ H-L CP beta } & \multicolumn{3}{|c|}{ Risk prices } & \multirow[b]{2}{*}{ MAPE } \\
\hline & & & & & & & $C P$ & $L V L$ & $M K T$ & \\
\hline Avg. excess ret. & $4.3 \%$ & $4.9 \%$ & $5.9 \%$ & $5.8 \%$ & $6.8 \%$ & $2.4 \%$ & & & & \\
\hline CAPM alphas & $-1.8 \%$ & $-0.2 \%$ & $1.0 \%$ & $0.5 \%$ & $0.6 \%$ & $2.4 \%$ & & & 2.07 & $82 \mathrm{bp}$ \\
\hline KLN alphas & $-0.2 \%$ & $-0.3 \%$ & $0.6 \%$ & $-0.5 \%$ & $0.4 \%$ & $0.5 \%$ & 102.22 & -45.28 & -0.15 & $39 \mathrm{bp}$ \\
\hline$C P$ covariances $\left(\times 10^{5}\right)$ & 2.30 & 2.13 & 1.96 & 2.95 & 3.60 & 1.30 & & & & \\
\hline KLN alphas w/o LVL & $-1.1 \%$ & $0.1 \%$ & $1.4 \%$ & $0.0 \%$ & $-0.2 \%$ & $0.9 \%$ & 96.6 & & 0.93 & $56 \mathrm{bp}$ \\
\hline
\end{tabular}

The second exercise double sorts stocks into five quintiles based on their $C P$ exposure and then 
within $C P$ quintile based on their book-to-market $(B M)$ ratio. This results in a $5 \times 5$ sort (see Table IA.V in the Online Appendix). For each $B M$ group, we find a positive spread between high and low- $C P$ exposure portfolios, with spreads ranging from $0.5 \%$ to $4.6 \%$ per year. We also find that the spread between high and low $B M$ portfolios is positive in each $C P$ group. This could imply that $C P$ exposures and $B M$ are related, yet not the same. Or it could reflect estimation error in $C P$ exposures which prevents $C P$ exposure from fully subsuming $B M$ exposure.

Turning to the pricing, we find that the CAPM model cannot explain the heterogeneity in average returns on the 25 portfolios along either dimension. The MAPE of the CAPM is $171 b p$ per year. In contrast, our three-factor model eliminates a substantial fraction of the spread along both $C P$ and $B M$ dimensions. The MAPE reduces to 100bp. Ex-post $C P$ exposures are higher for the portfolios with higher ex-ante $C P$ exposures as well as for portfolios with higher $B M$ ratios. In further support for our model, we find comparable market price of risk estimates to the benchmark ones, but from this double-sorted cross-section of equity portfolios (without bonds). ${ }^{20}$ Taken together, these results suggest that there are separate spreads along the dimensions of ex-ante $C P$ exposure and $B M$ ratio. However, both spreads are to a large extent accounted for by our model, and with risk prices that are similar to ones we estimated using other cross-sections of assets.

\section{Conclusion}

Our paper provides new evidence that the value premium reflects compensation for macroeconomic risk. Times of low returns on value stocks versus growth stocks are times when future economic activity is low and future cash-flows on value stocks are low relative to those on growth stocks. We find that several bond market variables such as the slope of the yield curve and the Cochrane-Piazzesi factor are leading indicators of these business cycle turning points. Innovations to these factor are contemporaneously highly positively correlated with returns on value stocks, but uncorrelated with returns on growth stocks.

\footnotetext{
${ }^{20}$ For the market price of $C P$ risk we find 71 (compared to 74 for the benchmark estimate on the post-1963 sample), for $L V L$ risk we estimate $-24(-20)$, and for $M K T$ we have 0.8 (1.3).
} 
Based on this connection, we estimate a parsimonious three-factor pricing model that explains return differences between average excess returns on book-to-market sorted stock portfolios, the aggregate stock market portfolio, government bond portfolios sorted by maturity, and corporate bond portfolios. The first factor is the traditional market return factor, the second one is the level of the term structure, and the third factor is the $C P$ factor or the yield spread. We estimate a positive market price of risk for the latter risk factor, consistent with the notion that positive innovations represent good news about future economic activity.

Our paper establishes that transitory shocks to the real economy operating at business cycle frequencies play a key role in the cross-section of stock returns. Future work on structural Dynamic Asset Pricing Models should bring the business cycle explicitly inside the model as a key state variable. Clearly, more work on dynamic equilibrium asset pricing models is needed to help us fully understand why the market compensates exposure to innovations to this state variable so generously. 


\section{References}

Ang, Andrew, and Geert Bekaert, 2007, Stock return predictability: Is it there?, Review of Financial Studies 20 (3), 651-707. 6, 22

Baker, Malcolm, and Jeffrey Wurgler, 2012, Comovement and predictability relationships between bonds and the cross-section of stocks, Review of Asset Pricing Studies June. 6

Bakshi, Gurdip, and Zhiwu Chen, 1997, An alternative valuation model for contingent claims, Journal of Financial Economics 44, 123-165. 4

— , 2005, Stock valuation in dynamic economies, Journal of Financial Markets 8, 111-151. 4

Bansal, Ravi, Robert F. Dittmar, and Dana Kiku, 2007, Cointegration and consumption risks in asset returns, Review of Financial Studies forthcoming. 5

Bansal, Ravi, Robert F. Dittmar, and Christian Lundblad, 2005, Consumption, dividends and the crosssection of equity returns, Journal of Finance 60(4), 1639 - 1672. 5

Bansal, Ravi, Dana Kiku, and Amir Yaron, 2010, Long-run risks, the macroeconomy, and asset prices, American Economic Review: Papers and Proceedings 100(2), 1-4. 4

Bansal, Ravi, and Bruce N. Lehman, 1997, Growth optimal portfolio restrictions on asset pricing models, Macroeconomic Dynamics 1, 333-354. 5

Bansal, Ravi, and Ivan Shaliastovich, 2010, A long-run risks explanation of predictability puzzles in bond and currency markets, Working Paper Duke University and the Wharton School. 5, 16

Bansal, Ravi, and Amir Yaron, 2004, Risks for the long run: A potential resolution of asset prizing puzzles, The Journal of Finance 59, 1481-1509. 4, 5

Basu, Susanto, 1977, The investment performance of common stocks in relation to their price to earnings ratios: A test of the efficient market hypothesis, Journal of Finance 32, 663-82. 1

Bekaert, Geert, Eric Engstrom, and Steven Grenadier, 2010, Stock and bond returns with moody investors, Journal of Empirical Finance 17 (5), 867-894. 4, 17

Bekaert, Geert, Eric Engstrom, and Yuhang Xing, 2009, Risk, uncertainty and asset prices, Journal of Financial Economics 91, 59-82. 4, 17

Binsbergen, Jules van, and Ralph Koijen, 2010, Predictive regressions: A present-value approach, Journal of Finance 65 (4). 7

Brennan, Michael J., Ashley W. Wang, and Yihong Xia, 2004, Estimation and test of a simple model of intertemporal capital asset pricing, The Journal of Finance 59 (4), 1743-1775. 6

Brooks, Jordan, 2011, Unspanned risk premia in the term structure of interest rates, Ph.D. thesis New York University. 10

Campbell, John, Adi Sunderam, and Luis Viceira, 2012, Inflation bets or deflation hedges? the changing risk of nominal bonds, Working Paper Harvard University. 5, 17, 24

Campbell, John Y., and John H. Cochrane, 1999, By force of habit: A consumption-based explanation of aggregate stock market behavior, Journal of Political Economy 107, 205-251. 5 
Campbell, John Y., Christopher Polk, and Tuomo Vuolteenaho, 2010, Growth or glamour? fundamentals and systematic risk in stock returns., The Review of Financial Studies 23(1), 305-344. 6

Campbell, John Y., and Tuomo Vuolteenaho, 2004, Good beta, bad beta, American Economic Review 94(5), 1249-1275. 6

Chen, Long, 2009, On the reversal of return and dividend predictability: A tale of two periods, Journal of Financial Economics 92, 128-151. 9

Chen, Nai-Fu, Richard Roll, and Stephen A. Ross, 1986, Economic forces and the stock market, Journal of Business 59, 383-403. 5

Cochrane, John H., 2008, The dog that did not bark: A defense of return predictability, Review of Financial Studies 21(4), 1533-1575. 1

- and Lars Peter Hansen, 1992, Asset pricing explorations for macroeconomics, in Olivier J. Blanchard, and Stanley Fischer, ed.: NBER Macroeconomics Annual: 1992 . pp. 115-165 (MIT Press: Cambridge, MA). 5

Cochrane, John H., and Monika Piazzesi, 2005, Bond risk premia, American Economic Review 95, 138-160. $10,22,1,9$

— , 2008, Decomposing the yield curve, Working Paper, University of Chicago. 3, 22, 25

Cooper, Ilan, and Richard Priestly, 2008, Time-varying risk premiums and the output gap, Review of Financial Studies 22, 2801-2833. 10

Daniel, Kent, and Tobias Moskowitz, 2011, Momentum crashes, Working paper Chicago Booth and Columbia GSB. 19

David, Alexander, and Pietro Veronesi, 2009, What ties return volatilities to price valuations and fundamentals?, Working Paper Chicago Booth. 17

De Bondt, Werner F.-M., and Richard Thaler, 1985, Does the stock market overreact?, Journal of Finance 40, 793-805. 1

Duffie, Darrell, and Raymond Kan, 1996, A yield factor model of interest rates, Mathematical Finance 6, 379-406. 20

Fama, Eugene F., and Kenneth R. French, 1992, The cross-section of expected stock returns, Journal of Finance 47, 427-465. 1, 21, 30

, 1993, Common risk factors in the returns on stocks and bonds, Journal of Financial Economics $33,3-56$. 30, 31

Ferson, Wayne E., and Campbell R. Harvey, 1991, The variation of economic risk premiums, Journal of Political Economy 99, 385-415. 5

Gabaix, Xavier, 2012, Variable rare disasters: An exactly solved framework for ten puzzles in macro finance, Quarterly Journal of Economics 127(2), 645-700. 4

Gilchrist, Simon, and Egon Zakrajsek, 2012, Credit spreads and business cycle fluctuations, American Economic Review Forthcoming. 10 
Hansen, Lars Peter, John C. Heaton, and Nan Li, 2008, Consumption strikes back? measuring long-run risk, Journal of Political Economy 116 (2), 260-302. 5, 7

Hansen, Lars Peter, and Ravi Jagannathan, 1997, Assessing specific errors in stochastic discount factor models, Journal of Finance 52, 557-590. 11

Joslin, Scott, Michael Priebsch, and Kenneth Singleton, 2010, Risk premiums in dynamic term structure models with unspanned macro risks, Working Paper Stanford University and MIT. 10

Kazemi, Hossein, 1992, An intertemporal model of asset prices in a markov economy with a limiting stationary distribution, Review of Financial Studies 5, 85-104. 5

Lakonishok, Josef, Andrei Schleifer, and Robert W. Vishny, 1994, Contrarian investment, extrapolation, and risk, The Journal of Finance 49 (5), 1541-1578. 1

Larrain, Borja, and Motohiro Yogo, 2007, Does firm value move too much to be justified by subsequent changes in cash flow?, Journal of Financial Economics 87(1), 200-226. 7

Lettau, Martin, and Jessica Wachter, 2009, The term structures of equity and interest rates, Working Paper University of Pennsylvania Wharton School. 4, 17, 25

Ludvigson, Sydney, and Serena Ng, 2009, Macro factors in bond risk premia, Forthcoming Review of Financial Studies. 10

Lustig, Hanno, Stijn Van Nieuwerburgh, and Adrien Verdelhan, 2012, The wealth-consumption ratio, Review of Asset Pricing Studies 3(1), 38-94. Review of Asset Pricing Studies. 5

Menzly, Lior, Tano Santos, and Pietro Veronesi, 2004, Understanding predictability, Journal of Political Economy 112, 1-47. 5

Petkova, Ralitsa, 2006, Do the fama-french factors proxy for innovations in predictive variables?, Journal of Finance 61(2), 581-612. 6

Piazzesi, Monika, and Martin Schneider, 2006, Equilibrium yield curves, National Bureau of Economic Analysis Macroeconomics Annual. 5

Santos, Jesus, and Pietro Veronesi, 2010, Habit formation, the cross-section of stock returns and the cash flow risk puzzle, Journal of Financial Economics 98, 385-413. 5

Wachter, Jessica, 2006, A consumption-based model of the term structure of interest rates, Journal of Financial Economics 79, 365-399. 5, 16

Yoon, Pyung Sig, and Laura T. Starks, 1995, Signaling, investment opportunities, and dividend annoucements, Review of Financial Studies 8 (4), 995-1018. 3, 9

Zhang, Lu, 2005, The value premium, Journal of Finance 60 (1), 67-103. 5 


\section{Online Appendix (Not for Publication)}

\section{A. Additional Results for Section 2}

Dividends Around NBER Recessions pre-1952 The main text shows the behavior of log annual real dividends on value (fifth book-to-market), growth (first book-to-market), and market portfolios in the left panel of Figure 2 as well as the difference in dividend growth between value and growth portfolios in the right panel of Figure 2. Figure IA.1 shows the corresponding evidence for the period 1926 until 1952. The message of these figures is very much consistent with the discussion in the main text.
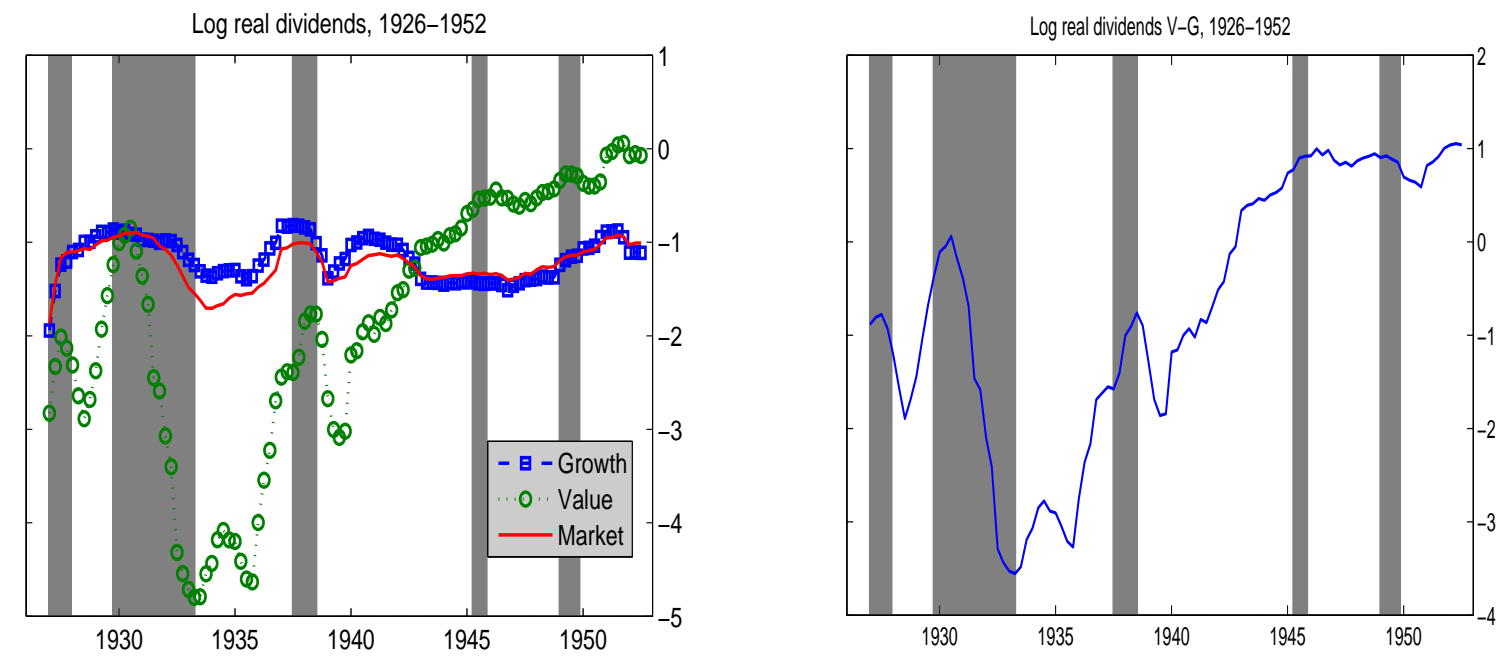

Figure IA.1: Dividends on value, growth, and market portfolios pre-1952.

The left panel plots the log real dividend on book-to-market quintile portfolios 1 (growth, dashed line with squares) and 5 (value, dotted line with circles) and on the CRSP value-weighted market portfolio. The right panel plots the log real dividend on book-to-market quintile portfolios 5 (value) minus the log real dividend on the boot-to-market portfolio 1 (growth). Dividends are constructed form cumand ex-dividend returns on these portfolios. Monthly dividends are annualized by summing dividends received during the year. The data are monthly from December 1926 until June 1952 and are sampled every three months in the figure.

Predicting GDP growth with CP In the main text we show that the bond factors $Z$ forecast future economic activity, as measured by the $C F N A I$ index. As an alternative to CFNAI, we consider real gross domestic product (GDP) growth (seasonally adjusted annual rates) from the National Income and Product Accounts. The GDP data are available only at quarterly frequency, but go back to 1952 when the $C P$ series starts. This gives us a longer sample than for CFNAI, which starts in 1967 . When $Z=C P$, our results update a regression that appears in the working paper version of Cochrane and Piazzesi (2005). The yield factor $Z$ in a given quarter is set equal to the value in the last month of the quarter. We estimate

$$
\Delta G D P_{t+k}=c_{k}+\beta_{k} Z_{t}+\varepsilon_{t+k},
$$

where $k$ is the forecast horizon expressed in quarters. Table IA.I shows the coefficient estimates $\beta_{k}$ in Panel B. For comparison, Panel A predicts CFNAI with the same variables using the same quarterly frequency. CFNAI then refers to the last month of the quarter. The predictors have been scaled to have the same standard deviation within each sample so that the point estimates are directly comparable for different 
predictors $Z$. In addition to $C P$ and $Y S P$, we also consider the best linear forecaster of GDP growth 5 quarters out, the horizon over which we get the highest overall predictability. We call this yield curve predictor $Y G D P$.

We find that all three predictors strongly forecast annual GDP growth 4 to 8 quarters ahead. That is, they predict GDP growth over the following year and over the year thereafter. The yield spread YSP is again a stronger predictor at shorter horizons while $C P$ is a stronger predictor at longer horizons. $C P$ predicts GDP growth at longer horizons even better than $Y G D P$. The $R^{2}$ value for $C P(Y S P)$ at $k=5$ quarters is $5.5 \%(9.6 \%)$, compared to $22.1 \%$ for $Y G D P$, the theoretical maximum. At $k=8$ quarters, the $R^{2}$ value for $C P(Y S P)$ is $6.9 \%(4.4 \%)$, compared to $8.4 \%$ for $Y G D P$. For longer horizons, $C P$ has the highest $R^{2}$. All variables lose statistical significance for horizons of 10 quarters or more. The results in Panel A confirm what we learned in the main text: $C P$ predicts economic activity strongly, and more strongly so at longer horizons. The $Y S P$ predicts $C F N A I$ about as well as $Y G D P$ at intermediate horizons.

\section{Table IA.I: Predicting Quarterly CFNAI and GDP Growth}

This table reports slope coefficients from predictive regressions. The predictors $Z$ are listed in the first row. They are the CP factor, the yield spread YSP, and the best linear forecaster of real GDP growth 5 quarters ahead, YGDP. The forecast horizon is listed in the first column. All predictors have the same standard deviation over the sample so that the slope coefficients within each panel are directly comparable. In Panel A, the bond market variables forecast $C F N A I$ (last month of the quarter). In Panel B, they forecast real four-quarter GDP growth, measured quarterly. The data in Panel A are quarterly for 1967.I through 2012.IV while the data in Panel B are quarterly for 1952.III until 2012.IV.

\begin{tabular}{|c|c|c|c|c|c|c|}
\hline \multirow[b]{2}{*}{$k$} & $\mathrm{CP}$ & YSP & YGDP & $\mathrm{CP}$ & YSP & YGDP \\
\hline & \multicolumn{3}{|c|}{ Panel A: CFNAI } & \multicolumn{3}{|c|}{ Panel B: GDP Growth } \\
\hline 4 & 15.60 & 18.88 & 29.85 & 0.33 & 0.47 & 0.72 \\
\hline 5 & 19.35 & 19.74 & 31.21 & 0.38 & 0.50 & 0.77 \\
\hline 6 & 25.56 & 20.26 & 25.93 & 0.37 & 0.44 & 0.68 \\
\hline 7 & 28.81 & 20.38 & 19.67 & 0.40 & 0.39 & 0.58 \\
\hline 8 & 25.19 & 16.51 & 10.43 & 0.42 & 0.34 & 0.46 \\
\hline 9 & 22.45 & 13.81 & 7.58 & 0.37 & 0.23 & 0.24 \\
\hline 10 & 20.06 & 11.71 & 4.29 & 0.34 & 0.17 & 0.14 \\
\hline 11 & 17.74 & 8.85 & 0.82 & 0.29 & 0.09 & 0.02 \\
\hline 12 & 11.14 & 4.49 & -4.00 & 0.22 & 0.03 & 0.00 \\
\hline
\end{tabular}

CP, YSP, and NBER Recessions Figure IA.2 plots the $C P$ and $Y S P$ factors over time (right axis) while drawing in NBER recessions (shaded areas). Consistent with the economic forecasting regressions, the $C P$ and $Y S P$ factors are low before the start of most recessions in the post-1952 sample. They subsequently increases over the course of a recession, especially towards the end of the recession when better times are around the corner. In nearly every recession, the CP and YSP factors are substantially higher at the end than at the beginning of the recession. In the three deepest post-war recessions, the 1974, 1982, and 2008 recessions, CP dips in the middle of the recession -suggesting that bond markets fear a future deterioration of future economic prospects- before recovering.

Real GDP in $C P$-event Time We also study the behavior of real annual GDP growth in $C P$-event time. GDP growth rates are available over the entire post-war sample, whereas CFNAI only starts in 


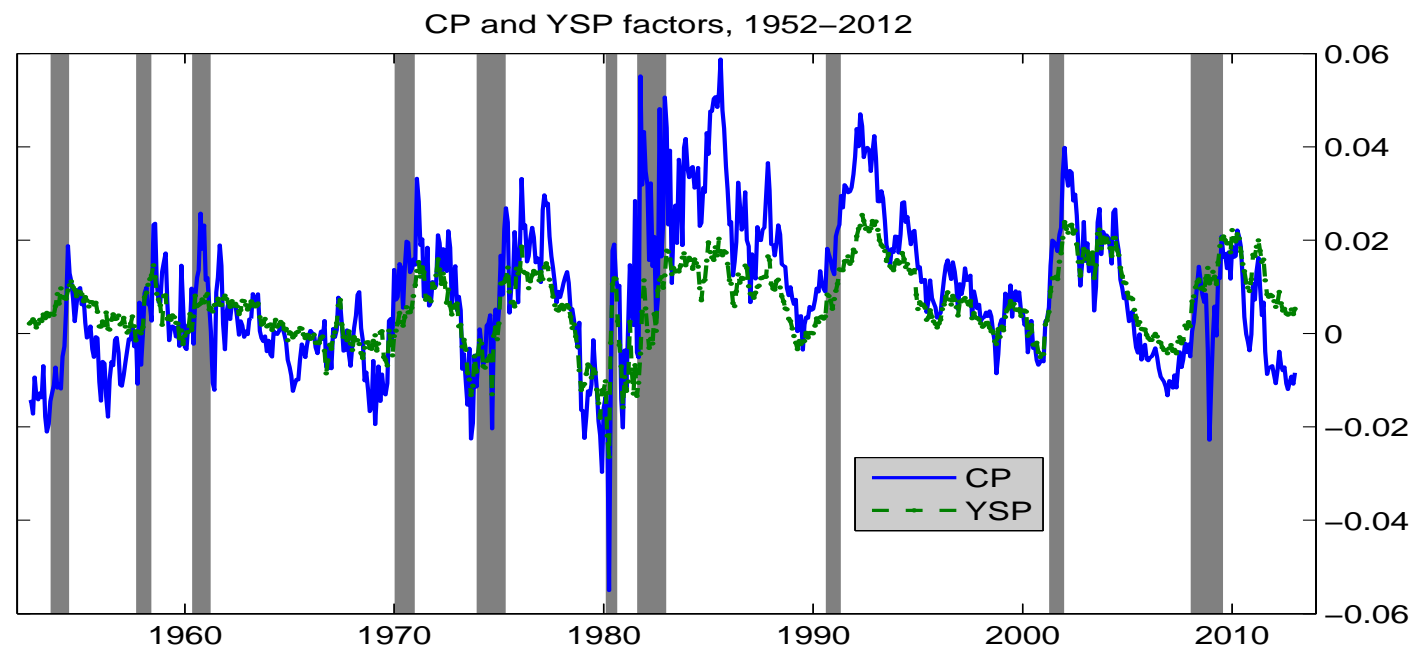

Figure IA.2: $C P$ factor and NBER recessions.

The figure plots the $C P$ factor (solid line, against the right axis) and the NBER recessions (shaded areas). The sample is July 1952 until December 2011.

1967. Figure IA.3 is the same as Figure 4 in the main text, except that real GDP growth is plotted in the bottom right-hand side panel instead of CFNAI. Like CFNAI, GDP growth also shows a clean cycle around low- $C P$ events. GDP grows at a rate that is $1.3 \%$ point above average two quarters before the event, the growth rate slows down to $0.6 \%$ points above the average in the event quarter, and growth further falls to a rate of $1.8 \%$ points below average five quarters after the event. The amplitude of this cycle $(3.1 \%$ points $)$ is economically large, representing 1.24 standard deviations of GDP growth.

Low- $Y S P$ Events Figure IA.4 is the same as Figure 4 in the main text, except that we condition on low realizations of the yield spread rather than low realizations of the $C P$ factor. Like the $C P$ factor, the yield spread first falls towards period 0 and later increases. Economic activity (and also GDP growth, not shown) fall following the low $Y S P$ event, consistent with the predictability evidence. Also, dividend growth on value minus growth falls, but with a substantial lag.

One-factor Model One may wonder whether the facts our paper documents are consistent with a one-factor model that differentially affects cash flow growth rates and therefore returns on value versus growth stocks. The data suggest that they are not. An adequate description of dividend dynamics contains at least two shocks: one shock that equally affects dividend growth rates on all portfolios and a second shock (to the $Z$ factor) that affects value dividends relative to growth dividends.

To see this, we orthogonalize V-G dividend growth to the dividend growth rate on the market portfolio. Figure IA.5 compares the dynamics of dividend growth on value minus growth around low-CP events (left panel, which repeats the bottom left panel of Figure 4) to those of dividend growth on the market portfolio (middle panel), and of the orthogonal component of V-G dividend growth (right panel). All three dividend growth series are demeaned over the full sample. The figure shows that the dividend growth on the market portfolio falls in the aftermath of a low-CP event, consistent with the facts on aggregate economic activity or GDP growth. The dividend growth rate on the market portfolio falls by $3.7 \%$ in the ten quarters following the $C P$ events. This is however a much smaller effect than the $19.9 \%$ point decline in V-G 

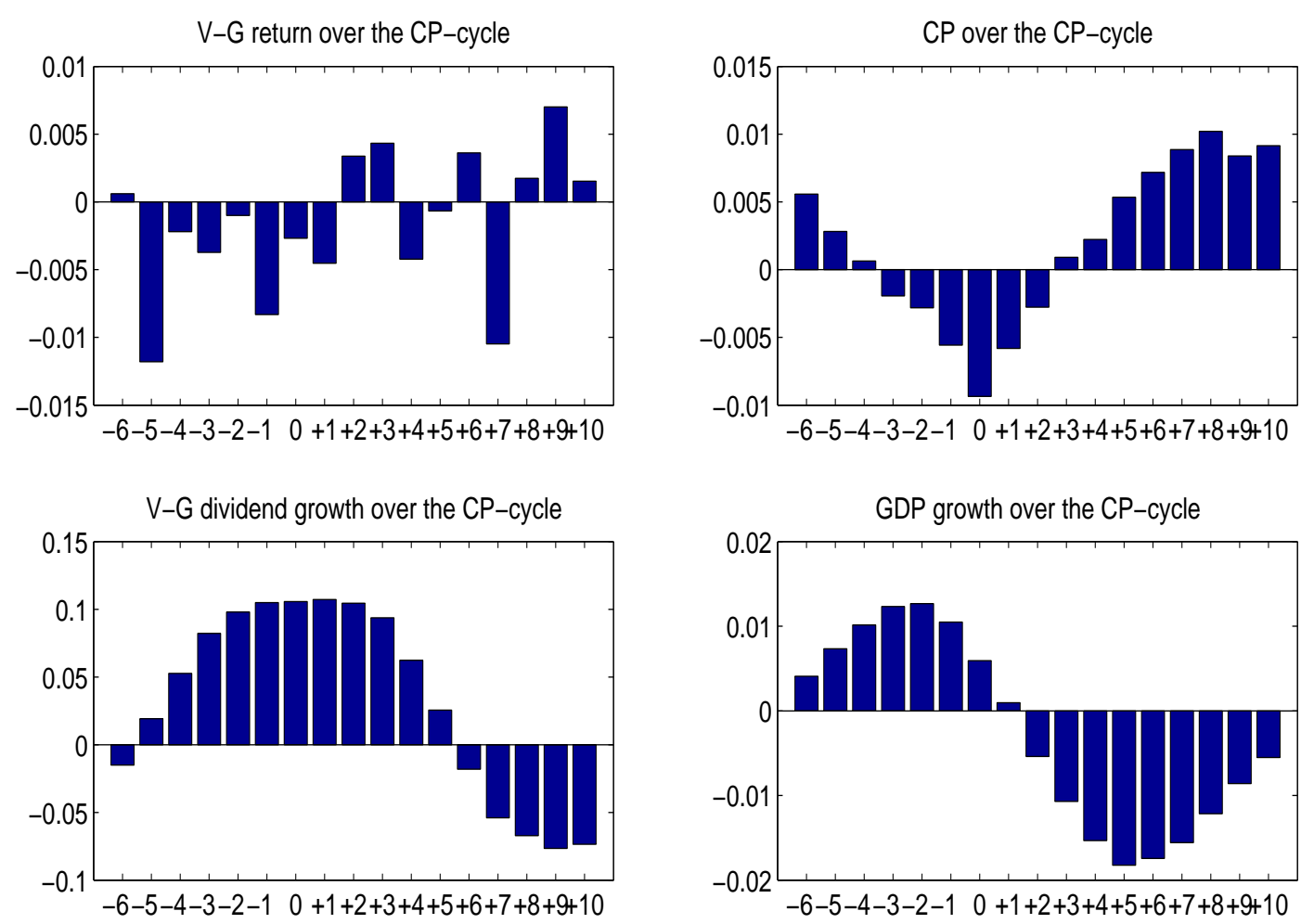

Figure IA.3: Low-CP Events with GDP Growth

The figure plots four quarterly series in event time. The event is defined as a quarter in which the quarterly CP factor in its respective lowest $25 \%$ of observations. This selection leads to 60 events out of 242 quarters. The sample runs from 1953.III until 2012.IV. In each panel, the period labeled ' 0 ' is the quarter in which the event takes place. The labels $-1,-2,-3$, etc refer to one, two, three, etc quarters before the event whereas the labels $+1,+2,+3$, etc. refer to one, two, three, etc quarters after the event. The top left panel plots the realization of the quarterly log return on value minus growth. The bottom left panel reports annual log dividend growth on value minus growth. The top right panel plots the CP factor. The bottom right panel plots real GDP growth. Real GDP growth is demeaned over the full sample.

dividend growth. Furthermore, the part of V-G dividend growth that is orthogonal to the market dividend growth, in the right panel, has qualitatively and quantitatively similar dynamics around $C P$ events as the raw V-G dividend growth in the left panel. It falls by $14.7 \%$ points in the ten quarters following an average low-CP event. The $R^{2}$ of the regression of $\mathrm{V}-\mathrm{G}$ dividend growth rate on the market dividend growth rate is only $14 \%$, leaving a lot of the dynamics in dividend growth on $\mathrm{V}-\mathrm{G}$ unaccounted for by dividend growth on the market portfolio.

There are several other reasons why our facts are inconsistent with a simple one-factor model, such as the CAPM. First, we can orthogonalize the $C P$ factor to the excess market portfolio return. The orthogonal component of $C P$ predicts dividend growth on $\mathrm{V}-\mathrm{G}$ as well as the raw $C P$ series does. The reason is that the $C P$ factor is nearly orthogonal to the excess stock market return; the $R^{2}$ of the orthogonalization regression is $2 \%$. Second, low-CP events do not coincide with periods of low aggregate stock market returns. Third, the evidence is inconsistent with a conditional tail-beta explanation. In periods of low market returns, the conditional beta of value stocks is lower than that of growth stocks. The theoretical model of Appendix D articulates this two-shock structure of cash flow growth. It features a common and permanent cash-flow shock that affects all portfolios alike, and a business-cycle frequency shock that 

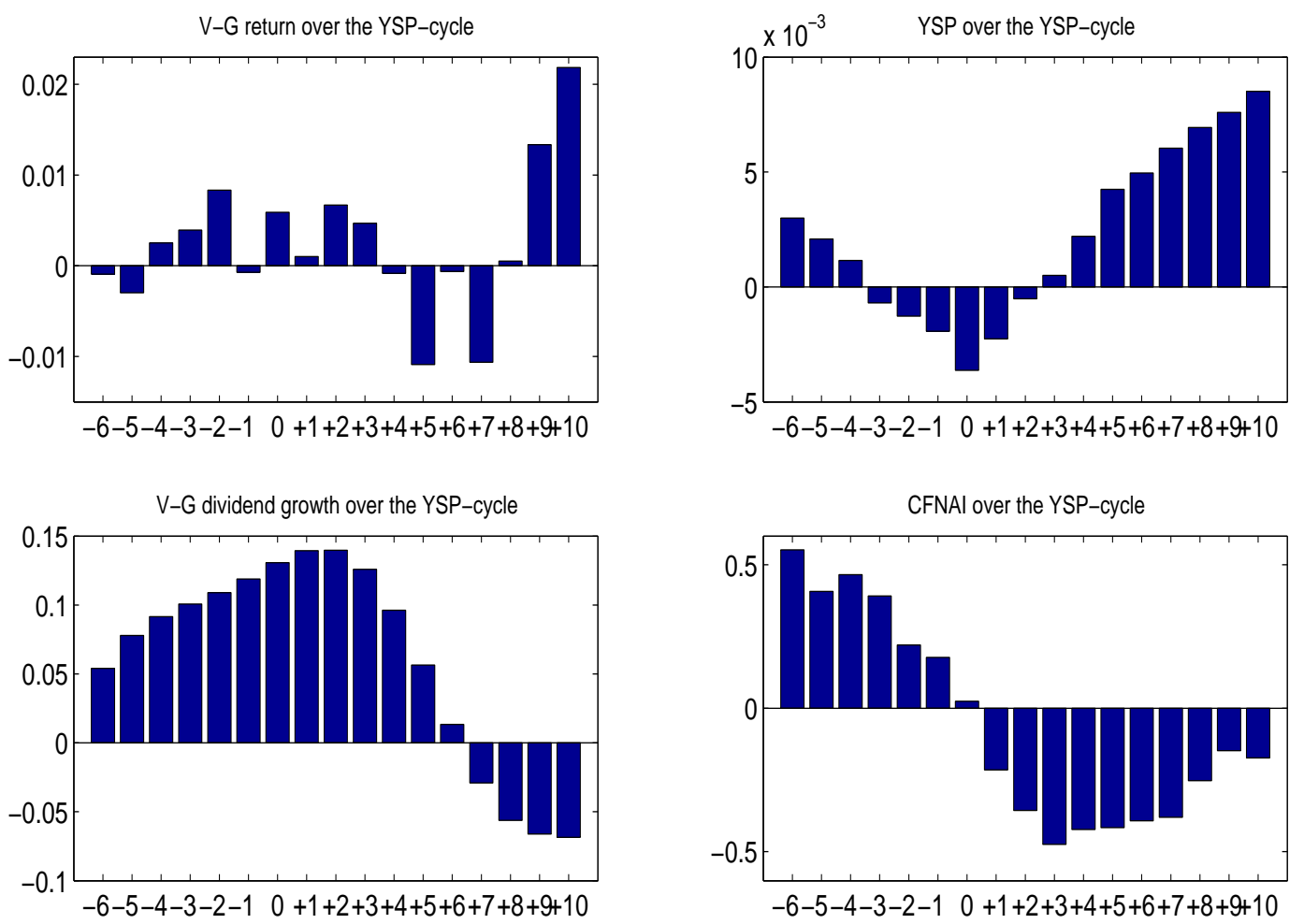

Figure IA.4: Low $C P$ Events

The figure plots four quarterly series in event time. The event is defined as a quarter in which the quarterly $Y S P$ factor in its respective lowest $25 \%$ of observations. This selection leads to 60 events out of 242 quarters. The sample runs from 1953.III until 2012.IV. In each panel, the period labeled ' 0 ' is the quarter in which the event takes place. The labels $-1,-2,-3$, etc refer to one, two, three, etc quarters before the event whereas the labels $+1,+2,+3$, etc. refer to one, two, three, etc quarters after the event. The top left panel plots the realization of the quarterly log return on value minus growth. The bottom left panel reports annual log dividend growth on value minus growth. The top right panel plots the $Y S P$ factor. The bottom right panel plots the CFNAI index of economic activity. The latter is available only from 1967.II onwards. Formally, the graph reports $c_{k}+\beta_{k}$ from a regression $X_{t+k}=c_{k}+\beta_{k} \mathcal{I}_{Y S P_{t}<L B}+\epsilon_{t+k}$, for various $k$, where $\mathcal{I}$ is an indicator variable, LB is the 25th percentile of $Y S P$, and $X$ is the dependent variable which differs in each of the four panels. Value-minus growth returns and value-minus-growth dividend growth have been demeaned over the full sample; CFNAI is also mean zero by construction.

differentially affects dividend growth rates of value and growth stocks.

Real GDP and $Y S P$ around Low-value Events Figure IA.6 shows the analogous figure to Figure 5 in the main text, except that real GDP growth is plotted in the bottom right-hand side panel instead of CFNAI and the yield spread $Y S P$ is plotted in the top right-hand side panel instead of $C P$. GDP growth is demeaned over the full sample. GDP growth is only modestly below average in period 0 (-0.33\% points), but falls to $-1.1 \%$ points below average two-to-three quarters after the event. The change from 4 quarters before to 3 quarters after is $1.6 \%$ points, which is almost two-thirds of a standard deviation of real GDP growth. Like $C P$, the yield spread $Y S P$ shows a v-shaped pattern around the low-value event, consistent with innovations to the $Y S P$ being positively correlated with low value returns. 


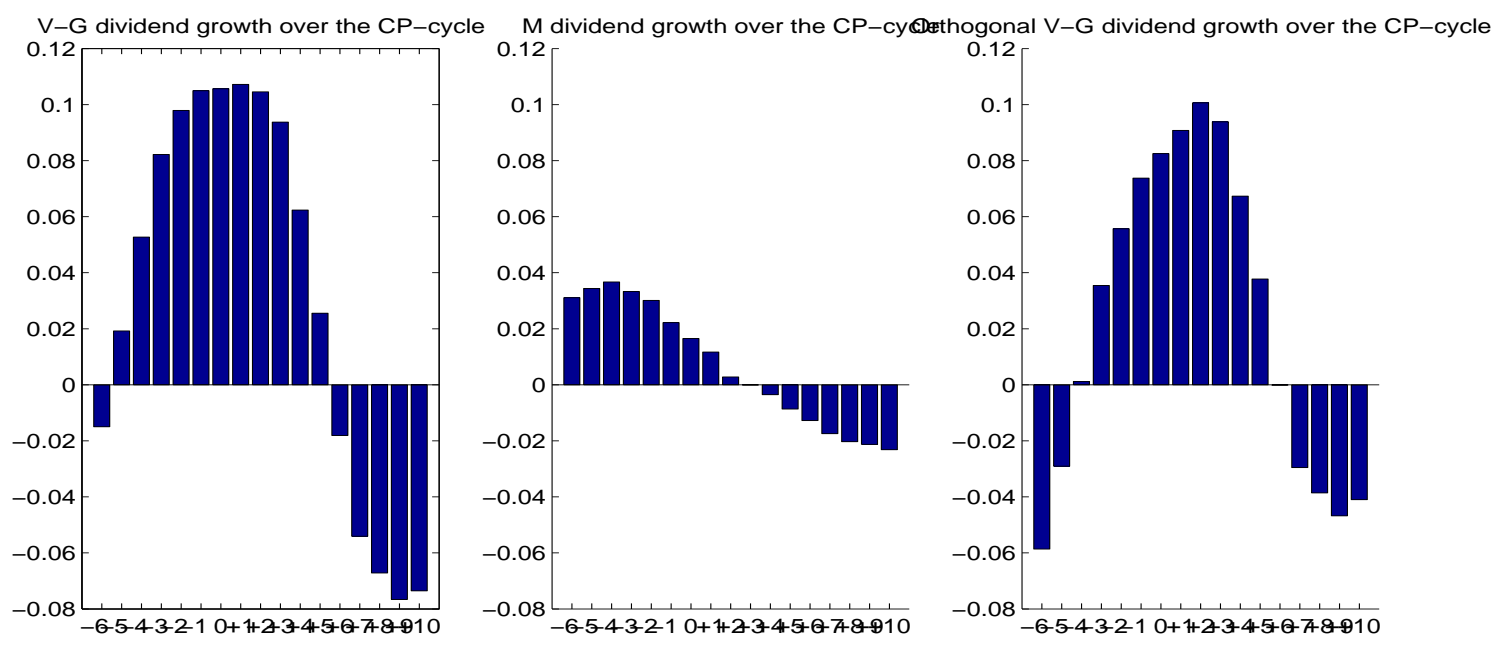

Figure IA.5: Dividend Growth Around Low-CP Events

The figure plots three quarterly series in event time. The event is defined as a quarter in which the quarterly CP factor in its respective lowest $25 \%$ of observations. This selection leads to 60 events out of 242 quarters. The sample runs from 1953.III until 2012.IV. In each panel, the period labeled ' 0 ' is the quarter in which the event takes place. The labels $-1,-2$, -3 , etc refer to one, two, three, etc quarters before the event whereas the labels $+1,+2,+3$, etc. refer to one, two, three, etc quarters after the event. The left panel plots annual log dividend growth on value minus growth, the middle panel plots annual log dividend growth on the market portfolio, and the right panel plots annual log dividend growth on value minus growth, orthogonalized to annual log dividend growth on the market portfolio. All three series have mean-zero over the full sample.

Dividend Growth Rates around Low-value Events Figure IA.7 compares the dynamics of dividend growth on value minus growth around value crash events (left panel, repeats the bottom left panel of Figure 5 in the main text) to the dynamics of dividend growth on the market portfolio (middle panel), and the part of V-G dividend growth that is orthogonal to market dividend growth rates (right panel). All three dividend growth series are demeaned over the full sample. The figure shows that (a) the dividend growth on the market portfolio falls in the aftermath of a low-CP event, consistent with the facts on aggregate economic activity or GDP growth, (b) that this effect is much smaller than that on V-G dividend growth, and (c) that the part of V-G dividend growth that is orthogonal to the market dividend growth, in the right panel, has qualitatively and quantitatively similar dynamics around low-value events as the raw V-G dividend growth in the left panel.

\section{B. How Pricing Stocks and Bonds Jointly Can Go Wrong}

Consider two factors $F_{t}^{i}, i=1,2$, with innovations $\eta_{t+1}^{i}$. We normalize $\sigma\left(\eta_{t+1}^{i}\right)=1$. Let $\operatorname{cov}\left(\eta_{t+1}^{1}, \eta_{t+1}^{2}\right)=$ $\rho=\operatorname{corr}\left(\eta_{t+1}^{1}, \eta_{t+1}^{2}\right)$. We also have two cross-sections of test assets with excess, geometric returns $r_{t+1}^{k i}$, $i=1,2$ and $k=1, \ldots, K_{i}$, with innovations $\varepsilon_{t+1}^{k i}$. We assume that these returns include the Jensen's correction term. Suppose that both cross-sections exhibit a one-factor pricing structure:

$$
E\left(r_{t+1}^{k i}\right)=\operatorname{cov}\left(\varepsilon_{t+1}^{k i}, \eta_{t+1}^{i}\right) \lambda_{i}, i=1,2 .
$$

The first factor perfectly prices the first set of test assets, whereas the second factor prices the second set of test assets. We show below that this does not imply that there exists a single SDF that prices both sets of assets. 

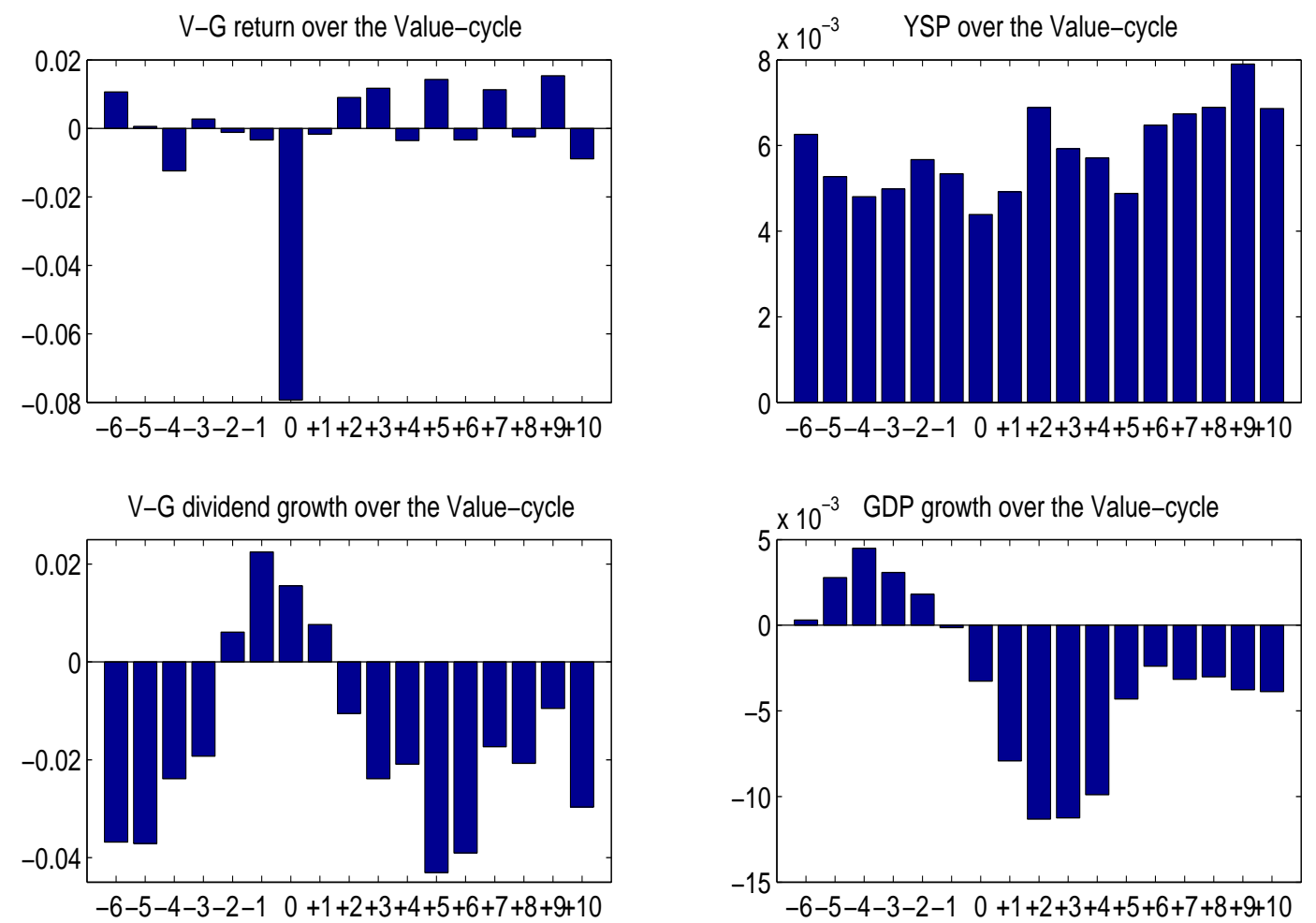

Figure IA.6: Low-value Events

The figure plots four quarterly series in event time. The event is defined as a quarter in which both the realized log real return on the fifth book-to-market portfolio (value) and the realized log return on value minus growth (first book-to-market portfolio) are in their respective lowest $30 \%$ of observations. This intersection leads to 37 events out of 242 quarters (15\%). The sample runs from 1953.III until $2012 . I V$. In each panel, the period labeled ' 0 ' is the quarter in which the event takes place. The labels $-1,-2,-3$, etc refer to one, two, three, etc quarters before the event whereas the labels $+1,+2,+3$, etc. refer to one, two, three, etc quarters after the event. The top left panel plots the realization of the quarterly log return on value minus growth. The bottom left panel reports annual log dividend growth on value minus growth. The top right panel plots the slope of the yield curve $(Y S P)$. The bottom right panel plots real GDP growth. Real GDP growth is demeaned over the full sample.

Consider the following model of unexpected returns for both sets of test assets:

$$
\begin{aligned}
\varepsilon_{t+1}^{k 1} & =E\left(r_{t+1}^{k 1}\right) \eta_{t+1}^{1}, \\
\varepsilon_{t+1}^{k 2} & =E\left(r_{t+1}^{k 2}\right) \eta_{t+1}^{2}+\alpha_{2 k} \eta_{t+1}^{3},
\end{aligned}
$$

with $\operatorname{cov}\left(\eta_{t+1}^{2}, \eta_{t+1}^{3}\right)=0$. Unexpected returns on the first set of test assets are completely governed by innovations to the first factor, whereas unexpected returns on the second set of test assets contain a component $\alpha_{2 k} \eta_{t+1}^{3}$ that is orthogonal to the component governed by innovations to the second factor. These $\eta^{3}$ shocks are not priced (by assumption). We assume that they are correlated with the $\eta^{1}$ shocks: $\operatorname{cov}\left(\eta_{t+1}^{1}, \eta_{t+1}^{3}\right) \neq 0$.

This structure implies:

$$
\operatorname{cov}\left(\varepsilon_{t+1}^{k i}, \eta_{t+1}^{i}\right)=E\left(r_{t+1}^{k i}\right) \operatorname{var}\left(\eta_{t+1}^{i}\right)=E\left(r_{t+1}^{k i}\right)
$$



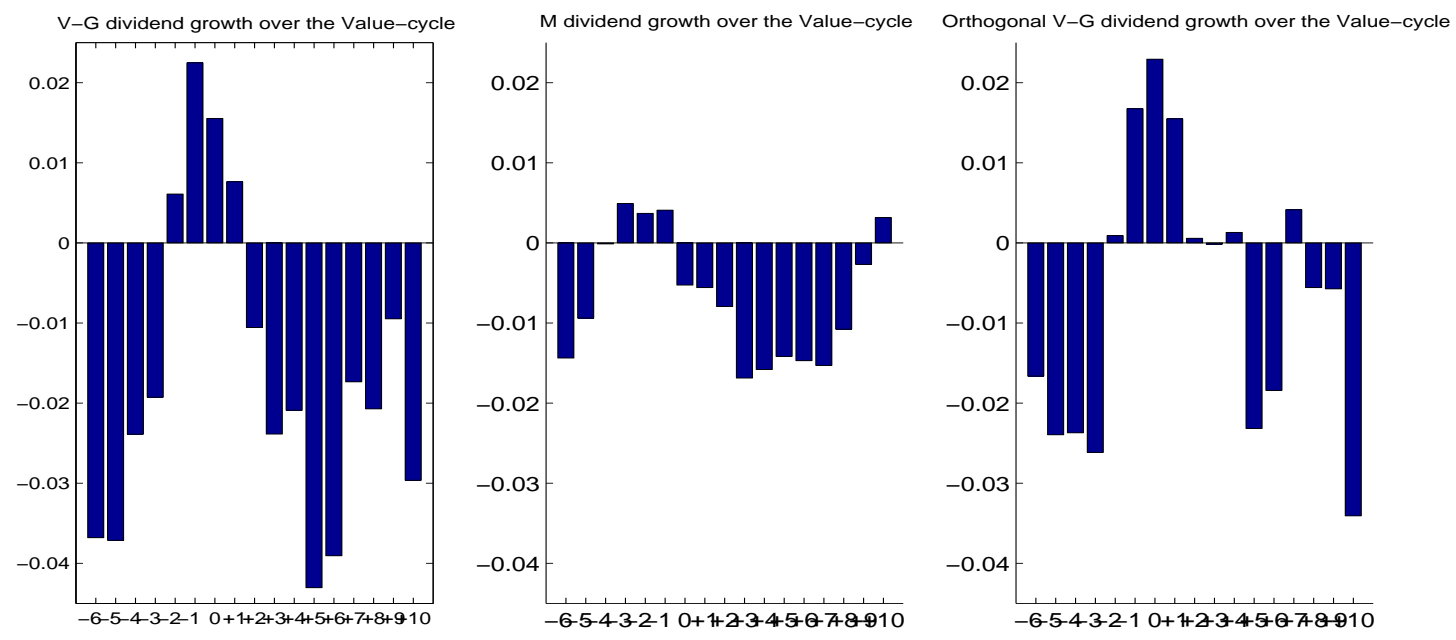

Figure IA.7: Dividend Growth Around Low-value Events

The figure plots three quarterly series in event time. The event is defined as a quarter in which both the realized log real return on the fifth book-to-market portfolio (value) and the realized log return on value minus growth (first book-to-market portfolio) are in their respective lowest $30 \%$ of observations. This intersection leads to 35 events out of 238 quarters (15\%). The sample runs from $1953 . I I I$ until 2011.IV. In each panel, the period labeled ' 0 ' is the quarter in which the event takes place. The labels $-1,-2,-3$, etc refer to one, two, three, etc quarters before the event whereas the labels $+1,+2,+3$, etc. refer to one, two, three, etc quarters after the event. The left panel plots annual log dividend growth on value minus growth, the middle panel plots annual log dividend growth on the market portfolio, and the right panel plots annual log dividend growth on value minus growth, orthogonalized to annual log dividend growth on the market portfolio.

and hence $\lambda_{i}=1, i=1,2$. Then we have:

$$
\begin{aligned}
& \operatorname{cov}\left(\varepsilon_{t+1}^{k 1}, \eta_{t+1}^{1}\right)=\quad E\left(r_{t+1}^{k 1}\right), \quad \operatorname{cov}\left(\varepsilon_{t+1}^{k 1}, \eta_{t+1}^{2}\right)=E\left(r_{t+1}^{k 1}\right) \rho, \\
& \operatorname{cov}\left(\varepsilon_{t+1}^{k 2}, \eta_{t+1}^{1}\right)=\left(r_{t+1}^{k 2}\right) \rho+\alpha_{2 k} \operatorname{cov}\left(\eta_{t+1}^{1}, \eta_{t+1}^{3}\right), \quad \operatorname{cov}\left(\varepsilon_{t+1}^{k 2}, \eta_{t+1}^{2}\right)=E\left(r_{t+1}^{k 2}\right) .
\end{aligned}
$$

The main point is that, if $\alpha_{2 k}$ is not proportional to $E\left(r_{t+1}^{k 2}\right)$, then there exist no $\Lambda_{1}$ and $\Lambda_{2}$ such that:

$$
E\left(r_{t+1}^{k i}\right)=\operatorname{cov}\left(\varepsilon_{t+1}^{k i}, \eta_{t+1}^{1}\right) \Lambda_{1}+\operatorname{cov}\left(\varepsilon_{t+1}^{k i}, \eta_{t+1}^{2}\right) \Lambda_{2}
$$

On the other hand, if there is proportionality and $\alpha_{2 k}=\alpha E\left(r_{t+1}^{k 2}\right)$, then we have:

$$
\operatorname{cov}\left(\varepsilon_{t+1}^{k 2}, \eta_{t+1}^{1}\right)=E\left(r_{t+1}^{k 2}\right)\left(\rho+\alpha \operatorname{cov}\left(\eta_{t+1}^{1}, \eta_{t+1}^{3}\right)\right)=E\left(r_{t+1}^{k 2}\right) \xi
$$

and $\Lambda_{1}$ and $\Lambda_{2}$ are given by:

$$
\Lambda_{1}=\frac{1-\rho}{1-\xi \rho} \text {, and } \Lambda_{2}=\frac{1-\xi}{1-\xi \rho} \text {. }
$$

This setup is satisfied approximately in our model, where the first set of test assets are the book-tomarket portfolios, $\eta^{1}$ are $C P$ innovations, the second set of test assets are the bond portfolios, and $\eta^{2}$ are $L V L$ innovations. Unexpected bond returns contain a component $\eta^{3}$ that is uncorrelated with $L V L$ 
innovations, but that is correlated with $C P$ innovations. Unexpected book-to-market portfolio returns, in contrast, are largely uncorrelated with $L V L$ innovations. The result above illustrates that consistent risk pricing is possible because unexpected bond returns' exposure to $C P$ shocks has a proportionality structure. This can also be seen in the top panel of Figure 6.

\section{Additional Results for Section 3}

This section considers several exercises investigating the robustness of our empirical results in Section 3. First, we provide details on the estimation of the time-varying component of the market prices of risk. Second, we we use a different weighting matrix in the market price of risk estimation. Third, we provide detailed results for two alternative yield spread factors. Fourth, we study additional sets of test assets. Fifth, we provide detailed results for the stock-level exercise.

\section{C.1. Time-varying Risk Prices}

Having estimated the constant market prices of risk, $\Lambda_{0}$, we turn to the estimation of the matrix $\Lambda_{1}$, which governs the time variation in the prices of risk. We allow the price of level risk $\Lambda_{1(2)}$ and the price of market risk $\Lambda_{1(3)}$ to depend on the $Z$ factor, where $Z$ is $C P, Y S P, Y G R$, or $Y A P$. We use two predictive regressions to pin down this variation in risk prices. We regress excess returns on a constant and lagged $Z$ :

$$
r x_{t+1}^{j}=a_{j}+b_{j} Z_{t}+\eta_{t+1}^{j},
$$

where we use either excess returns on the stock market portfolio or an equally-weighted portfolio of all bond returns used in estimation. Using equation (5), it then follows:

$$
\left(\begin{array}{c}
\Lambda_{1(2)} \\
\Lambda_{1(3)}
\end{array}\right)=\left(\begin{array}{c}
\Sigma_{X, \operatorname{Market}(2: 3)} \\
\Sigma_{X, \operatorname{Bonds}(2: 3)}
\end{array}\right)^{-1} \times\left(\begin{array}{c}
b_{\text {Market }} \\
b_{\text {Bonds }}
\end{array}\right)
$$

Following this procedure in the full sample, we find $\hat{\Lambda}_{1(2)}=-890$ and $\hat{\Lambda}_{1(3)}=44$ when $Z=C P$. This implies that equity and bond risk premia are high when $C P$ is high, consistent with the findings of Cochrane and Piazzesi (2005). We find similar results with $\hat{\Lambda}_{1(2)}=-736$ and $\hat{\Lambda}_{1(3)}=115$ when $Z=Y S P$.

\section{C.2. Bootstrap Exercise}

One possibility is that the $\mathrm{CP}$ factor is spuriously related to the cross-section of stock and bond returns. That spurious relationship could arise because the test assets have a strong factor structure with roughly three dimensions (value-growth, market, and bond maturity) and we have three persistent asset pricing factors to explain them (see Lewellen, Schanken, and Nagel 2010). Furthermore, the CP factor is a generated regressor. To investigate this possibility, we construct a set of bond yields that have the same persistence and covariance structure as in the data but that are otherwise pure noise. That is, their innovations are random. From those spurious bond yields, we estimate the CP factor, the yield spread YSP, and the level factor LVL. We combine CP or YSP with LVL and MKT factors to price the cross-section of test assets. We repeat this exercise 5,000 times and count the number of times the mean absolute pricing error (MAPE) among the test assets is higher than the point estimate in the data. That is the p-value of our MAPE. Note that this procedure takes into account the generated nature of the CP factor. 
Specifically, we first stack five bond yields of maturities one through five years in a vector, $\bar{y}_{t}$. The data are the standard Fama-Bliss bond yields. We estimate a first-order VAR for these yields at monthly frequency:

$$
\bar{y}_{t+1}=\mu_{y}+\Gamma_{y} \bar{y}_{t}+\Sigma_{y} u_{t+1} \text {. }
$$

Denote the VAR coefficient estimates by $\hat{\mu}_{y}, \hat{\Gamma}_{y}$, and $\hat{\Sigma}_{y}$. The $T \times 5$ panel of yield innovations is $u$. Next, in each bootstrap iteration we draw with replacement a $T \times 5$ panel of yield innovations from the observed innovations. We impose that these innovations have a covariance matrix equal to $\hat{\Sigma}_{y} \hat{\Sigma}_{y}^{\prime}$. The sample length is the same as in the data. Using $\hat{\mu}_{y}$ and $\hat{\Gamma}_{y}$, the simulated yield innovations, and the initial yield vector from the data, we rebuild a panel of bond yields. We also draw a panel of $T \times 11$ test asset returns with replacement, preserving the cross-correlation structure between the test asset returns. Thus, for each bootstrap iteration we obtain a panel of re-sampled returns and bond yields, where the bond yields are entirely random.

We then run the exact same estimation code as we do for the real data and record the MAPE. This includes re-estimating the $C P$ factor from the simulated yields or constructing the yield spread $Y S P$. It includes estimating the LVL factor as the first principal component of the generated bond yields. It also includes re-estimating the first-order VAR for the three asset pricing factors (CP or YSP, LVL, and MKT) to obtain the VAR innovations which we need to perform the cross-sectional asset pricing estimation. And it includes forming unexpected test asset returns as residuals from regressions of returns on the lagged conditioning variable (CP or YSP). All estimation error introduced by these estimation steps will be reflected in our p-values below.

We repeat this exercise 5,000 times. We then compute the fraction of times the MAPE we find in our paper is larger than the MAPE we find using random factors. This is the p-value we report in the paper. If our model fares better than when using random yield-based pricing factors, we expect a low p-value. Note that because we draw the market return jointly with the other returns, the reference point for the MAPE is the CAPM pricing kernel.

Table IA.II: Bootstrap p-values

P-values from the bootstrap exercise for various test assets and pricing models. The abbreviations in the table stand for: MKT $=$ market, bond $=$ Treasury portfolios, $\mathrm{BM}=$ book-to-market portfolios, Credit $=$ credit portfolios.

\begin{tabular}{lcc}
\hline & \multicolumn{2}{c}{ Pricing models } \\
\cline { 2 - 3 } & & \\
Test assets & $\mathrm{CP}$ & YSP \\
\hline $\mathrm{MKT}+5$ bond $+5 \mathrm{BM}$ & $8.6 \%$ & $35.1 \%$ \\
$\mathrm{MKT}+5$ bond $+5 \mathrm{BM}+4$ Credit & $3.5 \%$ & $11.5 \%$ \\
\hline
\end{tabular}

Using this bootstrap exercise, we analyze the pricing performance of various models (with CP or YSP as the yield curve factor) and for different sets of test assets (with or without corporate bond portfolios). The results are summarized in Table IA.II. We find that for both pricing models, the results are stronger with the larger cross-section that includes corporate bonds. Second, even though the pricing model that includes the $C P$ factor instead of the yield spread requires an additional estimation step, the significance of the reduction in pricing errors is higher. These findings clarify that our pricing results are not a consequence of random factors, despite the strong factor structure inherent in a cross-section that includes equity, Treasury bond, and corporate bond portfolios. 


\section{C.3. Weighted Least-Squares}

Our cross-sectional estimation results in Table 2 assume a GMM weighting matrix equal to the identity matrix. This is equivalent to minimizing the root mean-squared pricing error across the 11 test assets. The estimation devotes equal attention to each pricing error and leads to a RMSE of 48bp per year. A natural alternative to the identity weighting matrix is to give more weight to the assets that are more precisely measured. We use the inverse covariance matrix of excess returns, as in Hansen and Jagannathan (1997). This amounts to weighting the bond pricing errors more heavily than the stock portfolio pricing errors in our context. When using the Hansen-Jagannathan distance matrix, we find a MAPE of 53bp per year compared to 41bp per year. However, the weighted RMSE drops from 48bp to 25bp per year. The reason for the improvement in RMSE is that the pricing errors on the bonds decrease substantially, from a MAPE of $43 \mathrm{bp}$ to $12 \mathrm{bp}$ per year. Finally, the price of risk estimates in $\hat{\Lambda}_{0}$ are comparable to those in the benchmark case. The price of $C P$ risk remains positive and is estimated to be somewhat lower than in the benchmark case, at 48.3 (with a standard error of 12.2). The market price of $L V L$ risk remains statistically negative (-14.7 with standard error of 6.3), and the price of $M K T$ risk remains positive (2.67 with a standard error of 1.1). The null hypothesis that all pricing error parameters are jointly zero continues to be strongly rejected. We conclude that our results are similar when we use a different weighting matrix.

\section{C.4. Other Yield Factors that Predict Growth}

A natural question is whether the best linear predictor of economic activity continues to be a good pricing factor for the cross-section of test assets. To investigate this question, we regress $C F N A I_{t+k}$, with $k=12$, on the one- through five-year bond yields dated $t$. We label the result of this linear projection $Y G R$, and use it alongside the $M K T$ and $L V L$ factors in our asset pricing exercise.

The best predictor predicts economic activity 12-month ahead considerably better: the $R^{2}$ is $18.5 \%$, double the $8 \%$ for $C P$ and the $9.5 \%$ for $Y S P$. Y YR is a statistically significant predictor of CFNAI at horizons from 3 to 21 months out. The $C P$ factor significantly predicts economic activity 3 to 30 months out. The $R^{2}$ at 21 months lead-lag peaks at $14.7 \%$. $C P$ turns out to be just about the best linear predictor of future economic activity 18-24 months ahead. The $Y S P$ significantly predicts economic activity 3 to 24 months into the future. It reaches its maximum predictability at 18 month horizon with an $R^{2}$ of 10.5\%. YAP significantly predicts CFNAI 9 to 27 months into the future. It reaches its maximum $R^{2}$ at 21 months with an $R^{2}$ of $8.5 \%$.

The first three columns of Table IA.III show that the $Y G R$ SDF generates a low pricing error in the full sample and in the post-1980 sample. It continues to do well once we add credit portfolios and reestimate the SDF. The results are comparable to the $C P$ SDF. Also, the market price of risk estimates are comparable to those of the $C P$ SDF model. We strongly reject the null that all market price of risk estimates are zero. We cannot reject the null that all pricing errors are zero. The p-values are the highest of all of our models.

The last three columns of Table IA.III show that the $Y A P$ SDF results in a very low MAPE of 29bp in the full sample. This is by construction. The risk price estimate of $Y A P$ (which has the same volatility of $C P$ through a rescaling) is comparable to that of $C P$ and not statistically different from it. Pricing errors continue to be low in the post-1980 sample, even though the linear combination is kept constant across samples. The results for the $Y A P$ and $C P$ SDF models are similar because $Y A P$ has a high correlation of $74 \%$ with $C P$. Like $C P$ it is a predictor of economic activity at somewhat higher lag lengths than $Y S P$ and $Y G R$. I.e., it is an early warning indicator of economic activity. 


\section{Table IA.III: Alternative Yield Curve Factors}

This table reports pricing errors on five book-to-market sorted quintile stock portfolios, the value-weighted market portfolio, five bond portfolios of maturities 1, 2, 5, 7, and 10 years, and four credit-sorted portfolios. They are expressed in percent per year (monthly numbers multiplied by 1200). We also report the mean absolute pricing error across all securities (MAPE) and the estimates of the prices of risk. The first three columns correspond to the $Y G R \mathrm{SDF}$, while the last three columns refer to the $Y A P$ SDF model. $Y G R$ is the fitted value of a regression of macro-economic activity $C F N A I_{t+12}$ on the one- through five-year yields at time $t$. $Y A P$ is the linear combination of one- through five-year yields which best prices the 11 test assets in the full sample (minimizes the MAPE in column 4). The first and fourth columns are for the full 1952-2012 sample, while the other columns are for the 1980-2012 sample.

\begin{tabular}{|c|c|c|c|c|c|c|}
\hline \multicolumn{7}{|c|}{ Panel A: Pricing Errors (\% per year) } \\
\hline & \multicolumn{3}{|c|}{ YGR SDF } & \multicolumn{3}{|c|}{ YAP SDF } \\
\hline $10-\mathrm{yr}$ & 0.25 & 0.74 & 0.87 & -0.19 & 0.00 & 0.42 \\
\hline $7-y r$ & 0.27 & 0.15 & 0.63 & 0.33 & 0.11 & 0.52 \\
\hline $5-\mathrm{yr}$ & -0.18 & -0.53 & 0.39 & -0.06 & 0.09 & 0.42 \\
\hline $2-y \mathrm{r}$ & -0.57 & -0.92 & -0.15 & 0.00 & -0.26 & -0.02 \\
\hline $1-y r$ & -0.74 & -0.52 & -0.06 & -0.14 & -0.02 & 0.12 \\
\hline Market & -0.73 & -1.15 & -1.11 & -0.61 & -0.86 & -0.90 \\
\hline BM1 & -0.11 & -1.07 & -0.64 & 0.02 & 0.03 & -0.18 \\
\hline BM2 & -1.36 & 0.39 & 0.04 & 0.12 & 0.67 & 0.61 \\
\hline BM3 & 0.39 & 0.20 & -0.21 & 0.48 & 0.06 & 0.06 \\
\hline BM4 & 1.08 & 0.37 & 0.79 & -0.63 & -0.72 & -0.48 \\
\hline BM5 & 0.87 & 1.50 & 1.54 & 0.61 & 0.79 & 1.00 \\
\hline Credit1 & & & -0.78 & & & -0.82 \\
\hline Credit2 & & & -0.71 & & & -0.56 \\
\hline Credit3 & & & -0.63 & & & -0.24 \\
\hline Credit4 & & & 0.06 & & & 0.20 \\
\hline MAPE & 0.59 & 0.45 & 0.57 & 0.29 & 0.33 & 0.44 \\
\hline \multicolumn{7}{|c|}{ Panel B: Prices of Risk Estimates } \\
\hline MKT & 1.16 & 2.23 & 2.55 & 2.45 & 2.06 & 2.20 \\
\hline LVL & -4.43 & -13.28 & -11.86 & -19.99 & -22.45 & -19.81 \\
\hline YGR/YAP & 112.01 & 79.83 & 50.76 & 71.37 & 53.37 & 46.87 \\
\hline \multicolumn{7}{|c|}{ Panel C: P-values of $\chi^{2}$ Tests } \\
\hline$\Lambda_{0}=0$ & $1.80 \%$ & $4.22 \%$ & $2.19 \%$ & $0.82 \%$ & $2.41 \%$ & $2.69 \%$ \\
\hline Pr. err. $=0$ & $40.03 \%$ & $77.07 \%$ & $35.51 \%$ & $24.52 \%$ & $33.47 \%$ & $4.65 \%$ \\
\hline
\end{tabular}




\section{C.5. Other Test Assets}

Table IA.IV shows three exercises where we replace the book-to-market sorted equity portfolios by other equity portfolios. In the first four columns we use ten market capitalization-sorted portfolios alongside the bond portfolios and the market. The first column shows the risk premia to be explained (risk neutral SDF). Small firms (S1) have 3.6\% higher risk premia than large stocks (S10). Our CP SDF model in the second column manages to bring the overall mean absolute pricing error down from $6.27 \%$ per year to $0.34 \%$ per year, while our YSP SDF model has an even lower MAPE of 31bp. The market prices of risk are not statistically different from those estimated on book-to-market portfolios instead of size portfolios. We fail to reject the null that all pricing errors are zero at the $1 \%$ level but not at the $5 \%$ level. These MAPEs are somewhat lower than the 57bp in the Fama-French model in the fourth column. The Fama-French model does better eliminating the spread between small and large stocks, whereas our model does better pricing the bond portfolios.

The next three columns use earnings-price-sorted decile stock portfolios. The highest earnings-price portfolio has an average risk premium that is $6.3 \%$ higher per year than the lowest earnings-price portfolio. Our $C P$ SDF model reduces this spread in risk premia to $1.8 \%$ per year, while continuing to price the bonds reasonably well. The MAPE is 111 basis points per year compared to 142 for the YSP SDF, and $76 \mathrm{bp}$ in the Fama-French model.

The last three columns use the five-by-five market capitalization and book-to-market double sorted portfolios. Our CP SDF model manages to bring the overall mean absolute pricing error down from $7.7 \%$ per year to $1.3 \%$ per year while the $Y S P$ SDF model has a 1.2\% MAPE. This is again comparable to the three-factor Fama-French model's MAPE of $1.2 \%$.

The market price of risk estimates $\Lambda_{0}$ in Panel B of Table IA.IV are comparable to those we found for the book-to-market portfolios in Table 2. Panel $\mathrm{C}$ shows that we reject the null hypothesis that all market prices of risk are zero for all three sets of test assets. We fail to reject the null hypothesis that all pricing errors are zero on the size and earnings-price portfolios. We conclude that these results are in line with our benchmark results and that they further strengthen the usefulness of our empirical three-factor model.

\section{C.6. Individual Firm Returns}

In Table IA.V, we first sort individual stocks into five portfolios based on their exposure to $C P$ shocks in the previous 60 months. We then sort the stocks in each of the groups into five groups based on their $\mathrm{B} / \mathrm{M}$ ratio. This results in 25 portfolios that differ by their $C P$ exposure and $\mathrm{B} / \mathrm{M}$ ratio. We report the same statistics as in Table 4 for the single sorts based on $C P$ exposures only. We discuss the sample selection, sorting procedure, and results in the main text.

\section{Structural Model with Business Cycle Risk}

This appendix sets up and calibrates a structural asset pricing model that connects our empirical findings in a transparent way. The model formalizes the relationships between the returns on value and growth stocks, the $C P$ factor, and the state of the macro-economy. It does so in a unified pricing framework that can quantitatively account for the observed risk premia on stock and bond portfolios, while being consistent with the observed dynamics of dividend growth rates, inflation, and basic properties of the term structure of interest rates. Its role is largely pedagogical: to clarify the minimal structure necessary to 


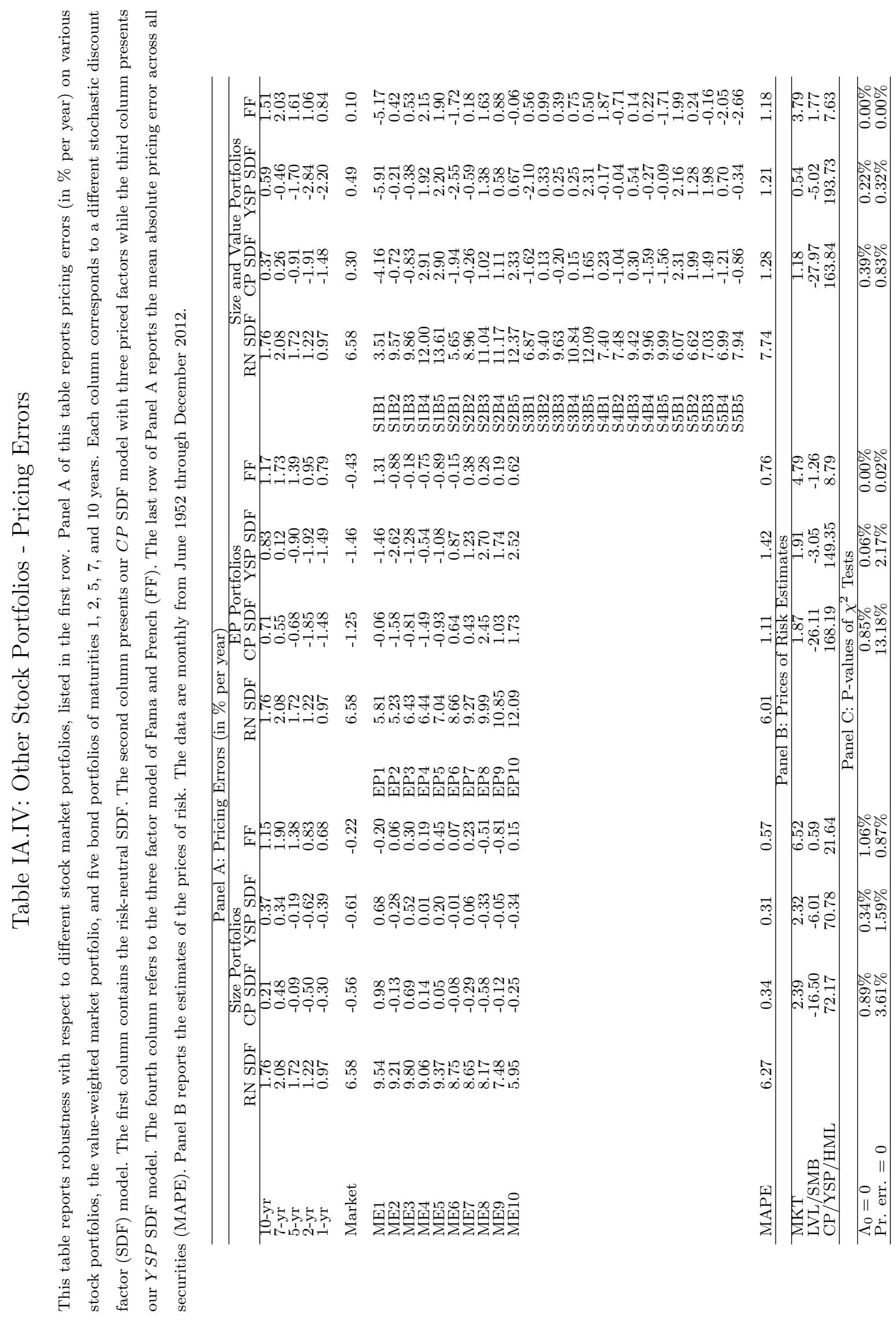




\section{Table IA.V: Individual Firm Returns: Double Sorts}

This table reports the results of sorting individual firms into 25 portfolios based on their exposure to $C P$ shocks and B/M ratio. We use 60-month rolling window estimates of $C P$ betas, where we require at least 12 months of data for a stock to be included in one of the portfolios. We first sort stocks on $C P$ betas into five portfolios, and then sort each of these groups into 5 portfolios based on their B/M ratio. The table reports the average excess return per portfolio, the CAPM alphas, the alphas for the KLN model, the $C P$ exposures of the five portfolios, the risk prices, and MAPE for the different models. The data are monthly from July 1963 through December 2010.

\begin{tabular}{|c|c|c|c|c|c|c|c|c|c|c|}
\hline Average excess returns & Low B/M & & & & High B/M & H-L B/M & & & & \\
\hline \multirow[t]{4}{*}{ Low $C P$ exposure } & $2.1 \%$ & $3.2 \%$ & $7.7 \%$ & $7.0 \%$ & $8.0 \%$ & $5.9 \%$ & & & & \\
\hline & $4.6 \%$ & $5.1 \%$ & $4.7 \%$ & $7.3 \%$ & $7.4 \%$ & $2.8 \%$ & & & & \\
\hline & $5.2 \%$ & $5.1 \%$ & $6.0 \%$ & $6.8 \%$ & $8.8 \%$ & $3.6 \%$ & & & & \\
\hline & $5.4 \%$ & $5.4 \%$ & $7.1 \%$ & $10.9 \%$ & $8.7 \%$ & $3.3 \%$ & & & & \\
\hline High $C P$ exposure & $4.7 \%$ & $7.8 \%$ & $8.2 \%$ & $9.2 \%$ & $10.1 \%$ & $5.4 \%$ & & & & \\
\hline High-low $C P$ exposure & $2.6 \%$ & $4.6 \%$ & $0.5 \%$ & $2.2 \%$ & $2.1 \%$ & & & & & \\
\hline \multirow[b]{2}{*}{ CAPM alphas } & \multirow{2}{*}{\multicolumn{4}{|c|}{ Low B/M }} & \multirow[b]{2}{*}{ High B/M } & \multirow[b]{2}{*}{ H-L B/M } & \multicolumn{3}{|c|}{ Risk prices } & \\
\hline & & & & & & & $C P$ & $L V L$ & $M K T$ & MAPE \\
\hline \multirow[t]{4}{*}{ Low $C P$ exposure } & $-5.8 \%$ & $-3.8 \%$ & $0.9 \%$ & $0.1 \%$ & $0.5 \%$ & $6.3 \%$ & \multirow{6}{*}{\multicolumn{3}{|c|}{2.50}} & 171bp \\
\hline & $-1.8 \%$ & $-1.1 \%$ & $-0.8 \%$ & $1.5 \%$ & $0.7 \%$ & $2.5 \%$ & & & & \\
\hline & $-1.0 \%$ & $-0.9 \%$ & $0.8 \%$ & $1.2 \%$ & $2.7 \%$ & $3.7 \%$ & & & & \\
\hline & $-1.3 \%$ & $-0.9 \%$ & $0.8 \%$ & $4.8 \%$ & $2.2 \%$ & $3.5 \%$ & & & & \\
\hline High $C P$ exposure & $-3.1 \%$ & $0.6 \%$ & $1.2 \%$ & $2.0 \%$ & $2.5 \%$ & $5.6 \%$ & & & & \\
\hline \multirow[t]{2}{*}{ High-low $C P$ exposure } & $2.7 \%$ & $4.5 \%$ & $0.3 \%$ & $1.9 \%$ & $2.0 \%$ & & & & & \\
\hline & \multirow{2}{*}{\multicolumn{4}{|c|}{ Low B/M }} & \multirow[b]{2}{*}{ High B/M } & \multirow[b]{2}{*}{ H-L B/M } & \multicolumn{3}{|c|}{ Risk prices } & \multirow[b]{2}{*}{ MAPE } \\
\hline KLN alphas & & & & & & & $C P$ & $L V L$ & $M K T$ & \\
\hline \multirow[t]{4}{*}{ Low $C P$ exposure } & $-1.3 \%$ & $-2.3 \%$ & $0.8 \%$ & $-0.8 \%$ & $-1.0 \%$ & $0.3 \%$ & \multirow{6}{*}{\multicolumn{4}{|c|}{$\begin{array}{llll}71.34 & -24.44 & 0.78 & 100 \mathrm{bp}\end{array}$}} \\
\hline & $1.0 \%$ & $0.1 \%$ & $-1.6 \%$ & $-0.9 \%$ & $-0.1 \%$ & $-1.1 \%$ & & & & \\
\hline & $1.2 \%$ & $0.0 \%$ & $-1.2 \%$ & $-1.0 \%$ & $1.8 \%$ & $0.6 \%$ & & & & \\
\hline & $-0.6 \%$ & $-0.4 \%$ & $0.6 \%$ & $2.5 \%$ & $1.7 \%$ & $2.3 \%$ & & & & \\
\hline High $C P$ exposure & $-0.6 \%$ & $2.2 \%$ & $-0.8 \%$ & $0.5 \%$ & $0.2 \%$ & $0.8 \%$ & & & & \\
\hline High-low $C P$ exposure & $0.7 \%$ & $4.5 \%$ & $-1.6 \%$ & $1.3 \%$ & $1.2 \%$ & & & & & \\
\hline$C P$ covariances $\left(\times 10^{5}\right)$ & Low B/M & & & & High B/M & $\mathrm{H}-\mathrm{L} \mathrm{B} / \mathrm{M}$ & & & & \\
\hline \multirow[t]{4}{*}{ Low $C P$ exposure } & -0.27 & 2.34 & 3.61 & 5.37 & 6.91 & 7.18 & & & & \\
\hline & -0.02 & 1.55 & 3.41 & 5.36 & 5.07 & 5.09 & & & & \\
\hline & -0.05 & 1.76 & 4.43 & 4.89 & 4.60 & 4.64 & & & & \\
\hline & 2.12 & 2.18 & 3.46 & 5.60 & 4.54 & 2.42 & & & & \\
\hline High $C P$ exposure & 2.02 & 2.51 & 5.60 & 5.86 & 7.05 & 5.03 & & & & \\
\hline High-low $C P$ exposure & 2.29 & 0.16 & 1.99 & 0.49 & 0.14 & & & & & \\
\hline
\end{tabular}


account for the observed moments. We start by describing the setup and provide the derivations of the asset pricing expressions. We also discuss the parameters used in the numerical example, and how they were chosen.

\section{D.1. Setup}

The model has one key state variable, $s$, which measures macroeconomic activity. One interpretation of $s$ is as a leading business cycle indicator. This state variable follows an autoregressive process, with modest persistence, and its innovations $\varepsilon_{t+1}^{s}$ are the first priced source of risk.

$$
s_{t+1}=\rho_{s} s_{t}+\sigma_{s} \varepsilon_{t+1}^{s} .
$$

Higher values of $s$ denote higher economic activity. The model permits an interpretation of $s$ as a signal about future economic activity. Since this variable moves at business cycle frequency, the persistence $\rho_{s}$ is moderate.

Real dividend growth on asset $i=\{G, V, M\}$ (Value, Growth, and the Market) is given by:

$$
\Delta d_{t+1}^{i}=\gamma_{0 i}+\gamma_{1 i} s_{t}+\sigma_{d i} \varepsilon_{t+1}^{d}+\sigma_{i} \varepsilon_{t+1}^{i} .
$$

If $\gamma_{1 i}>0$, dividend growth is pro-cyclical. The shock $\varepsilon_{t+1}^{d}$ is an aggregate dividend shock, while $\varepsilon_{t+1}^{i}$ is an (non-priced) idiosyncratic shock; the market portfolio has no idiosyncratic risk; $\sigma_{M}=0$. The key parameter configuration is $\gamma_{1 V}>\gamma_{1 G}$ so that value stocks are more exposed to cyclical risk than growth stocks. As is the data (Section 2.2.1), a low value for $s$ is associated with lower future dividend growth on $V$ minus $G$. Below, we will calibrate $\gamma_{1 V}$ and $\gamma_{1 G}$ to capture the decline in dividend growth value minus growth over the course of recessions.

Inflation is the sum of a constant, a mean-zero autoregressive process which captures expected inflation, and an unexpected inflation term:

$$
\begin{aligned}
& \pi_{t+1}=\bar{\pi}+x_{t}+\sigma_{\pi} \varepsilon_{t+1}^{\pi}, \\
& x_{t+1}=\rho_{x} x_{t}+\sigma_{x} \varepsilon_{t+1}^{x} .
\end{aligned}
$$

All shocks are cross-sectionally and serially independent and standard normally distributed. It would be straightforward to add a correlation between inflation shocks and shocks to the business cycle variable. This inflation process is common in the literature (e.g., Wachter, 2006; Bansal and Shaliastovich, 2010).

To simplify our analysis, we assume that market participants' preferences are summarized by a real stochastic discount factor (SDF), whose log evolves according to the process:

$$
-m_{t+1}=y+\frac{1}{2} \Lambda_{t}^{\prime} \Lambda_{t}+\Lambda_{t}^{\prime} \varepsilon_{t+1}
$$

where the vector $\varepsilon_{t+1} \equiv\left(\varepsilon_{t+1}^{d}, \varepsilon_{t+1}^{x}, \varepsilon_{t+1}^{s}\right)^{\prime}$ and $y$ is the real interest rate. The risk price dynamics are affine in the state of the economy $s_{t}$ :

$$
\Lambda_{t}=\Lambda_{0}+\Lambda_{1} s_{t}
$$

As in the reduced form model in the main text, the structural model features three priced sources of risk: aggregate dividend growth risk, which carries a positive price of risk $\left(\Lambda_{0}(1)>0\right)$, inflation risk $\left(\Lambda_{0}(2)<0\right)$, and cyclical risk $\left(\Lambda_{0}(3)>0\right)$. Choosing $\Lambda_{1}(2)<0$ makes the price of inflation risk counter-cyclical. As we show below, this makes bond risk premia increase pro-cyclical. We also set $\Lambda_{1}(1)>0$ resulting in 
a pro-cyclical price of aggregate dividend risk. The log nominal SDF is given by $m_{t+1}^{\$}=m_{t+1}-\pi_{t+1}$. For similar approaches to the SDF, see Bekaert, Engstrom, and Xing (2009), Bekaert, Engstrom, and Grenadier (2010), Lettau and Wachter (2009), Campbell, Sunderam, and Viceira (2012), and David and Veronesi (2009).

\section{D.2. Asset Prices}

We now study the equilibrium bond and stock prices in this model. The model generates an affine nominal term structure of interest rates. It also generates a one-factor model for the nominal bond risk premium: All variation in bond risk premia comes from cyclical variation in the economy, $s_{t}$. Thus, the $C P$ factor which measures the bond risk premium in the model is perfectly positively correlated with $s_{t}$, the (leading) indicator of macroeconomic activity.

\section{D.2.1. Bond Prices and Risk Premia}

It follows immediately from the specification of the real SDF that the real term structure of interest rates is flat at $y$. Nominal bond prices are exponentially affine in the state of the economy and in expected inflation:

$$
P_{t}^{\$}(n)=\exp \left(A_{n}^{\$}+B_{n}^{\$} s_{t}+C_{n}^{\$} x_{t}\right),
$$

with coefficients that follow recursions described in the proof below. As usual, nominal bond yields are $y_{t}^{\$}(n)=-\log \left(P_{t}^{\$}(n)\right) / n$.

Proof. The nominal SDF is given by:

$$
\begin{aligned}
m_{t+1}^{\$} & =m_{t+1}-\pi_{t+1} \\
& =-y-\bar{\pi}-x_{t}-\frac{1}{2} \Lambda_{t}^{\prime} \Lambda_{t}-\Lambda_{t}^{\prime} \varepsilon_{t+1}-\sigma_{\pi} \varepsilon_{t+1}^{\pi}
\end{aligned}
$$

The price of an $n$-period bond is given by:

$$
P_{t}^{n}=\exp \left(A_{n}^{\$}+B_{n}^{\$} s_{t}+C_{n}^{\$} x_{t}\right) .
$$

The recursion of nominal bond prices is given by:

$$
\begin{aligned}
P_{t}^{n}= & E_{t}\left(P_{t+1}^{n-1} M_{t+1}^{\$}\right) \\
= & E_{t}\left(\exp \left(A_{n-1}^{\$}+B_{n-1}^{\$} s_{t+1}+C_{n-1}^{\$} x_{t+1}-y-\bar{\pi}-x_{t}-\frac{1}{2} \Lambda_{t}^{\prime} \Lambda_{t}-\Lambda_{t}^{\prime} \varepsilon_{t+1}-\sigma_{\pi} \varepsilon_{t+1}^{\pi}\right)\right) \\
= & \exp \left(A_{n-1}^{\$}-y-\bar{\pi}-x_{t}-\frac{1}{2} \Lambda_{t}^{\prime} \Lambda_{t}^{+} B_{n-1}^{\$} \rho_{s} s_{t}+C_{n-1}^{\$} \rho_{x} x_{t}\right) \times \\
& E_{t}\left(\exp \left(B_{n-1}^{\$} \sigma_{s} \varepsilon_{t+1}^{s}+C_{n-1}^{\$} \sigma_{x} \varepsilon_{t+1}^{x}-\Lambda_{t}^{\prime} \varepsilon_{t+1}-\sigma_{\pi} \varepsilon^{\pi} t+1\right)\right) \\
= & \exp \left(A_{n-1}^{\$}-y-\bar{\pi}-x_{t}+B_{n-1}^{\$} \rho_{s} s_{t}+C_{n-1}^{\$} \rho_{x} x_{t}\right) \times \\
& \exp \left(\frac{1}{2}\left[B_{n-1}^{\$}\right]^{2} \sigma_{s}^{2}+\frac{1}{2}\left[C_{n-1}^{\$}\right]^{2} \sigma_{x}^{2}-B_{n-1}^{\$} \sigma_{s} \Lambda_{t}(3)-C_{n-1}^{\$} \sigma_{x} \Lambda_{t}(2)+\frac{1}{2} \sigma_{\pi}^{2}\right),
\end{aligned}
$$


which implies:

$$
\begin{aligned}
A_{n}^{\$} & =A_{n-1}^{\$}-y-\bar{\pi}+\frac{1}{2}\left[B_{n-1}^{\$} \sigma_{s}\right]^{2}+\frac{1}{2}\left[C_{n-1}^{\$} \sigma_{x}\right]^{2}+\frac{1}{2} \sigma_{\pi}^{2}-B_{n-1}^{\$} \sigma_{s} \Lambda_{0}(3)-C_{n-1}^{\$} \sigma_{x} \Lambda_{0}(2), \\
B_{n}^{\$} & =B_{n-1}^{\$} \rho_{s}-C_{n-1}^{\$} \sigma_{x} \Lambda_{1}(2), \\
C_{n}^{\$} & =-1+C_{n-1}^{\$} \rho_{x} .
\end{aligned}
$$

The starting values for the recursion are $A_{0}^{\$}=0, B_{0}^{\$}=0$, and $C_{0}^{\$}=0$.

The expression for $C_{n}^{\$}$ can be written more compactly as:

$$
C_{n}^{\$}=-\frac{1-\rho_{x}^{n}}{1-\rho_{x}} \rho_{x}<0
$$

implying that bond prices drop -and nominal interest rates increase- when inflation increases: $C_{n}^{\$}<0$. Consistent with the data, we assume that $\Lambda_{1}(2)<0$. It follows that $B_{n}^{\$}<0$, implying that nominal bond prices fall -and nominal interest rates rise- with the state of the economy $\left(s_{t}\right)$. Both signs seem consistent with intuition.

The nominal bond risk premium, the expected excess log return on buying an $n$-period nominal bond and selling it one period later (as a $n-1$-period bond), is given by:

$$
\begin{aligned}
E_{t}\left[r x_{t+1}^{\$}(n)\right] & =-\operatorname{cov}_{t}\left(m_{t+1}^{\$}, B_{n-1}^{\$} s_{t+1}+C_{n-1}^{\$} \pi_{t+1}\right) \\
& =\operatorname{cov}_{t}\left(\Lambda_{t}^{\prime} \varepsilon_{t+1}, B_{n-1}^{\$} s_{t+1}+C_{n-1}^{\$} x_{t+1}\right) \\
& =\Lambda_{t}(2) C_{n-1}^{\$} \sigma_{x}+\Lambda_{t}(3) B_{n-1}^{\$} \sigma_{s} \\
& =\underbrace{\Lambda_{0}(2) C_{n-1}^{\$} \sigma_{x}+\Lambda_{0}(3) B_{n-1}^{\$} \sigma_{s}}_{\text {Constant component bond risk premium }}+\underbrace{\Lambda_{1}(2) C_{n-1}^{\$} \sigma_{x} s_{t}}_{\text {Time-varying component bond risk premium }},
\end{aligned}
$$

In this model, all of the variation in bond risk premia comes from cyclical variation in the economy, $s_{t}$. This lends the interpretation of $\mathrm{CP}$ factor to $s_{t}$ which is consistent with our empirical evidence. Innovations to the $C P$ factor are innovations to $s\left(\varepsilon^{s}\right)$. Because $C_{n-1}^{\$}<0, \Lambda_{1}(2)<0$ generates lower bond risk premia when economic activity is low $\left(s_{t}<0\right)$.

The constant component of the bond risk premium partly reflects compensation for cyclical risk and partly exposure to expected inflation risk. Exposure to the cyclical shock contributes negatively to excess bond returns: A positive $\varepsilon^{s}$ shock lowers bond prices and returns, and more so for long than for short bonds. Exposure to expected inflation shocks contributes positively to excess bond returns: A positive $\varepsilon^{x}$ shock lowers bond prices and returns but the price of expected inflation risk is negative. Since common variation in bond yields is predominantly driven by the inflation shock in the model, the latter acts like (and provides a structural interpretation for) a shock to the level of the term structure $(L V L)$. Long bonds are more sensitive to level shocks, the traditional duration effect.

\section{D.2.2. Stock Prices, Equity Risk Premium, Value Premium}

The $\log$ price-dividend $(\mathrm{pd})$ ratio on stock (portfolio) $i$ is affine in $s_{t}$ :

$$
p d_{t}^{i}=A_{i}+B_{i} s_{t}
$$


where

$$
B_{i}=\frac{\gamma_{1 i}-\Lambda_{1}(1) \sigma_{d i}}{1-\kappa_{1 i} \rho_{s}}
$$

and the expression for $A_{i}$ is given in the proof below.

Proof. The return definition implies:

$$
\begin{aligned}
r_{t+1} & =\ln \left(\exp \left(p d_{t+1}\right)+1\right)+\Delta d_{t+1}-p d_{t} \\
& \simeq \ln (\exp (\overline{p d})+1)+\frac{\exp (\overline{p d})}{\exp (\overline{p d})+1}\left(p d_{t+1}-\overline{p d}\right)+\Delta d_{t+1}-p d_{t} \\
& =\kappa_{0}+\kappa_{1} p d_{t+1}+\Delta d_{t+1}-p d_{t}
\end{aligned}
$$

where:

$$
\begin{aligned}
\kappa_{0} & =\ln (\exp (\overline{p d})+1)-\kappa_{1} \overline{p d} \\
\kappa_{1} & =\frac{\exp (\overline{p d})}{\exp (\overline{p d})+1} .
\end{aligned}
$$

We conjecture that the log price-dividend ratio is of the form:

$$
p d_{t}=A+B s_{t},
$$

The price-dividend ratio coefficients are obtained by solving the Euler equation:

$$
E_{t}\left(M_{t+1}^{\$} R_{t+1}^{\$}\right)=1 .
$$

We suppress the dependence on $i$ in the following derivation:

$$
\begin{aligned}
1= & E_{t}\left(\exp \left(m_{t+1}-\pi_{t+1}+\kappa_{0}+\kappa_{1} p d_{t+1}+\Delta d_{t+1}-p d_{t}+\pi_{t+1}\right)\right) \\
0= & E_{t}\left(m_{t+1}\right)+\frac{1}{2} V_{t}\left(m_{t+1}\right)+E_{t}\left(\kappa_{0}+\Delta d_{t+1}+\kappa_{1} p d_{t+1}-p d_{t}\right) \\
& +\frac{1}{2} V_{t}\left(\Delta d_{t+1}+\kappa_{1} p d_{t+1}\right)+\operatorname{Cov}_{t}\left(-\Lambda_{t}^{\prime} \varepsilon_{t+1}, \Delta d_{t+1}+\kappa_{1} p d_{t+1}\right) \\
= & -y+\kappa_{0}+\gamma_{0}+\gamma_{1} s_{t}+\left(\kappa_{1}-1\right) A+\left(\kappa_{1} \rho_{s}-1\right) B s_{t} \\
& +\frac{1}{2} \sigma_{d}^{2}+\frac{1}{2} \sigma^{2}+\frac{1}{2} \kappa_{1}^{2} B^{2} \sigma_{s}^{2}-\Lambda_{t}(1) \sigma_{d}-\Lambda_{t}(3) \kappa_{1} B \sigma_{s} .
\end{aligned}
$$

This results in the system:

$$
\begin{aligned}
& 0=-y+\kappa_{0}+\gamma_{0}+\left(\kappa_{1}-1\right) A+\frac{1}{2} \sigma_{d}^{2}+\frac{1}{2} \sigma^{2}+\frac{1}{2} \kappa_{1}^{2} B^{2} \sigma_{s}^{2}-\Lambda_{0}(1) \sigma_{d}-\Lambda_{0}(3) \kappa_{1} B \sigma_{s}, \\
& 0=\left(\kappa_{1} \rho_{s}-1\right) B-\Lambda_{1}(1) \sigma_{d}+\gamma_{1},
\end{aligned}
$$

Rearranging terms, we get the following expressions for the pd ratio coefficients, where we make the 
dependence on $i$ explicit:

$$
\begin{aligned}
A_{i} & =\frac{\frac{1}{2} \sigma_{d i}^{2}+\frac{1}{2} \sigma_{i}^{2}+\frac{1}{2} \kappa_{1 i}^{2} B_{i}^{2} \sigma_{s}^{2}-\Lambda_{0}(1) \sigma_{d i}-\Lambda_{0}(3) \kappa_{1 i} B_{i} \sigma_{s}-y+\kappa_{0 i}+\gamma_{0 i}}{1-\kappa_{1 i}} \\
B_{i} & =\frac{\gamma_{1 i}-\Lambda_{1}(1) \sigma_{d i}}{1-\kappa_{1 i} \rho_{s}}
\end{aligned}
$$

We note that $B_{i}$ can be positive or negative depending on the importance of dividend growth predictability $\left(\gamma_{1 i}\right)$ and fluctuations in risk premia $\left(\Lambda_{1}(1) \sigma_{d i}\right)$. Stock $i$ 's price-dividend ratios is pro-cyclical $\left(B_{i}>0\right)$ when dividend growth is more pro-cyclical than the risk premium for the aggregate dividend risk of asset $i: \gamma_{1 i}>\sigma_{d i} \Lambda_{1}(1)$.

The equity risk premium on portfolio $i$ can be computed to be:

$$
\begin{aligned}
E_{t}\left[r x_{t+1}^{i}\right] & =\operatorname{cov}_{t}\left(-m_{t+1}^{\$}, r_{t+1}^{i}+\pi_{t+1}\right) \\
& =\operatorname{cov}\left(\Lambda_{t}^{\prime} \varepsilon_{t+1}, \kappa_{1 i} B_{i} \sigma_{s} \varepsilon_{t+1}^{s}+\sigma_{d i} \varepsilon_{t+1}^{d}\right) \\
& =\underbrace{\Lambda_{0}(1) \sigma_{d i}+\Lambda_{0}(3) \kappa_{1 i} B_{i} \sigma_{s}}_{\text {Constant component equity risk premium }}+\underbrace{\Lambda_{1}(1) \sigma_{d i} s_{t}}_{\text {Time-varying component equity risk premium }}
\end{aligned}
$$

The equity risk premium provides compensation for aggregate dividend growth risk (first term, $\varepsilon^{d}$ ) and for cyclical risk (second term, $\varepsilon^{s}$ ). Like bond risk premia, equity risk premia vary over time with the state of the economy $s_{t}$ (third term). The model generates both an equity risk premium and a value premium. The reason for the value premium can be traced back to the fact that value stocks' dividends are more sensitive to cyclical shocks than those of growth stocks. As we showed above, the data suggest that value stocks' dividends fall more in recessions than those of growth stocks $\left(\gamma_{1 V}>\gamma_{1 G}\right)$. With $\sigma_{d V} \approx \sigma_{d G}$, this implies that $B_{V}>B_{G}$. Because the price of cyclical risk $\Lambda_{0}(3)$ is naturally positive, the second term delivers the value premium. Put differently, in the model, as in the data, returns on value stocks are more exposed to bond risk premium shocks than returns on growth stocks.

\section{D.2.3. Link with Reduced-form Model}

To make the link with the reduced-form model of Section 3 clear, we study the link between the structural shocks and the reduced form shocks. In the model, shocks to the market return (MKT) are given a linear combination of $\varepsilon^{d}$ and $\varepsilon^{s}$ shocks:

$$
\varepsilon_{t+1}^{M K T} \equiv r_{t+1}^{M}-E_{t}\left[r_{t+1}^{M}\right]=\sigma_{d M} \varepsilon_{t+1}^{d}+\kappa_{1 M} B_{M} \sigma_{s} \varepsilon_{t+1}^{s}
$$

We construct the CP factor in the same way as in the data, from yields on 1- through 5-year yields and average excess bond returns. See footnote 7 . Since the model has a two-factor structure for bond yields and forward rates, we use only the two- and the five-year forward rates as independent variables in the $C P$ regression of average excess returns on forward rates. The model's $C P$ factor is perfectly correlated with the process $s$, and has a innovations that differs by a factor $\sigma^{C P}: \varepsilon_{t+1}^{C P}=\varepsilon_{t+1}^{s} \sigma^{C P}$. Finally, since expected inflation drives most of the variation in bond yields in the model, $L V L$ shocks in the model are proportional to expected inflation shocks: $\varepsilon_{t+1}^{L V L}=\varepsilon_{t+1}^{x} \sigma^{L}$. Denote $\tilde{\varepsilon}=\left[\varepsilon^{M K T}, \varepsilon^{L V L}, \varepsilon^{C P}\right]^{\prime}$. Associated with $\tilde{\varepsilon}$, we can define market prices of risk $\tilde{\Lambda}$, such that SDF innovations remain unaltered: $\Lambda_{t}^{\prime} \varepsilon_{t+1}=\tilde{\Lambda}_{t}^{\prime} \tilde{\varepsilon}_{t+1}$. It is easy to verify that $\tilde{\Lambda}_{0}(1)=\Lambda_{0}(1) / \sigma_{d M}, \tilde{\Lambda}_{0}(2)=\Lambda_{0}(2) / \sigma^{L}$, and $\tilde{\Lambda}_{0}(3)=\Lambda_{0}(3) / \sigma^{C P}-\kappa_{1 M} B_{M} \sigma_{s} \Lambda_{0}(1) /\left(\sigma_{d M} \sigma^{C P}\right)$. 
For each asset, we can compute covariances of unexpected returns with the $M K T, L V L$, and $C P$ shocks inside the model. In the model that first covariance is given by:

$$
\operatorname{cov}\left(r_{t+1}^{i}-E_{t}\left[r_{t+1}^{i}\right], \varepsilon_{t+1}^{M K T}\right)=\sigma_{d M} \sigma_{d i}+\kappa_{1 M} B_{M} \kappa_{1 i} B_{i} \sigma_{s}^{2} .
$$

A calibration where $B_{M} \approx 0$ and $\sigma_{d V} \approx \sigma_{d G}$ will replicate the observed pattern (the linearization constant $\kappa_{1 i}$ will be close to 1 for all portfolios). Second, the covariance of stock portfolio returns with CP shocks is given by:

$$
\operatorname{cov}\left(r_{t+1}^{i}-E_{t}\left[r_{t+1}^{i}\right], \varepsilon_{t+1}^{C P}\right)=\kappa_{1 i} B_{i} \sigma_{s} \sigma^{C P} .
$$

The model generates a value premium because of differential exposure to $C P$ shocks when $B_{V}>B_{G}$. When $\sigma_{d V} \approx \sigma_{d G}$, the stronger loading of expected dividend growth of value stocks to $s_{t}\left(\gamma_{1 V}>\gamma_{1 G}\right)$ makes $B_{V}>B_{G}$. Put differently, in the model -as in the data- returns on value stocks are more exposed to bond risk premium shocks than returns on growth stocks. Third, stock return innovations have a zero covariance with $L V L$ shocks in the model by construction, similar to the small exposures in the data.

Likewise, we can compute covariances of bond return innovations with the $M K T, L V L$, and $C P$ shocks. In that order, they are:

$$
B_{n}^{\$} \kappa_{1 M} B_{M} \sigma_{s}, \quad C_{n}^{\$} \sigma_{x} \sigma^{L}, \quad B_{n}^{\$} \sigma_{s} \sigma^{C P} .
$$

When $B_{M} \approx 0$, exposure of bond returns to the market factor shocks is close to zero. Exposure to level shocks is negative: an increase in the level of interest rates reduces bond prices and returns. Exposure to $\mathrm{CP}$ shocks is also negative: an increase in the bond risk premium reduces bond prices and returns. Both exposures become more negative with the horizon because $B_{n}^{\$}$ and $C_{n}^{\$}$ increase in absolute value with maturity $n$.

\section{D.3. Calibration}

This section describes our calibration. We start by describing how we define recessions in the model. We construct recessions in the model in a procedure that mimics the NBER dating algorithm and that matches the frequency and duration of recessions. Second, we describe the calibration of dividends and inflation processes. Third, we describe the choice of market price of risk parameters.

Recessions in the Model In order to measure how dividends change over the recession, we have to define recessions in the model. Our algorithm mimics several of the features of the NBER dating procedure: (i) The recession is determined by looking back in time at past real economic activity ( $s_{t}$ in the model) and its start is not known in real time, (ii) there is a minimum recession length, and (iii) it captures the notion that the economy went through a sequence of negative shocks and that economic activity is at a low level. We split each recession into three equal periods and refer to the last month of each period as the first, second, and third stage of the recession. The $s$ process is negative at the start of the recession, falls considerably in the first stage of a recession, continues to fall in the second stage, and partially recovers in the last stage. Our recession dating procedure is novel, matches the empirical distribution of recession duration, and generates interesting asset pricing dynamics during recessions, to which we return to below. We now describe the recession dating procedure in detail.

Recessions in the model are determined by the dynamics of the state process $s_{t}$. Define the cumulative shock process $\chi_{t} \equiv \sum_{k=0}^{K} \varepsilon_{t-k}^{s}$, where the parameter $K$ governs the length of the backward-looking window. Let $\underline{\chi}$ and $\bar{\chi}$ be the $p_{1}^{t h}$ and $p_{2}^{t h}$ percentiles of the distribution of $\chi_{t}$, respectively, and let $\underline{s}$ be the be the $p_{3}^{t h}$ percentile of the distribution of the $s$ process. Whenever $\chi_{t}<\underline{\chi}$, we find the first negative shock between 
$t-K$ and $t$; say it occurs in month $t-j$. If, in addition, $s_{t-j}<\underline{s}$, we say that the recession started in month $t-j$. We say that the recession ends the fist month that $\chi_{t+i}>\bar{\chi}$, for $i \geq 1$. We assume that a new recession cannot start before the previous one has ended.

We find the recession parameters $\left(K, p_{1}, p_{2}, p_{3}\right)$ by matching features of the fifteen recessions in the 1926-2009 data. In particular, we consider the fraction of recession months (19.86\% in the data), the average length of a recession (13.3 months), the minimum length of a recession (6 months), the $25^{\text {th }}$ percentile ( 8 months), the median (11 months), the $75^{\text {th }}$ percentile (14.5 months), and the maximum length (43 months). We simulate the process for $s_{t}$ for 10,000 months, determine recession months as described above, and calculate the weighted distance between the seven moments in the simulation and in the data. We iterate on the procedure to find the four parameters that minimize the distance between model and data. ${ }^{21}$ The best fit has $19.70 \%$ of months in recession, an average length of 12.0 months, a minimum of $6,25^{\text {th }}$ percentile of 8 , median of $11,75^{\text {th }}$ percentile of 14 , and maximum of 43 months. The corresponding parameters are $K=7$ months, $p_{1}=17, p_{2}=37$, and $p_{3}=29$.

To describe how the variables of interest behave over the course of a recession, it is convenient to divide each recession into three equal stages, and to keep track of the value in the last month of each stage. More precisely, we express the variable in percentage difference from the peak, which is the month before the recession starts. For example, if a recession lasts 9 (10) months, we calculate how much lower dividends are in months 3,6, and 9 (10) of the recession, in percentage terms relative to peak. Averaging these numbers over recessions indicates the typical change of the variable of interest in three stages of a recession. The third-stage number summarizes the behavior of the variable over the entire course of the recession. We apply this procedure equally to the data and the model simulation.

We set $\rho_{s}=.9355$ to exactly match the 12 -month autocorrelation of the CP factor of .435. This low annual autocorrelation is consistent with the interpretation of $s$ as a business-cycle frequency variable. We set $\sigma_{s}=1$; this is an innocuous normalization. The $s$ process is negative at the start of the recession (1.6 standard deviations below the mean), falls considerably in the first stage of a recession (to 3.2 standard deviations below the mean), continues to fall in the second stage (to -3.9 standard deviations), and partially recovers in the last stage (to -2.9 standard deviations).

Dividend and Inflation Parameters We calibrate parameters to match moments of real dividend growth on the market portfolio, value portfolio (fifth book-to-market quintile), and growth portfolio (first quintile) for 1927-2009 (997 months). Since nominal bond yields are unavailable before 1952, we compare our model's output for nominal bond yields and associated returns to the average for 1952-2009. In our model simulation, we reinvest monthly dividends at the risk-free rate to compute an annual real dividend series, replicating the procedure in the data. We calculate annual inflation as the twelve-month sum of log monthly inflation, as in the data.

The most important parameter is $\gamma_{1 i}$, which measures how sensitive dividend growth is to changes in real economic activity. In light of the empirical evidence presented in Section II.A of the main paper, we choose $\gamma_{1 i}$ to match the log change in annual real dividends between the peak of the cycle and the last month of the recession. In the data, the corresponding change is $-21.0 \%$ for value stocks (the fifth $\mathrm{BM}$ portfolio), $+2.2 \%$ for growth stocks (first BM portfolio), and $-5.2 \%$ for the market portfolio (CRSP value-weighted portfolio). Given the parameters governing the $s$ dynamics and the recession determination described above, the model matches these changes exactly for $\gamma_{1 G}=-.4 e-4, \gamma_{1 V}=97.6 e-4$, and $\gamma_{1 M}=24.8 e-4$. Note that $\gamma_{1 V}>\gamma_{1 G}$ delivers the differential fall of dividends on value and growth stocks.

\footnotetext{
${ }^{21}$ The weighting matrix is diagonal and takes on the following values: $.9, .9, .7, .5, .7, .5$, and .5 , where the weights are described in the same order as the moments in the text. We use an extensive grid search and limit ourselves to integer values for the parameters.
} 
This is the central mechanism behind the value premium.

The rest of the dividend growth parameters are chosen to match the observed mean and volatility. We choose $\gamma_{0 G}=.0010, \gamma_{0 V}=.0044$, and $\gamma_{0 M}=.0010$ to exactly match the unconditional mean annual log real dividend growth of $1.23 \%$ on growth, $5.26 \%$ on value, and $1.23 \%$ on the market portfolio. We choose $\sigma_{d M}=2.09 \%$ to exactly match the unconditional volatility of annual log real dividend growth of $10.48 \%$. We set $\sigma_{d G}=1.94 \%$ and $\sigma_{d V}=2.23 \%$ in order to match the fact that the covariance of growth stocks with market return innovations is slightly higher than that of value stocks. However, the difference needs to be small to prevent the value premium from being due to differential exposure to market return shocks. To be precise, this difference makes the contribution of the market factor to the value premium equal to $0.44 \%$ per year, the same as in the data. We set the idiosyncratic volatility parameter for growth $\sigma_{G}=3.48 \%$ to match exactly the $13.75 \%$ volatility of dividend growth on growth stocks, given the other parameters. We set $\sigma_{V}=10.94 \%$ because the volatility of dividend growth on value stocks of $48.93 \%$. The 12 -month autocorrelation of annual log real dividend growth in the model results from these parameter choices and is -.01 for $\mathrm{G}, .21$ for $\mathrm{V}$, and .29 for $\mathrm{M}$, close to the observed values of .11, .16, and .29, respectively.

Inflation parameters are chosen to match mean inflation, and the volatility and persistence of nominal bond yields. We choose $\bar{\pi}=.0026$ to exactly match average annual inflation of $3.06 \%$. We choose $\rho_{x}=.989$ and $\sigma_{x}=.03894 \%$ to match the unconditional volatility and 12-month autocorrelation of nominal bond yields of maturities 1- through 5-years (1952-2009 Fama-Bliss data). In the model, volatilities decline from $3.13 \%$ for 1 -year to $2.58 \%$ for 5 -year bonds. In the data, volatilities decline from $2.93 \%$ to $2.72 \%$. The 12-month autocorrelations of nominal yields range from .88 to .84 in the model, and from .84 to .90 in the data. Our parameters match the averages of the autocorrelations and volatilities across these maturities. We choose the volatility of unexpected inflation $\sigma_{\pi}=.7044 \%$ to match the volatility of inflation of $4.08 \%$ in the data. The 12-month autocorrelation of annual inflation is implied by these parameter choices and is .59 in the model, close to the .61 in the data. We set the real short rate $y=.0018$, or $2.1 \%$ per year, to match the mean 1-year nominal bond yield of $5.37 \%$ exactly, given all other parameters.

Market Prices of Risk We set $\Lambda_{0}(1)=.2913$ to match the unconditional equity risk premium on the market portfolio of $7.28 \%$ per year (in the 1927-2009 data). The market price of expected inflation risk $\Lambda_{0}(1)=-.0986$ is set to match the 5-1-year slope of the nominal yield curve of $0.60 \%$. The term structure behaves nicely at longer horizons with 10 -year yields equal to $6.27 \%$ per year, and 30 -year yields equal to $6.49 \%$ per year. The average of the annual bond risk premium on 2-year, 3-year, 4-year, and 5-year bond returns, which is the left-hand side variable of the $C P$ regression, is $0.75 \%$ in the model compared to $0.87 \%$ in the data. The mean $C P$ factor is .0075 in model and .0075 in the data. We set the market price of cyclical risk $\Lambda_{0}(3)=.0249$ in order to match the $5.22 \%$ annual value premium (in the 1927-2009 data).

We set $\Lambda_{1}(1)=.1208$ in order to generate a slightly negative $B_{M}=-0.000624$. As argued above, the near-zero $B_{M}$ prevents the value premium from arising from exposure to market return shocks, and it prevents bond returns from being heavily exposed to market risk. The slight negative sign delivers a slightly positive contribution of exposure to market return shocks to bond excess returns, as in the data. In particular, it generates a 15 basis point spread between ten-year and 1-year bond risk premia coming from market exposure, close to the 30 basis points in the post-1952 data. Finally, we set $\Lambda_{1}(2)=-0.0702$ in order to exactly match the volatility of the $C P$ factor of $1.55 \%$. The volatility of the average annual bond risk premium on 2-year, 3-year, 4-year, and 5 -year bonds is $3.93 \%$ in the model and $3.72 \%$ in the data. As mentioned above, $\rho_{s}$ is chosen to match the persistence of $C P$. Thus the model replicates the mean, volatility, and persistence of the $C P$ factor and the nominal bond risk premium. The maximum annualized log Sharpe ratio implied by the model, $E\left[\sqrt{\Lambda_{t}^{\prime} \Lambda_{t}}\right] \sqrt{(12)}$ is 1.44. Unfortunately, there is no easy comparison with the numbers in the empirical section (bottom panel of Table 2). 
Risk Premium Decomposition The main result from the calibration exercise is that we are able to replicate the three-factor risk premium decomposition we uncovered in Section 3. Figure IA.8 is the model's counterpart to Figure 6 in the data. It shows a good quantitative match for the relative contribution of each of the three sources of risk to the risk premia for growth, value, and market equity portfolios, as well as for maturity-sorted government bond portfolios. This fit is not a forgone conclusion, but results from the richness of the model and the choice of parameters. For example, differential exposure to the market factor could have well been the source of the value risk premium in the model given that the market shocks are linear combinations of permanent dividend growth and transitory cyclical shocks. Or, bonds of different maturity could have differential exposure to the market factor shocks. The data show no heterogeneity in both types of exposures. The model has just enough richness to replicate these patterns.

Figure IA.8: Decomposition of annualized excess returns in model.

The figure plots the risk premium (expected excess return) decomposition into risk compensation for exposure to the $C P$ factor, the $L V L$ factor, and the $M K T$ factor. Risk premia, plotted against the left axis, are expressed in percent per year. The top panel is for the five bond portfolios (1-yr, 2-yr, 5-yr, 7-yr, and 10-yr) whereas the bottom panel is for growth (G), value (V), and market (M) stock portfolios. The results are computed from a 10,000 month model simulation under the calibration described in detail in Online Appendix D.3.

We conclude that the model delivers a structural interpretation for the $M K T, L V L$, and $C P$ shocks. $C P$ shocks reflect (transitory) cyclical shocks to the real economy, which naturally carry a positive price of risk. The $L V L$ shock captures an expected inflation shock, and the $M K T$ shock mostly captures a (permanent) dividend growth shock. The model quantitatively replicates the unconditional risk premium on growth, value, and market equity portfolios, and bond portfolios of various maturities, as well as the decomposition of these risk premia in terms of their $M K T, L V L$, and $C P$ shock exposures. Furthermore, it matches some simple features of nominal term structure of interest rates and bond risk premia. It does so for plausibly calibrated dividend growth and inflation processes.

\section{D.4. Asset Pricing Dynamics over the Cycle}

Finally, our model implies interesting asset pricing dynamics over the cycle. The $C P$ factor, or nominal bond risk premium, starts out negative at the start of the recession, falls substantially in the first stage of the recession, falls slightly more in the second stage, before increasing substantially in the third stage of the recession. This pattern for bond risk premia is reflected in realized bond returns. In particular, the negative risk premium shocks at the start of a recession increase bond prices and returns, and more so on long-term than short-term bonds. An investment of $\$ 100$ made at the peak in a portfolio that goes long the 30-year and short the 3-month nominal bond gains $\$ 8.0$ in the first stage of the recession. The gain further increases to $\$ 11.7$ in the second stage, before falling back to a $\$ 7.4$ gain by the last month of the recession. The latter increase occurs as consequence of the rising bond risk premium. Taken over the entire recession, long bonds gain in value so that they are recession hedges Campbell, Sunderam, and Viceira (2012). The same is true in the data, where the gain on long-short bond position is $\$ 6.1$ by the last month of the recession. Value stocks are risky in the model. Their price-dividend ratio falls by $21 \%$ in the first stage compared to peak, continues to fall to $-34 \%$, before recovering to $-29 \%$ by the end of the recession. In the data, the pd ratio on value stocks similarly falls by $16 \%$ in the first stage, falls further to $-26 \%$, before recovering to $+4 \%$. Value stocks perform poorly, losing more during the recession than growth stocks, both in the model and in the data.

One important feature the model (deliberately) abstracts from are discount rate shocks to the stock market. As a result, the price-dividend ratio and stock return are insufficiently volatile and reflect mostly 
cash-flow risk. While obviously counter-factual, this assumption is made to keep the exposition focussed on the main, new channel: time variation in the bond risk premium, the exposure to cyclical risk, and its relationship to the value risk premium. One could write down a richer model to address this issues, but only at the cost of making the model more complicated. Such a model would feature a market price of aggregate dividend risk which varies with some state variable $z$. The latter would follow an AR(1) process with high persistence, as in Lettau and Wachter (2009). All price-dividend ratios and expected stock returns would become more volatile and more persistent, generating a difference between the business-cycle frequency behavior of the bond risk premium and the generational-frequency behavior of the pd ratio. This state variable could differentially affect value and growth stocks, potentially lead to a stronger increase in the pd ratio of value than that of growth in the last stage of a recession. This would shrink the cumulative return gap between value and growth stocks during recessions, which the model now overstates. 